NUREG/CR-6016

ORNL-6748

\title{
Aging and Service Wear of Air-Operated Valves Used in Safety-Related Systems at Nuclear Power Plants
}

Manuscript Completed: August 1994

Date Published: May 1995

Prepared by

D. F. Cox, K. L. McElhaney, R. H. Staunton

Oak Ridge National Laboratory

Managed by

Martin Marietta Energy Systems, Inc.

Oak Ridge National Laboratory

Oak Ridge, TN 37831-6285

Prepared for

Division of Engineering Technology

Office of Nuclear Regulatory Research

U.S. Nuclear Regulatory Commission

Washington, DC 20555-0001

NRC JCN B0828

Under Contract No. DE-ACO5-84OR21400 



\section{DISCLAIMER}

This report was prepared as an account of work sponsored by an agency of the United States Government. Neither the United States Government nor any agency thereof, nor any of their employees, make any warranty, express or implied, or assumes any legal liability or responsibility for the accuracy, completeness, or usefulness of any information, apparatus, product, or process disclosed, or represents that its use would not infringe privately owned rights. Reference herein to any specific commercial product, process, or service by trade name, trademark, manufacturer, or otherwise does not necessarily constitute or imply its endorsement, recommendation, or favoring by the United States Government or any agency thereof. The views and opinions of authors expressed herein do not necessarily state or reflect those of the United States Government or any agency thereof. 


\section{DISCLAIMER}

Portions of this document may be illegible in electronic image products. Images are produced from the best available original document. 


\begin{abstract}
Air-operated valves (AOVs) are used in a variety of safetyrelated applications at nuclear power plants. They are often used where rapid stroke times are required or precise control of the valve obturator is required. They can be designed to operate automatically upon loss of power, which is often desirable when selecting components for response to design basis conditions.

The purpose of this report is to examine the reported failures of AOVs and determine whether there are identifiable trends in the failures related to predictable causes. This report examines the specific components that comprise a typical AOV, how those components fail, when they fail, and how such failures are discovered. It also examines whether current testing frequencies and methods are effective in predicting such failures.
\end{abstract}




\section{Contents}

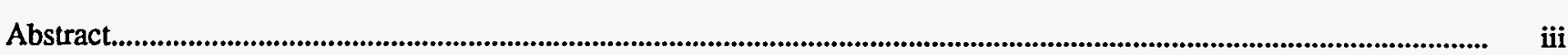

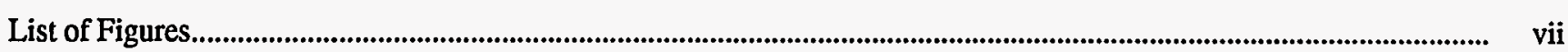

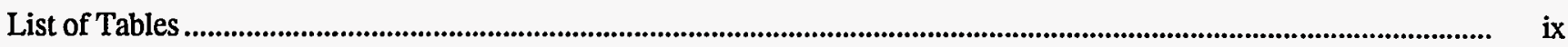

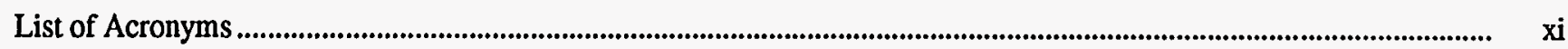

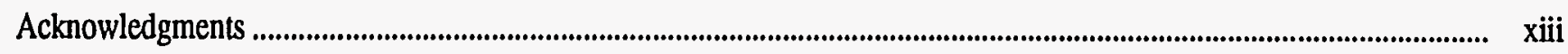

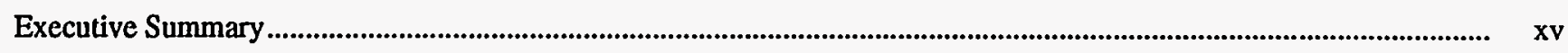

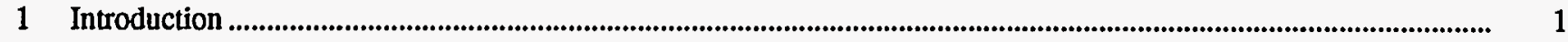

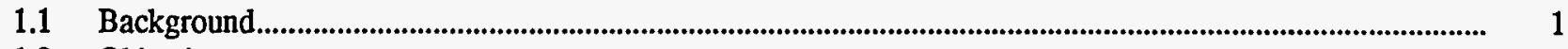

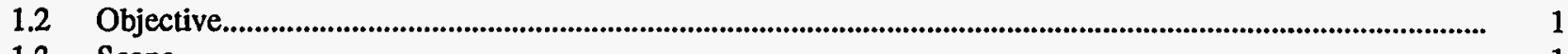

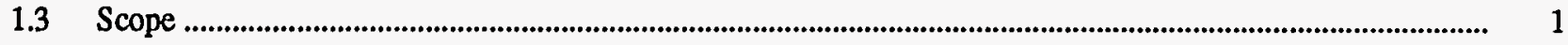

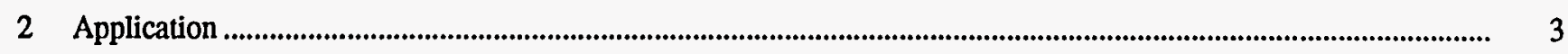

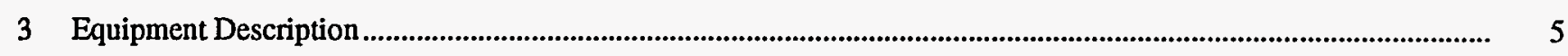

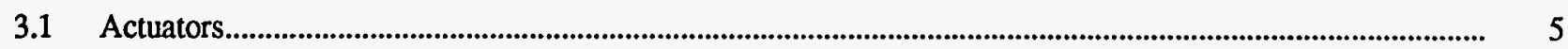

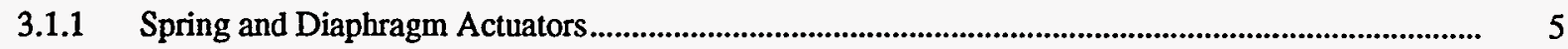

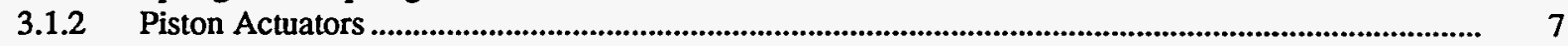

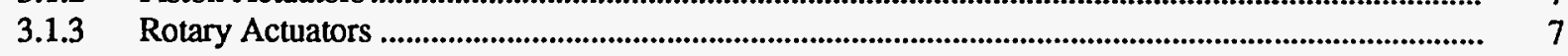

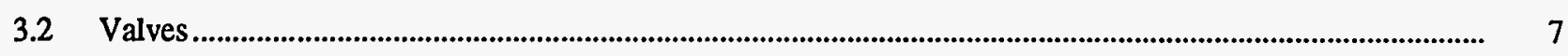

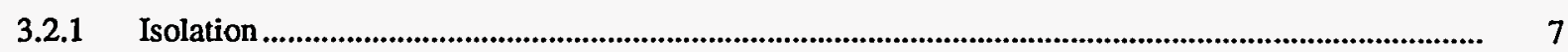

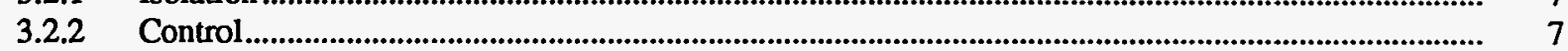

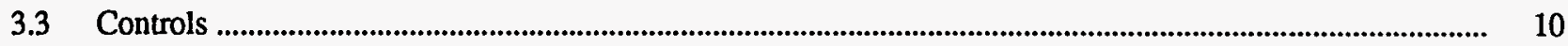

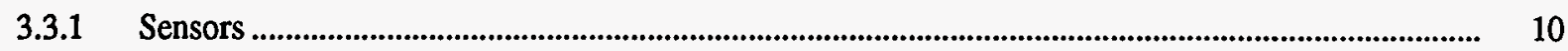

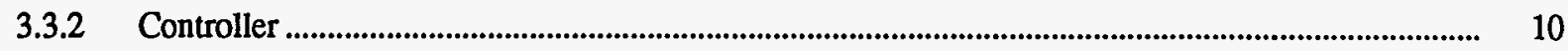

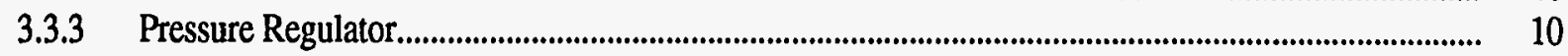

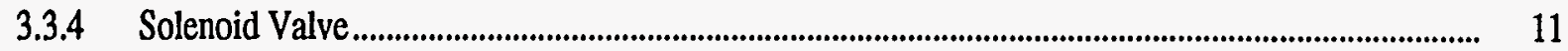

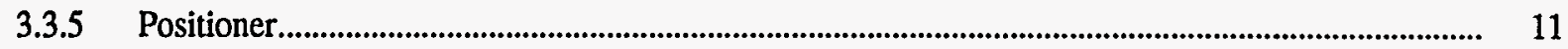

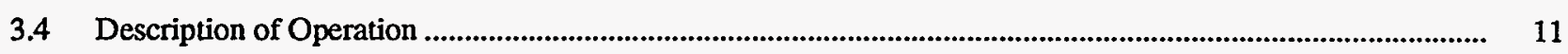

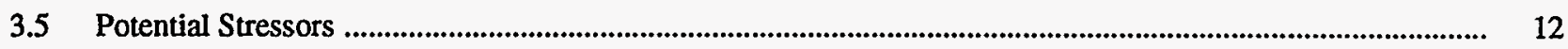

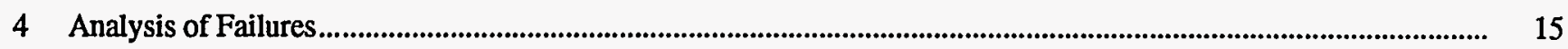

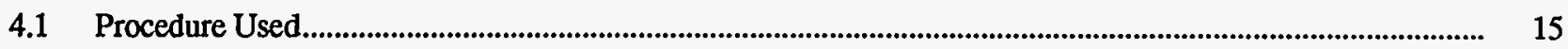

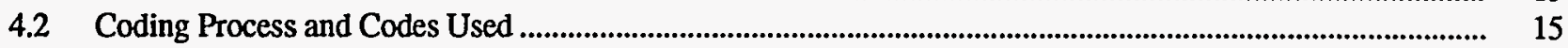

4.2.1 Plant Status Field.............................................................................................................. 15

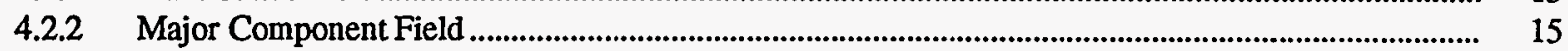

4.2.3 Specific Component Field .......................................................................................................... 16

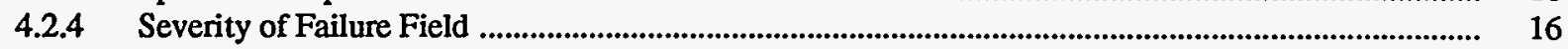

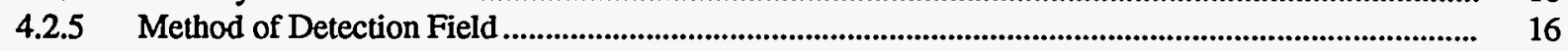

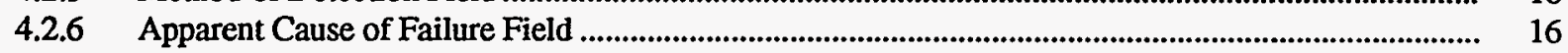

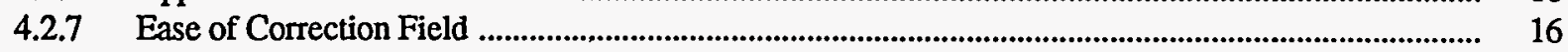

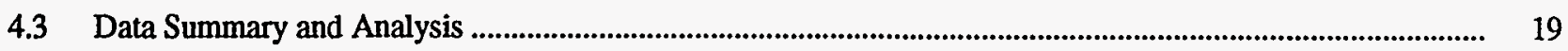

4.3.1 Combined Failures of Valves, Actuators, and Controls............................................................. 19

4.3.1.1 Major Component ................................................................................................................. 19

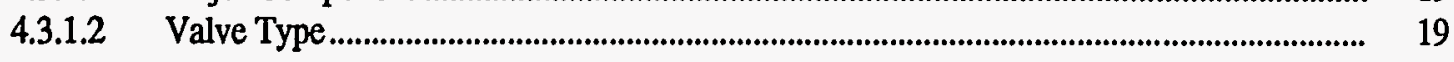


4.3.1.3 Normalizing the Data ..................................................................................................... 20

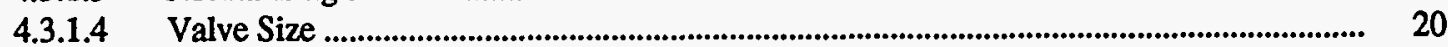

4.3.1.5 Plant Status at Failure Discovery .............................................................................................. 21

4.3.1.6 Method of Detection ............................................................................................................... 22

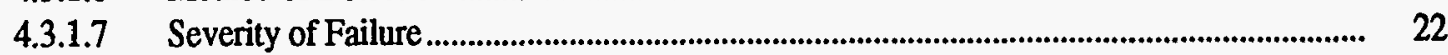

4.3.1.8 Apparent Cause ................................................................................................................. 22

4.3.1.9 Ease of Failure Correction ............................................................................................ 25

4.3.1.10 Comparison of Severity and Plant Status........................................................................ 25

4.3.1.11 Method of Failure Detection ................................................................................................... 26

4.3.1.12 Comparison of Severity and Major Component ............................................................... 28

4.3.1.13 Method of Detection vs Plant Status ................................................................................... 29

4.3.2 Failures Specific to Valves ........................................................................................................ 29

4.3.2.1 Failures by Valve Type and Population ............................................................................ 30

4.3.2.2 Relative Failures by Valve Function ................................................................................... $\quad 30$

4.3.2.3 Comparison of Valve Type and Severity of Failure ............................................................ 31

4.3.2.4 Severity of Failure vs Valve Function..................................................................................... 33

4.3.2.5 Comparison of Valve Type and Method of Detection ................................................................ 34

4.3.2.6 Comparison of Function to Apparent Cause ............................................................................. $\quad 35$

4.3.2.7 Comparison of Function and Ease of Correction................................................................. $\quad 35$

4.3.2.8 Comparison of Type and Method of Detection....................................................................... 36

4.3.2.9 Comparison of Type and Ease of Correction .......................................................................... 37

4.3.3 Failures Specific to Actuators and Controls........................................................................................... 38

4.4 Data Summary and Analysis ................................................................................................................... 40

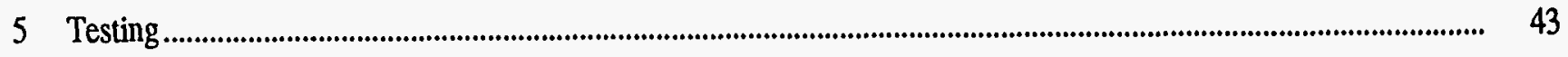

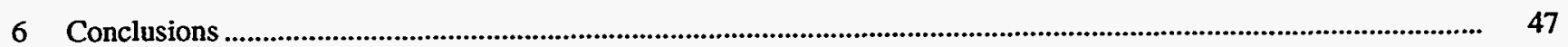

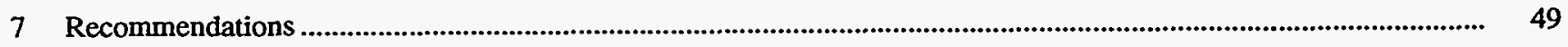

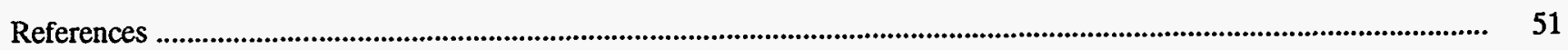

Appendix A-Specific Components Contributing to AOV Failure....................................................................................... 53 


\section{List of Figures}

Figure

Page

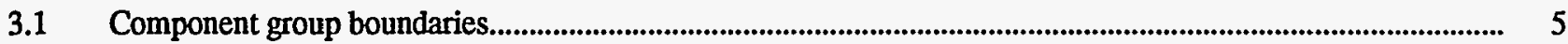

3.2 Typical direct and indirect spring and diaphragm valve actuators........................................................................... 6

3.3 Piston actuator with rotary motion ..................................................................................................................... 7

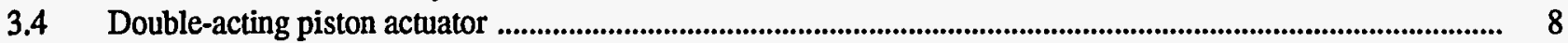

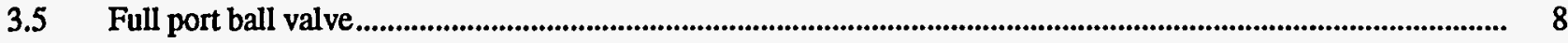

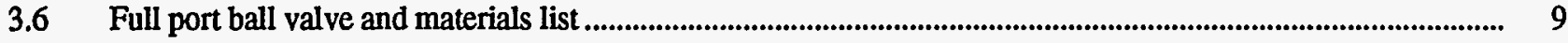

3.7 Exploded view of typical control valve trim ............................................................................................................... 10

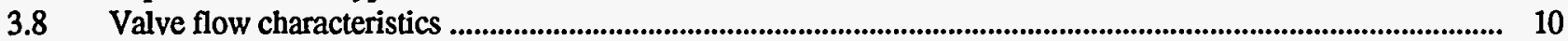

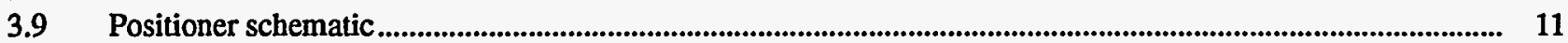

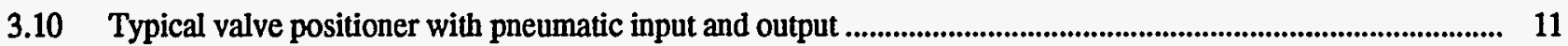

4.1 Major component area involved in failure................................................................................................. 19

4.2 Valve type distribution from AOV population.............................................................................................. 20

4.3 Relative failure rate of combined components compared to valve population for

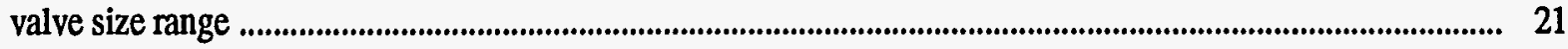

4.4 Plant status at failure for combined components........................................................................................... 22

4.5 Method of detection for combined components............................................................................................................, 23

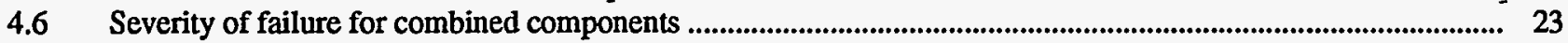

4.7 Distribution of failures by apparent cause for combined failures ............................................................................... 24

4.8 Ease of failure correction for combined components .................................................................................................... 25

4.9 Distribution of combined failures by severity of failure and plant status at failure ............................................... 26

4.10 Fraction of combined component failures for each size range by method of failure detection.................................. 27

4.11 Fractional distribution of severity of failure by major component involved.......................................................... 28

4.12 Percentage of failures for method of detection by plant status at failure ............................................................. 29

4.13 Distribution of valve-only failures by reported valve type ................................................................................ 30

4.14 Relative failure rate by valve-only function and distribution of valve population available to fail

4.15 Relative failures of valve type vs severity of failure

4.16 Valve-only failures for severity of failure by valve function ............................................................................. 33

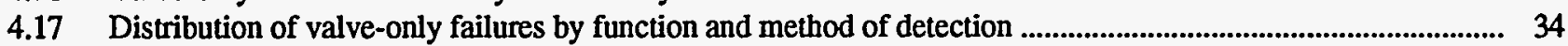

4.18 Valve-only failure distribution: fraction of valve failures for function vs apparent cause of failure..................... 35

4.19 Percentage of failures reported as valve failure by function and ease of correction ............................................... 36

4.20 Relative valve-only failures by valve type for method of detection ...................................................................... 37

$4.21 \quad$ Relative failures (valve-only) by valve type for ease of correction............................................................................ 38

4.22 Fraction of failures for actuator/controls by method of detection .......................................................................... 39

4.23 Fraction of failures attributed to valve operator vs severity of failure ...............................................................4. 40

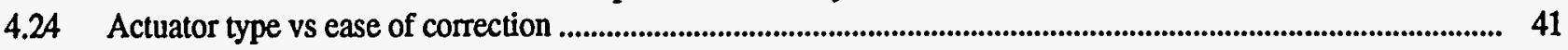

5.1 Comparison of test frequency and method of detection ............................................................................................. 43 



\section{List of Tables}

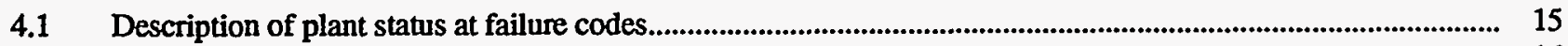

4.2 Description of major component codes .................................................................................................................. 16

4.3 Description of severity of codes ........................................................................................................................ 17

4.4 Description of method of discovery codes ....................................................................................................... 17

4.5 Description of failure cause codes ....................................................................................................................... 17

4.6 Description of ease of correction codes.................................................................................................................. 18

4.7 Relative failure rate of combined components compared to component population for

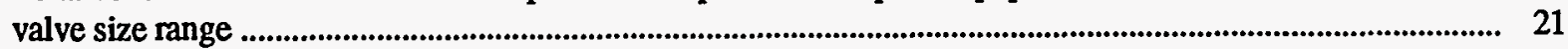

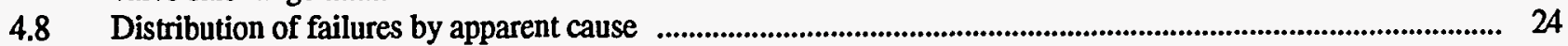

4.9 Distribution of combined failures by severity of failure and plant status at failure .............................................. 26

4.10 Fraction of combined component failures for each size range by method of failure detection.............................. 27

4.11 Distribution of failures for method of detection by plant status at failure................................................................ 30

4.12 Distribution of valve-only failures by reported valve type ................................................................................... 31

4.13 Distribution of valve population available to fail by valve-only function .......................................................... 31

4.14 Relative failure of valve type vs severity of failure................................................................................................... 32

4.15 Percentage of valve-only failures for severity of failure by valve function ........................................................... 33

4.16 Distribution of valve-only failures by function and method of detection .............................................................. 34

4.17 Percentage of failures reported as valve failure by function and ease of correction ............................................. 36

4.18 Failure counts (valve-only) by valve type and method of detection ..................................................................... 37

4.19 Failure counts by valve type and ease of correction............................................................................................. 38

4.20 Distribution of failures for actuator/controls by method of detection ...................................................................... 39

4.21 Fraction of failures attributed to valve operator vs severity of failure .................................................................... 40

$5.1 \quad$ Failure distribution for functional test frequency by method of detection ............................................................... 43

5.2 Comparison of major component to test frequency........................................................................................................ 44

5.3 Comparison of method of detection and component failed................................................................................... 45

A.1 Specific components contributing to AOV failure ................................................................................................ 53 



\section{List of Acronyms}

$\begin{array}{ll}\text { ADS } & \text { automatic depressurization system } \\ \text { AOV } & \text { air-operated valve } \\ \text { EDG } & \text { emergency diesel generator } \\ \text { MOV } & \text { motor-operated valve } \\ \text { MSIV } & \text { main steam isolation valve } \\ \text { MSPORV } & \text { main steam power-operated relief valve } \\ \text { NPAR } & \text { Nuclear Plant Aging Research } \\ \text { NPRDS } & \text { Nuclear Plant Reliability Data System } \\ \text { NRC } & \text { Nuclear Regulatory Commission } \\ \text { PORV } & \text { power-operated relief valve } \\ \text { QC } & \text { quality control } \\ \text { RCS } & \text { reactor coolant system }\end{array}$





\section{Acknowledgments}

The authors wish to thank the many people who took the time to contribute to this volume. Thanks to D. A. Casada, the project manager at Oak Ridge National Laboratory, for his advice and guidance in preparing this report.

Thanks also to the many vendors who spent time explaining the workings of their products and provided technical information on equipment function and design.
Thanks also go to all of the reviewers, editors, and typists. Their combined efforts have refined the basic information into a finished report. 



\section{Executive Summary}

Air-operated valves (AOVs) are used in a large number of safety-related systems at nuclear power plants. They are most often used for isolation or flow control in areas where electric operation is either not possible or not practical. An advantage of this type of valve actuator is that it can be configured to either open or close a valve automatically during a loss of air pressure or electric power. Unlike motor-operated valves, some AOV designs can "fail-safe" instead of "fail-as-is." This is accomplished by the use of mechanical springs to move the valve in the direction of its safety position and the use of air to move in the other direction.

\section{Background and Scope}

The scope of this project limited the failures to be examined to the following:

- Incipient failures are not required to be reported to the Nuclear Plant Reliability Data System. Since the incipient failures that were reported may not be representative of the actual number of incipient failures, they were excluded from this study.

- Both valve and operator failures were tabulated.

- Both spring and diaphragm actuators and piston actuators were included.

- Valves with inlets smaller than 2 in. were excluded as were sample valves.

- Main steam isolation valves and main steam poweroperated relief valves were also excluded because they will be the subject of other reports.

- Nonsafety-related valves were not considered, and external leakage such as packing or gasket leaks were not considered. To achieve a sample size that was representative of the population without being unmanageable, failures were limited to those that occurred between Jan. 1, 1988, and Dec. 31, 1990. The result was a data base comprised of more than 1500 records. These records have been examined, categorized, and tabulated, forming the basis for this report.

The physical component boundaries established for this report start on the air line at the pressure regulator and include all components downstream of the regulator (positioner, solenoid valve, controller). The transmitter that sends the control signal to the controller is not included.
The controller and all components between the controller and the valve are included.

\section{Equipment}

AOVs can be categorized by the actuator type (spring and diaphragm or piston), stem motion (linear travel or rotation), and valve function (control or isolation).

The spring and diaphragm actuator is a relatively simple device. It consists of a bonnet, diaphragm, yoke, diaphragm retum spring, stem, and stem coupling. Air enters the bonnet chamber through the air inlet, which may be located above or below the diaphragm. If air enters above the diaphragm, the diaphragm is forced down, compressing the spring, and closing the associated valve. Venting or loss of air pressure will cause the valve to open as the spring decompresses.

Cylinder actuators are constructed similar to diaphragm actuators. The bonnet and elastomer diaphragm are replaced with a cylinder and piston arrangement. Piston actuators can use springs for movement to the "fail-safe" position or can use air pressure for travel in both directions. Piston actuators provide a compact outline and the ability to use high pressures for valve actuation.

Valves that require stem rotation vs linear motion for movement of the flow controlling element, such as the disk or plug (hereafter referred to as the obturator) also require different actuator configurations. The actuators can still be spring and diaphragm or piston actuated. However, the translation of thrust to torque is accomplished by means of a rack and pinion or a linkage.

\section{Analysis of Failures}

Globe valves were the most common valve type in this study. The largest population of valves was $\geq 2$ in. and $<4$ in. in size. However the portion of the population with the highest failure rate was $\geq 12$ in. and $<20$ in. in size. The relative failure rates were highest for globe and gate valves, while the plug/ball and diaphragm types were the most reliable.

The AOV controls and actuator made up 78\% of the total combined failures. The valve body, seat, disc, etc., accounted for only $19 \%$ of the combined failures. Only 


\section{Executive}

$11 \%$ of the severe combined failures involved the valve body, while $49 \%$ of these severe failures involved the controller/positioner/air system. As seen in Appendix A, the failures in the controls and actuator were due to failures of only a few subcomponents, such as diaphragm ruptures and defective limit switches in the actuators and solenoid valves, air lines, and air regulators in the controls.

The controls system was responsible for a large fraction of the severe failures due to the fact that this system contains several high failure rate subcomponents (e.g., air regulator, solenoid, air line, fittings, etc.), the failures of which frequently compromise normal valve function.

\section{Testing}

Two basic types of testing were considered for this report: (1) surveillance or in-service testing and (2) diagnostic testing. Surveillance testing is done to verify that valves, their actuators, and their position-indicating mechanisms are functioning properly. It is not always practical to test plant equipment in such a way as to verify the ability of the equipment to function properly under all potential conditions. Many valves are required to operate at design basis conditions, which are impractical or impossible to simulate during normal plant operation. Therefore, critical parameters must be examined to give indication of valve and operator readiness. This need led to the development of many of the diagnostic systems currently on the market.

The purpose of testing is to verify several parameters. For this report, testing and its relationship to failure detection and prevention are examined. A clear relationship is shown between functional testing frequency and the fraction of failures discovered under demand conditions. The difference between the fraction of failures discovered by test and the fraction of failures discovered during demand conditions is greatest when periodic functional testing is not done.
Section 5 provides details on the percentage of failures for components that are tested quarterly vs the percentage of components that are not tested on a periodic basis. The percentage of failures are almost identical. This is true when the failures are considered as a percentage of total failures and also when failures are normalized and considered on a relative basis. This implies that current testing is not effective at detecting component degradation and is useful only for detecting failed components.

Preventive maintenance programs that may be in use are not effectively providing indications of degradation in several major components of pneumatic valve operators.

Code requirements (OM-10) are limited to testing stroke time, leak rate, and position indication. While measurement of these parameters will give indication of valve failure, they are not good indicators of incipient failure.

\section{Recommendations}

As a result of this study, several needs are indicated. Because usage of diagnostic systems for AOVs is increasing at nuclear power plants, a follow-up study is suggested. This study should concentrate on failure trends in recent years in light of the increasing use of relatively new diagnostic systems. Additionally, new test methods need to be developed to determine levels of degradation in both diaphragms and solenoid valves under augmented preventive maintenance programs.

In addition to these actions a more detailed study is suggested in order to determine the actual root cause of failures and to determine what part elevated-temperatures and other stressors may play in component degradation. 


\section{Introduction}

Air-operated valves (AOVs) are common to all nuclear power facilities, are found in most safety-related systems, and perform a variety of functions. Because of this widespread usage, combined with consequences of a failure in certain applications, this study was initiated.

\subsection{Background}

This study was initiated as part of the Nuclear Plant Aging Research (NPAR) efforts. This program is sponsored by the Nuclear Regulatory Commission (NRC), Office of Nuclear Regulatory Research.

AOVs are often used in applications where fail-safe operation without electric power is desirable. In these applications the valve may have to change position for accident mitigation. This is easily accomplished by selecting an actuator that employs springs to move the valve in the direction of its safety-related position and employs air to move the valve in the opposite direction. Actuators can be configured to open or close a valve on loss of power.

\subsection{Objective}

The objective ${ }^{1}$ of this NRC study was to develop an understanding of how AOVs age and to identify actions that can be taken to manage the aging process. The following were the technical objectives of the study:

1. Identify and characterize time-dependent degradation that, if unmitigated, could cause degradation of AOVs and thereby impair plant safety.

2 Develop supporting data and information to facilitate the understanding of, and therefore the management of, age-related degradation.

3. Identify methods of inspection, surveillance, and monitoring or methods of evaluating residual-life of AOVs, which will allow preemptive actions by utilities before loss of safety function.

\subsection{Scope}

The scope of this project limited the failures to be examined to the following parameters.

- Incipient failures were excluded because reporting of incipient failures in the Nuclear Plant Reliability Data System (NPRDS) is optional. Therefore the inclusion of incipient failures would only serve to skew the data.

- Both valve and operator failures were tabulated.

- Both spring and diaphragm actuators and piston actuators were included.

- Valves with inlets smaller than 2 in. were excluded as were sample valves.

- Main steam isolation valves (MSIVs) and main steam power-operated relief valves (MSPORVs) were also excluded because they will be the subject of other reports.

- Nonsafety-related valves were not considered, and external leakage such as packing or gasket leaks were not considered. To achieve a sample size that was representative of the population without being unmanageable, failures were limited to those that occurred between Jan. 1, 1988, and Dec. 31, 1990. The result was a data base comprised of more than 1500 records. These records have been examined, categorized, and tabulated, forming the basis for this report.

The physical component boundaries established for this report start on the air line at the pressure regulator and include all components downstream of the regulator (positioner, solenoid valve, controller). The transmitter that sends the control signal to the controller is not included. The controller and all components between the controller and the valve are included. 



\section{Application}

AOVs are used to control fluid flow in power plant processes. This control can be in the form of flow isolation or variable process control. Valves used for flow control or isolation account for $\sim 77 \%$ of the AOVs in safety-related systems at nuclear power plants. ${ }^{*}$ When AOVs are used as control valves they are part of a loop where the valve is the last component in the loop (Chap. 3, Fig. 3.1).

What follows are two applications of AOVs in nuclear power plants, along with a discussion of the potential consequences of valve failure.

- Emergency Diesel Generator (EDG) Starting Air Isolation Valve-Upon a start signal to the EDG, this valve is required to open, providing air to the cylinders to facilitate starting the EDG. Failure of the valve to open can cause a loss of the starting air train and subsequently a loss of redundancy for the starting air subsystem. Loss of the EDGs could degrade the ability of the plant to respond to safe-shutdown requirements in the event of a loss of off-site power.

- Reactor Coolant Pressurizer Spray Valve-During plant operation the pressurizer is filled with a mixture of water and steam. If the electrical load on the plant decreases, the reactor coolant system (RCS) temperature will increase. This causes an expansion of the RCS inventory, thus raising the water level in the pressurizer. This compresses the steam and raises the pressure in the pressurizer. In response to control signals the spray valve opens, spraying water into the steam. This condenses a portion of the steam and reduces the pressure to normal levels. If the valve fails or the pressure increase is beyond the capability of the pressurizer spray system, the pressurizer power-operated relief valves (PORVs) will open, venting steam to a relief tank. Failure of the PORVs will cause actuation of the safety relief valves.

It is recognized that the loss of any one train should not preclude the safe shutdown of a nuclear power plant. However, such a loss can force plant operators to rely on backup systems or alternate trains or channels to safely bring the plant down. Such a loss can also become a precursor to the failure of other components or systems. However, when a failure is predictable, it is quite possibly preventable.
While these failures may not lead to an accident, their prevention may help the utilities to avoid costly trips and unnecessary challenges to safety-related systems that could result in compound failures.

Below is a partial list of plant applications that utilize AOVs:

- Auxiliary Feedwater Discharge to Steam Generator Isolation and Flow Control Valve

- Auxiliary/Emergency Feed Turbine Trip Stop Valve

- Control Rod Drive Scram Discharge Volume Drain Valve

- Containment Spray Header Isolation Valve

- EDG Air Start Isolation Valve

- Feedwater Containment Isolation Valve

- Feedwater Regulating Valve Bypass Valve

- Main Feedwater Regulating Valve

- Standby Gas Treatment System Blower Isolation Valve Operator

- Standby Gas Treatment System Filter Isolation Valve Operator

- Air Start Isolation Valve for the High-Pressure Core Spray EDG

- High-Pressure Coolant Injection Discharge to Feedwater Check Valve Operator

- Low-Pressure Core Spray Containment Isolation Check Valve

- Main Steam Safety/Automatic Depressurization System (ADS) Valve

- Main Steam Turbine Bypass Valve

- Pressurizer PORV Operator

- Reactor Coolant Pressurizer Spray Valve

- Residual Heat Removal Refueling Water Storage Tank Suction Isolation Valve

- Reactor Core Isolation Cooling Discharge to Feedwater Check Valve

- Suppression Pool/Torus Vacuum Breaker Valve

It should be noted that the above list of valve applications is not restricted to AOVs. Other types of valve actuators are also used to perform these functions at some nuclear power plants.

\footnotetext{
*AOVs used for flow control or isolation are (normally) $\geq 2$ in. in nominal port diameter.
} 



\section{Equipment Description}

The devices commonly called AOVs are actually systems comprised of several independent components. For the purposes of this report, AOVs will be analyzed in three specific component groups. The first group will be the actuator. The actuator is the power-operated device that brings about a change in valve obturator position. Group two will be the valve, which consists of the pressure- retaining components that contain and direct fluid flow. Finally the third group is comprised of the actuator controls. These are made up of the sensor, controller, solenoid valve, pressure regulator, and positioner (Fig. 3.1).

AOVs can be categorized by the actuator type (spring and diaphragm or piston), stem motion (linear travel or rotation), and valve function (control or isolation). First, spring and diaphragm actuators will be described, then piston actuators (for linear travel), followed by actuators pro- viding rotary stem travel. This is followed by general valve descriptions, applications for control and isolation functions, and the components making up the control portion of the loop. The chapter ends with a discussion of potential stressors and their impact on the equipment operation. A discussion of the actual effects of these stressors follows in Chap. 4.

\subsection{Actuators}

\subsubsection{Spring and Diaphragm Actuators}

The spring and diaphragm actuator is a relatively simple device. It consists of a bonnet, diaphragm, yoke, diaphragm return spring, stem, and stem coupling (see Fig. 3.2). Air enters the bonnet chamber through the air inlet, which may

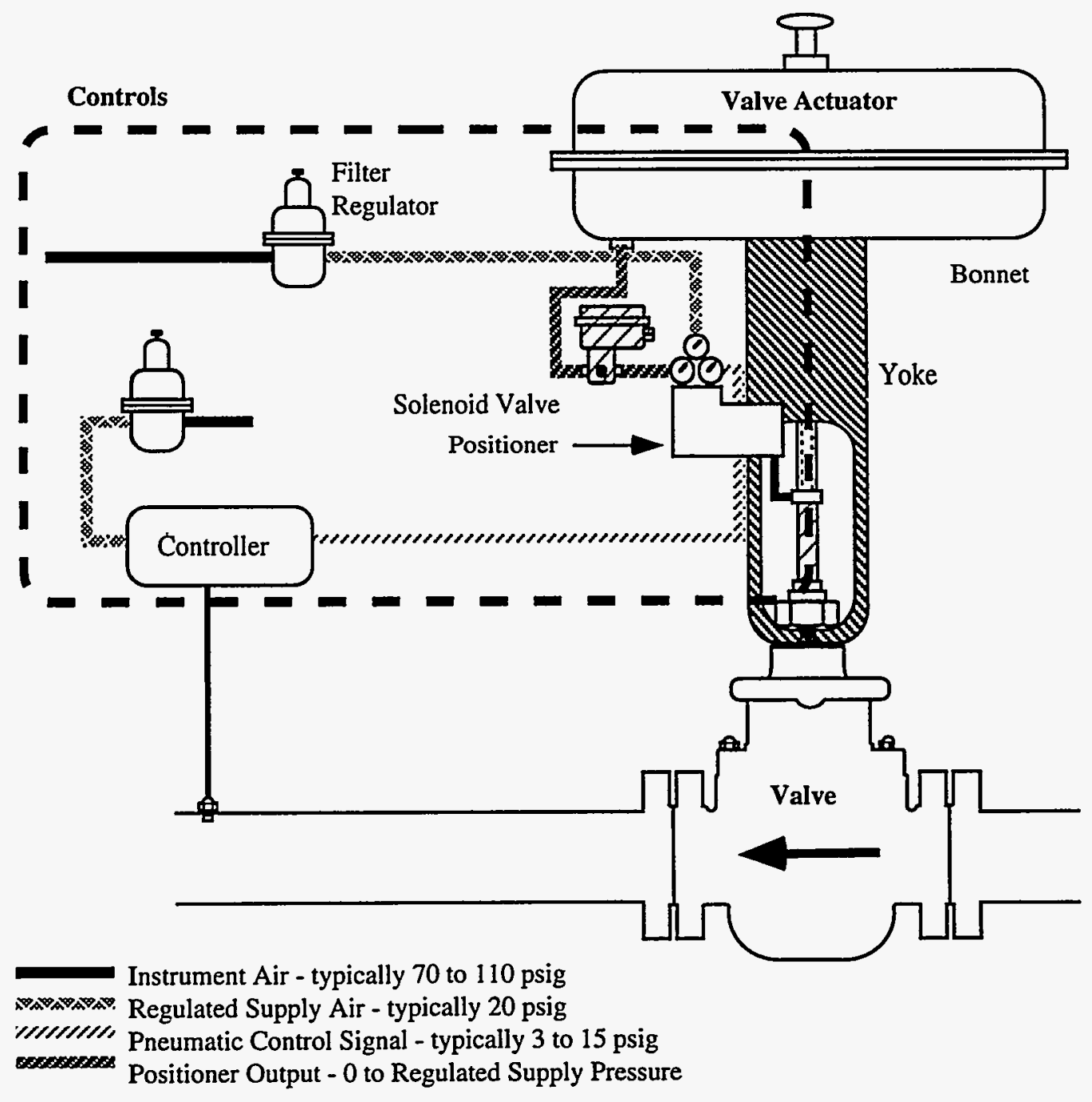

Figure 3.1 Component group boundaries 


\section{PARTS-DIRECT-ACTING}

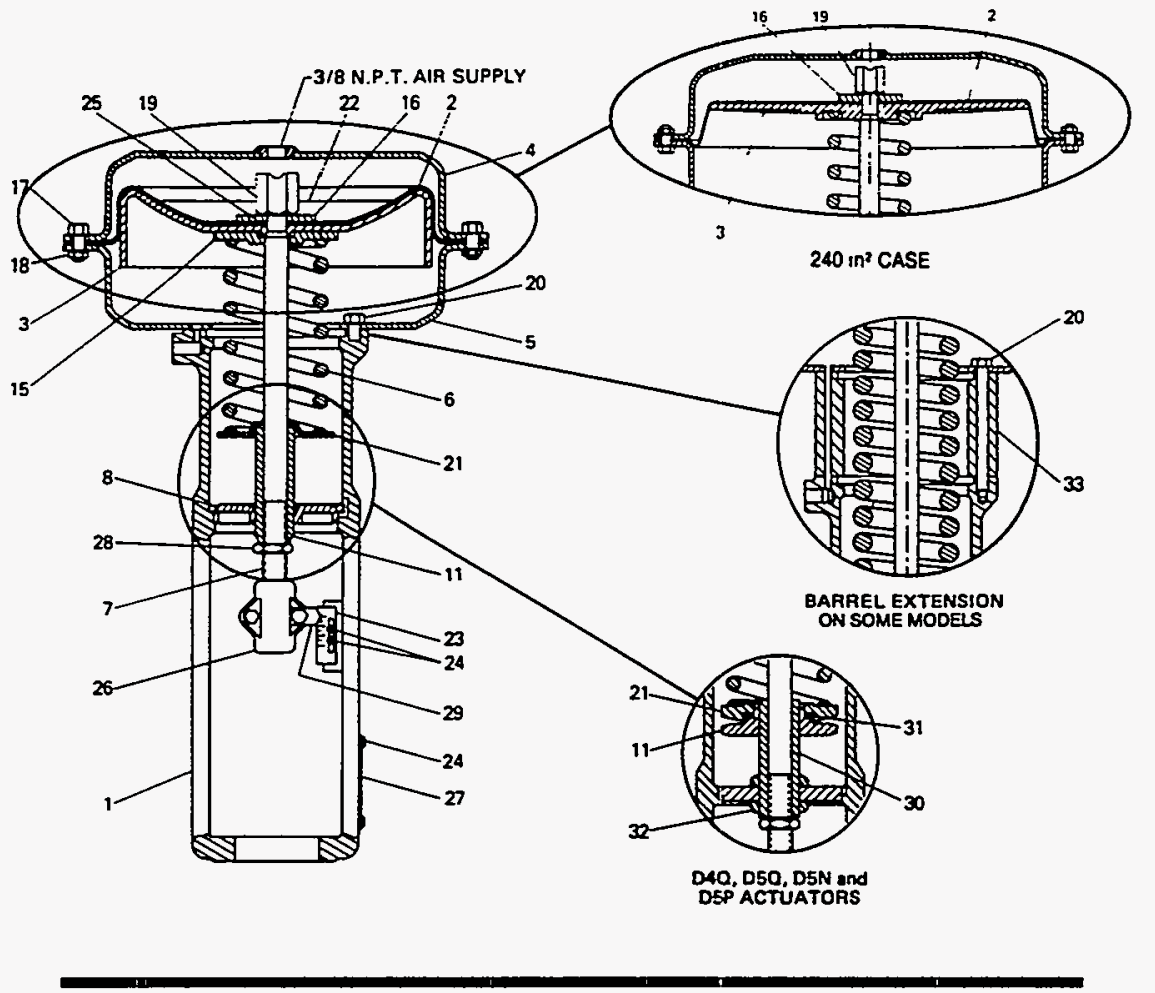

PARTS-REVERSE-ACTING

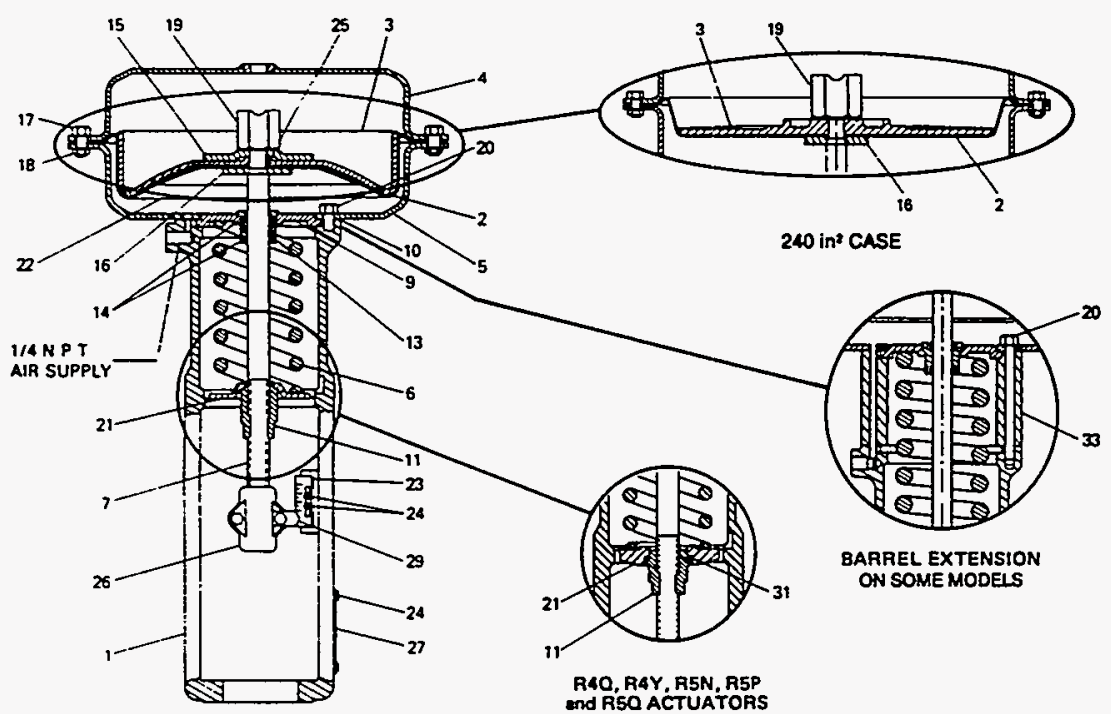

PARTS AND BILL OF MATERIALS

\begin{tabular}{|c|c|c|}
\hline $\begin{array}{l}\text { PART } \\
\text { NO. }\end{array}$ & $\begin{array}{l}\text { PART } \\
\text { MAME }\end{array}$ & MATEAIA \\
\hline $\begin{array}{l}1 \\
2\end{array}$ & \begin{tabular}{|l|} 
Spring Barrel \\
Diaphragm
\end{tabular} & $\begin{array}{l}\text { Cast Iron } \\
\text { Nitrile/ } \\
\text { Dacron }\end{array}$ \\
\hline 3 & Piston & Carbon steel \\
\hline 4 & $\begin{array}{l}\text { Upper Diaphragm } \\
\text { Case }\end{array}$ & Carbon stoel \\
\hline 5 & $\begin{array}{l}\text { Lower diaphragm } \\
\text { Case }\end{array}$ & Carbon ateel \\
\hline 6 & Spring & Carton stoel \\
\hline 7 & Spring Stem & $\begin{array}{l}303 \text { stainless } \\
\text { steol }\end{array}$ \\
\hline 8 & Barrel Bridge & $\begin{array}{l}\text { Stainless } \\
\text { stoel }\end{array}$ \\
\hline 9 & $\begin{array}{l}\text { Packing Box } \\
\text { Flange }\end{array}$ & Carbon stoel \\
\hline 10 & $\begin{array}{l}\text { Lower Case } \\
\text { Gasket }\end{array}$ & Neoprene \\
\hline $\begin{array}{l}11 \\
13\end{array}$ & $\begin{array}{l}\text { Spring } \\
\text { Packir }\end{array}$ & $\begin{array}{l}\text { Carton atool } \\
\text { Brass }\end{array}$ \\
\hline 14 & $\begin{array}{l}\text { Packing Box } \\
\text { O-Ring }\end{array}$ & Buna-N \\
\hline 15 & $\begin{array}{l}\text { Piston Back-up } \\
\text { Plate }\end{array}$ & Carbon steel \\
\hline 16 & $\begin{array}{l}\text { Diap } \\
\text { Buttc }\end{array}$ & Carbon stoel \\
\hline 17 & ad Cap & Carbe \\
\hline 18 & Hex Nut & Cart \\
\hline 19 & Hex Nut & Cart \\
\hline 20 & $\begin{array}{l}\text { Hex Head Cap } \\
\text { Screw }\end{array}$ & Irbon stoel \\
\hline 21 & $\begin{array}{l}\text { Spring Adjuster } \\
\text { Button }\end{array}$ & Carbon stoel \\
\hline 22 & Diaphragm Disc & Carbon steel \\
\hline 23 & $\begin{array}{l}\text { Travel Indicator } \\
\text { Scale }\end{array}$ & \\
\hline 24 & Self Tap Screw & Carbon steel \\
\hline 25 & $\begin{array}{l}\text { Diaphragm } \\
\text { O-fing }\end{array}$ & Una-N \\
\hline 26 & Split Coupling & Carbon stoel \\
\hline 27 & tion Tag & $\begin{array}{l}\text { Stainless } \\
\text { Steel }\end{array}$ \\
\hline 29 & $\begin{array}{l}\text { Trave! } \\
\text { Stainle }\end{array}$ & \\
\hline 30 & $\begin{array}{l}\text { Spring Adjuster } \\
\text { Screw }\end{array}$ & artbon ateel \\
\hline 31 & $\begin{array}{l}\text { Spring Adjuster } \\
\text { Thrust Bearing }\end{array}$ & steol \\
\hline 32 & Jam Nut & Carbon steel \\
\hline 33 & $\begin{array}{l}\text { Spring Barrel } \\
\text { Extension }\end{array}$ & Carbon steol \\
\hline 34 & $\begin{array}{l}\text { Hex Head Cap } \\
\text { Screw }\end{array}$ & Carb \\
\hline
\end{tabular}

Figure 3.2 Typical direct (air to extend) and indirect (air to retract) spring and diaphragm valve actuators. Source: Reprinted with permission from Neles-Jamesbury, Worcester, Massachusetts 
be located above or below the diaphragm. Air enters above the diaphragm for direct-acting actuators, forcing the diaphragm down, compressing the spring, and closing the associated valve. Venting or loss of air pressure will cause the valve to open as the spring decompresses. This is commonly referred to as a "fail open" valve actuator. A reversal of the air inlet and spring force direction would result in a reverse-acting or "fail closed" actuator.

\subsubsection{Piston Actuators}

Cylinder actuators are constructed very similarly to diaphragm actuators. The bonnet and elastomer diaphragm are replaced with a cylinder/piston arrangement. There are two types of piston actuator; one uses a spring for travel in the direction opposite air pressure (Fig. 3.3), and the other uses air pressure as the motive pressure in both directions (Fig. 3.4). Piston actuators provide a compact outline and the ability to use high pressures for valve actuation.

Another advantage of piston actuators is the ability to operate over a long stroke length. Without the limitations of diaphragm size, it is possible to utilize a greatly increased stroke to match required valve motion.

\subsubsection{Rotary Actuators}

Valves that require stem rotation vs linear motion for obturator movement also require different actuator configurations. The actuators may still be spring and diaphragm or piston type. However, the translation of thrust to torque is accomplished by means of a rack and pinion, cam, or other linkage (Fig. 3.3).

\subsection{Valves}

As mentioned previously, most valves can be separated into two basic categories: control or isolation. Control valves are used to modulate a process by means of flow, level, temperature, or pressure control. Isolation valves are designed for either on or off service and are required to change the fluid flow rate and pressure drop as little as possible when open. Many control valves used in nuclear power plants also have safety-related isolation functions.

\subsubsection{Isolation}

Because isolation valves are required to have minimal effect on the process fluid when open, they are normally designed with the maximum amount of flow area available to the fluid. Examples include gate valves, full port ball valves (Figs. 3.5 and 3.6), some butterfly valves, etc.

\subsubsection{Control}

Control valves are engineered such that slight changes in valve obturator position will quantitatively affect the flow

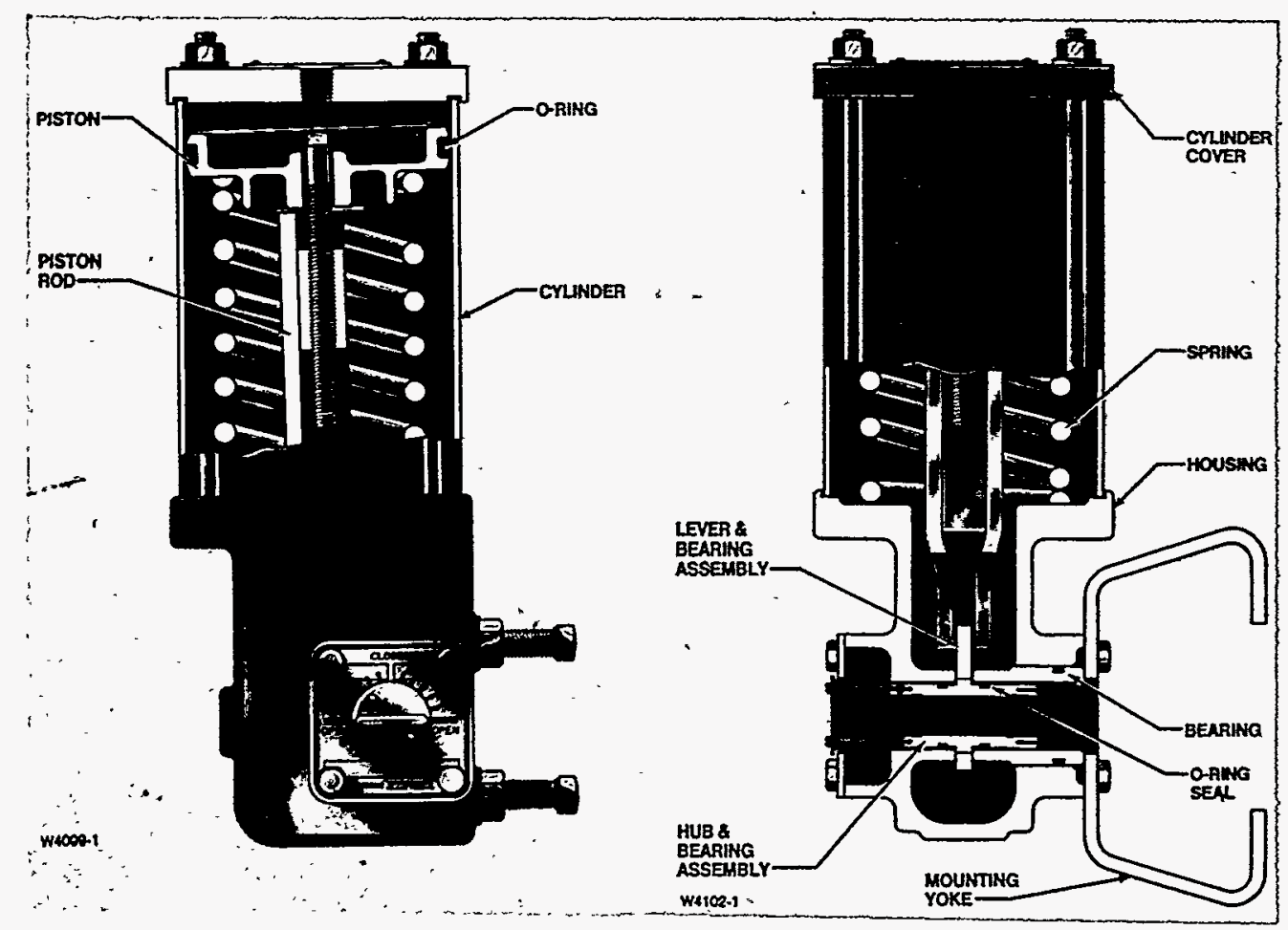

Figure 3.3 Piston actuator with rotary motion. Source: Reprinted with permission from Fisher Controls, Marshalltown, Iowa 


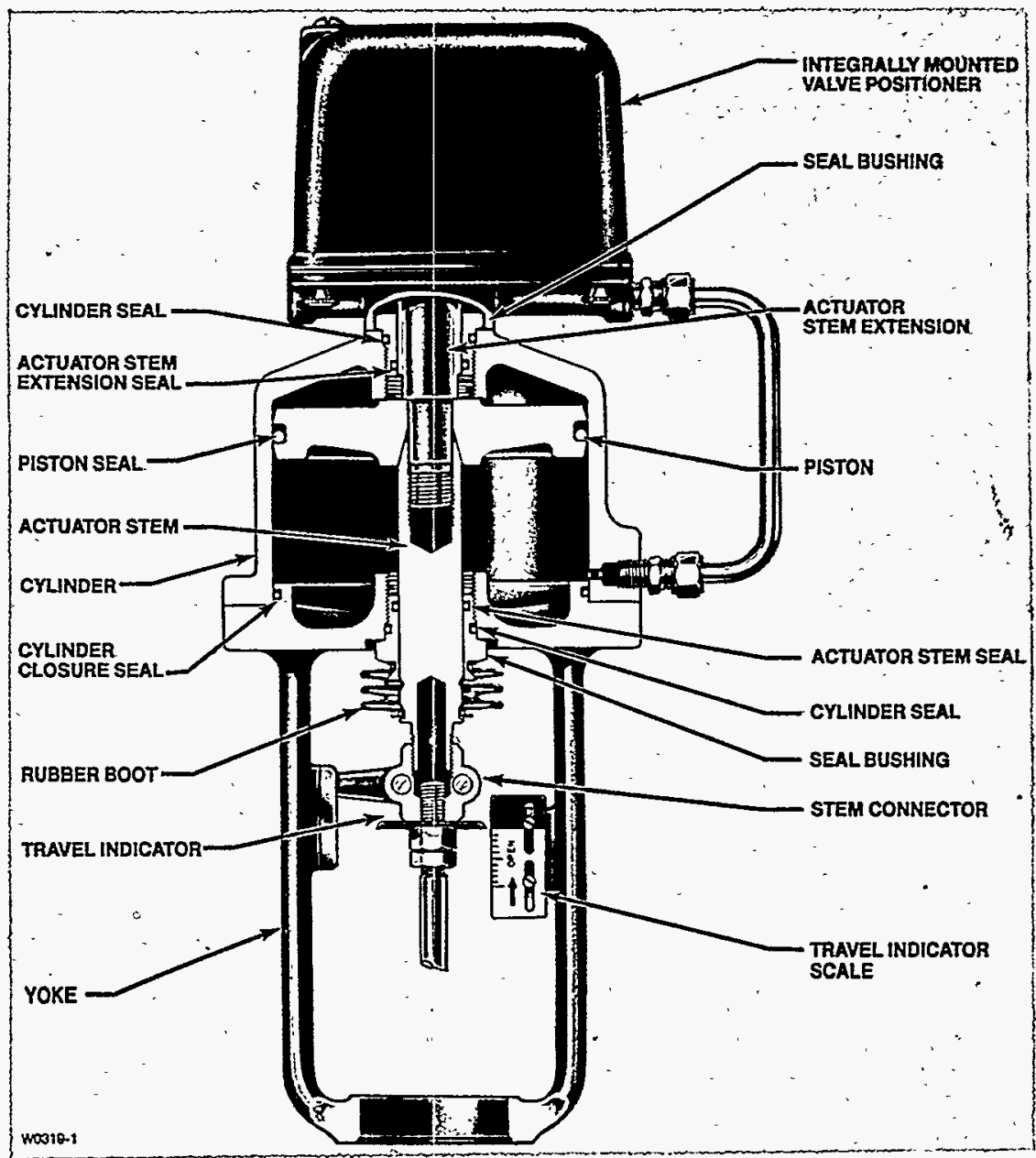

Figure 3.4 Double-acting piston actuator. Source: Reprinted with permission from Fisher Controls, Marshalltown, Iowa

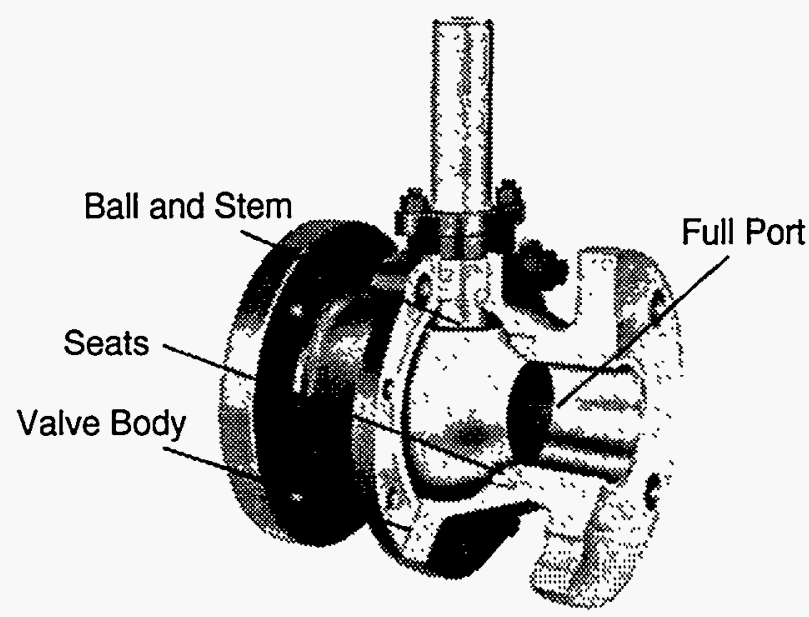

Figure 3.5 Full port ball valve. Source: Reprinted with permission from Neles-Jamesbury, Worcester, Massachusetts of process fluid (Fig. 3.7). Historically globe, ball, modified ball, and butterfly valves have been used for this service. It should be noted that control valves are typically unsuited when tight shutoff is required. Therefore control valves are usually not used as the sole means of isolation when valve seat leakage is not acceptable.

Control valves achieve a characteristic amount of flow relative to the amount of stem travel by changing the valve trim. The trim typically consists of the seat ring, plug, plug guides, stem, and cage. These are normally the parts exposed to the process fluid. It is the shape of the openings in the cage that give the valve its flow characteristic. The most common flow characteristics are quick opening, linear, and equal percent. $A$ graph of the flow coefficient, $C_{V}$, for each characteristic is shown in Fig. 3.8.

Valves with quick-opening trim provide a high percentage of flow with initial plug movement in the opening direction. The change in flow rate decreases the further the valve 
Equipment
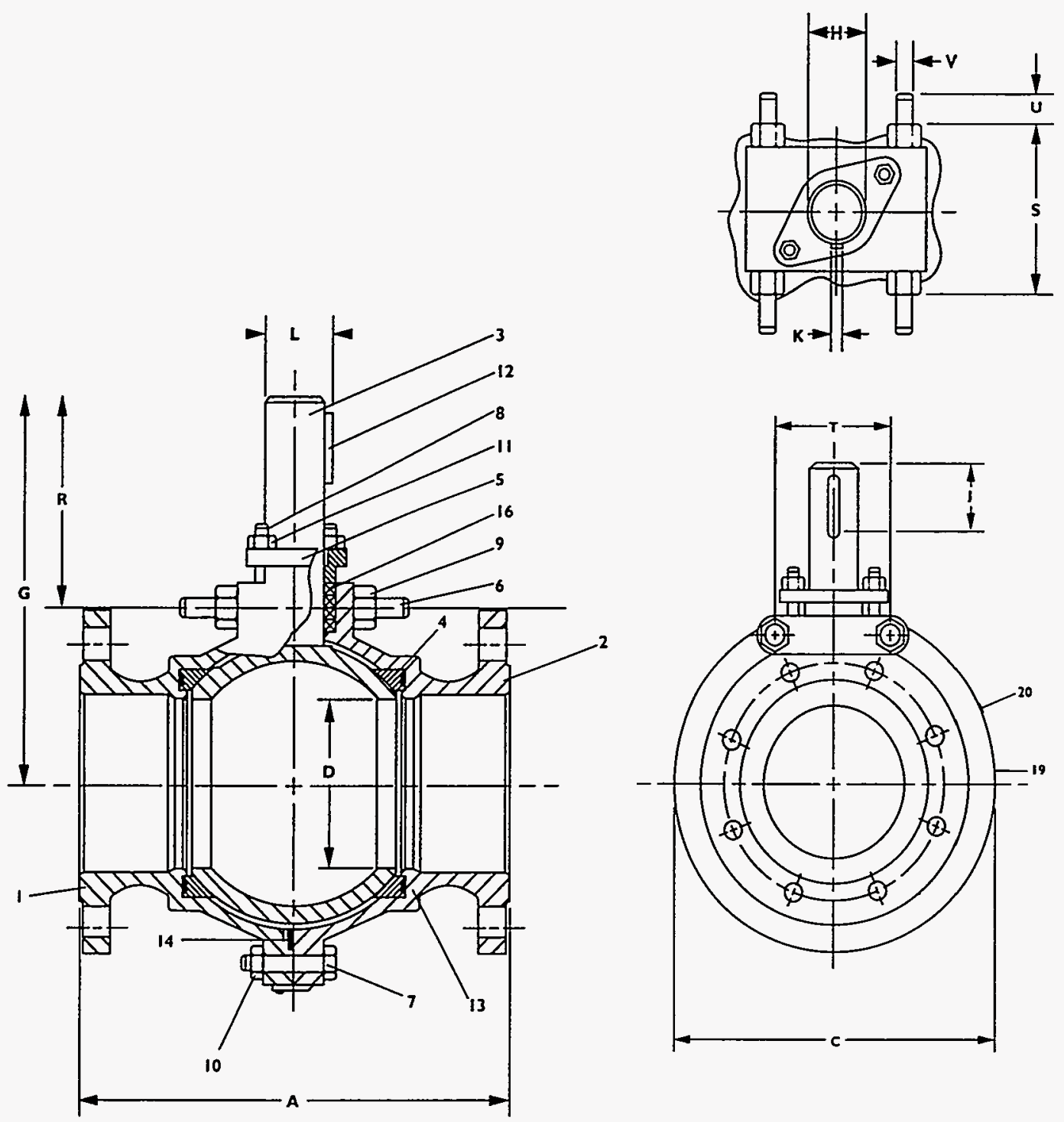

BILL OF MATERIAL AND PARTS LIST

\begin{tabular}{|c|c|c|c|}
\hline Item & Qty & Part & Material \\
\hline 1 & 1 & Body (Female) & CF8M stainless steel \\
\hline 2 & I & Body (Male) & CF8M stainless steel \\
\hline 3 & I & Stem-Ball' & $\begin{array}{l}\text { CF8M hard chrome plated } \\
\text { CFBM Ni boron coated } \\
\text { CFBM Electroless Ni plated }\end{array}$ \\
\hline 4 & 2 & Seat & $\begin{array}{l}\text { CF8M Stellite" faced } \\
\text { CF8M Celsit" } 50 \text { NB faced }\end{array}$ \\
\hline 5 & 1 & Packing Gland & CFBM stainless steel \\
\hline 6 & 2 & Neck Screw & $\begin{array}{l}\text { B7 carbon steel or B8M } \\
\text { stainless steel }\end{array}$ \\
\hline 7 & - & Hexagon Screw & $\begin{array}{l}\text { B7 carbon steel or 88M } \\
\text { stainless steel }\end{array}$ \\
\hline 8 & 2 & Stud & B8M stainless steel \\
\hline
\end{tabular}

\begin{tabular}{|c|c|l|l|}
\hline Item & Qty & \multicolumn{1}{|c|}{ Part } & \multicolumn{1}{|c|}{ Material } \\
\hline 9 & 4 & Hexagon Nut & $\begin{array}{l}\text { 2H carbon steel or 8M } \\
\text { stainless steel } \\
\text { 2H carbon steel or 8M } \\
\text { stainless steel }\end{array}$ \\
10 & - & Hexagon Nut & 8M stainless steel \\
11 & 2 & Hexagon Nut & AISI 329 stainless steel \\
12 & 1 & Key & PTFE or Graphite \\
13 & 2 & Back Seat Seal & PTFE or Graphite \\
14 & 1 & Body Seal & PTFE or Graphite \\
16 & - & Packing & 304 stainless steel \\
19 & 1 & ID Plate & Nickled steel \\
20 & 2 & Rivets & \\
& & & \\
\hline
\end{tabular}

- Quantity dependent on valve size

Figure 3.6 Full port ball valve and materials list. Source: Reprinted with permission from Neles-Jamesbury, Worcester, Massachusetts 


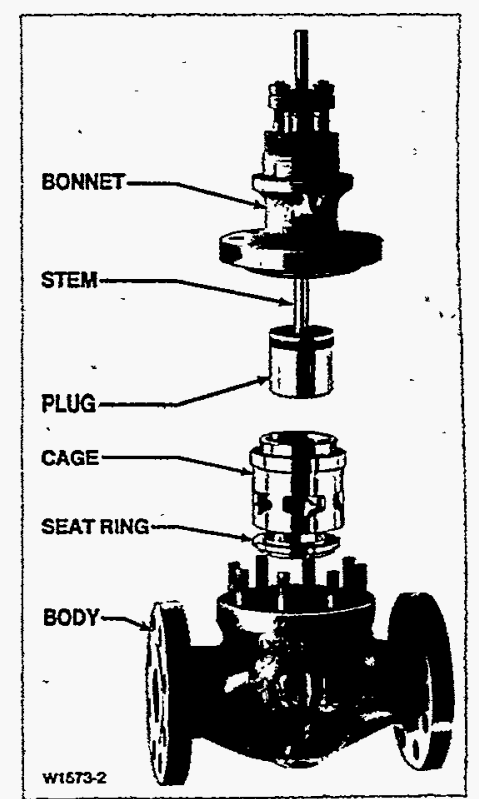

Figure 3.7 Exploded view of typical control valve trim. Source: Reprinted with permission from Fisher Controls, Marshalltown, Iowa

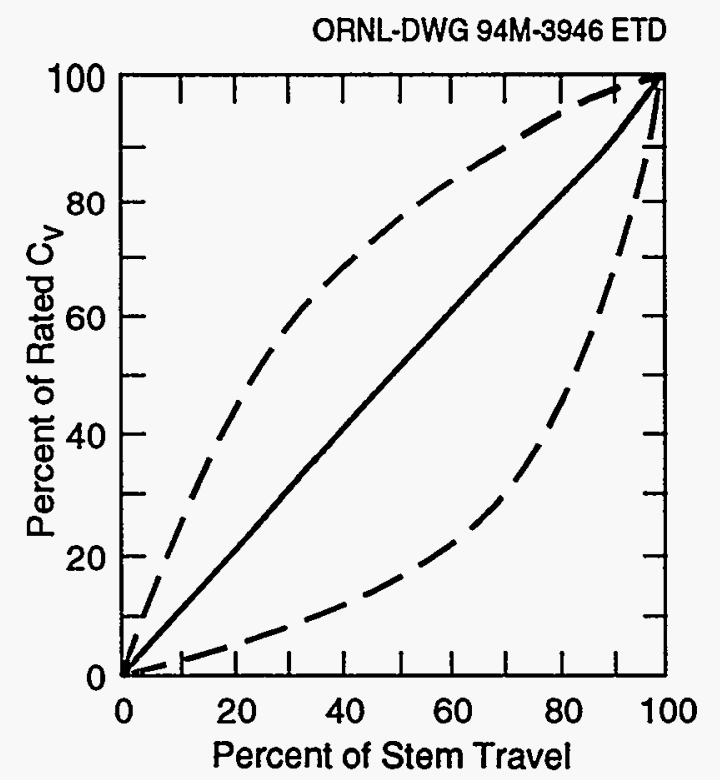

Figure 3.8 Valve flow characteristics: quick opening (top), linear (middle), and equal percentage (bottom)

opens. Linear trim provides equal increases in flow with equal amounts of stem travel. Equal percentage trim provides an equal percentage of flow change for incremental changes in stem travel relative to the flow rate prior to the change (e.g., if the valve is opened $10 \%$ of the stroke length, the flow rate will change $10 \%$ ).

\subsection{Controls}

The control portion of the system consists of the sensor, the controller, the solenoid valve for isolation systems, or the positioner for control systems, and a pressure regulator on the supply air line (Fig. 3.1).

\subsubsection{Sensors}

Sensors (or transmitters) supply a signal based on the status of the measured parameter (normally pressure, temperature, flow, or level). This signal may be either electronic or pneumatic, depending on the sensor type. For a pneumatic controller the signal commonly ranges from 3 to 15 or 6 to $30 \mathrm{psig}$. Electronic sensors commonly supply signals in the range of 1 to 5,4 to 20 , or 10 to $50 \mathrm{~mA}$ dc. This signal is then compared to the reference value or set point in the controller.

\subsubsection{Controller}

The controller receives input from the sensor, compares it to a preset value (pressure, temperature, level, etc.), and then sends a signal to the valve or positioner to cause valve obturator movement, returning the controlled parameter to a value within the limits set in the controller.

The type of output from the controller is dependent on whether a positioner is used with the control valve. If a positioner is used, the controller will send a control signal to the positioner, which will then send supply air to the valve to supply the motive force for valve movement. If a positioner is not used, the controller must supply air directly to the valve actuator as motive force to cause valve obturator movement. It may be the same as the input signal (pneumatic or electronic) or may be converted from electronic to pneumatic. The output signal from an electropneumatic controller typically ranges from 3 to 15,6 to 30 , or 3 to $27 \mathrm{psig}$.

\subsubsection{Pressure Regulator}

The pressure regulator receives input from the instrument air system and decreases it to a value that is usable by the positioner and/or the actuator. Failure of the regulator could either isolate the air supply or pass it on with no pressure drop. If the air supply is isolated, there is no motive force for the actuator. The other extreme would supply air to the positioner and/or the actuator at levels that could either cause physical damage to these components in the form of diaphragm rupture or excess seating loads. The excess seating loads could cause obturator damage, seat damage, or stem damage. A combination of the above is also possible. 


\subsubsection{Solenoid Valve}

Solenoid valves are often used when there is a desire to bypass control loop logic. An example of this would be a valve that has a normal function of controlling a process and a safety function of isolation. When the solenoid valve receives the isolation signal, it will exhaust air from the valve actuator diaphragm housing regardless of input from the controller or positioner. For spring and diaphragm actuators or piston actuators (direct or reverse acting), a threeway solenoid is a common method of controlling the air supplied to/released from the actuator. Double-acting applications tend to use four-way solenoid valves. Aging of solenoid valves has been documented in NUREG/CR-4819 Vol. 2, "Aging and Service Wear of Solenoid-Operated Valves Used in Safety Systems of Nuclear Power Plants," by R.C. Kryter. ${ }^{2}$

\subsubsection{Positioner}

The positioner functions to accurately position the valve stem. Stem motion translates to changes in the volume of fluid flowing through the valve. There are three basic types of positioner used on AOVs: pneumatic, pneumaticelectric, and dual position. All three types of positioners operate by balancing the forces between the controller signal and the valve stem position.

A positioner for a spring and diaphragm actuator is shown schematically in Fig. 3.9 and graphically in Fig.3.10. The positioner responds to a signal from the controller to change valve position. [For this example, the valve under consideration is a reverse-acting control valve (air to open), and the parameter to be controlled is flow rate.] Using

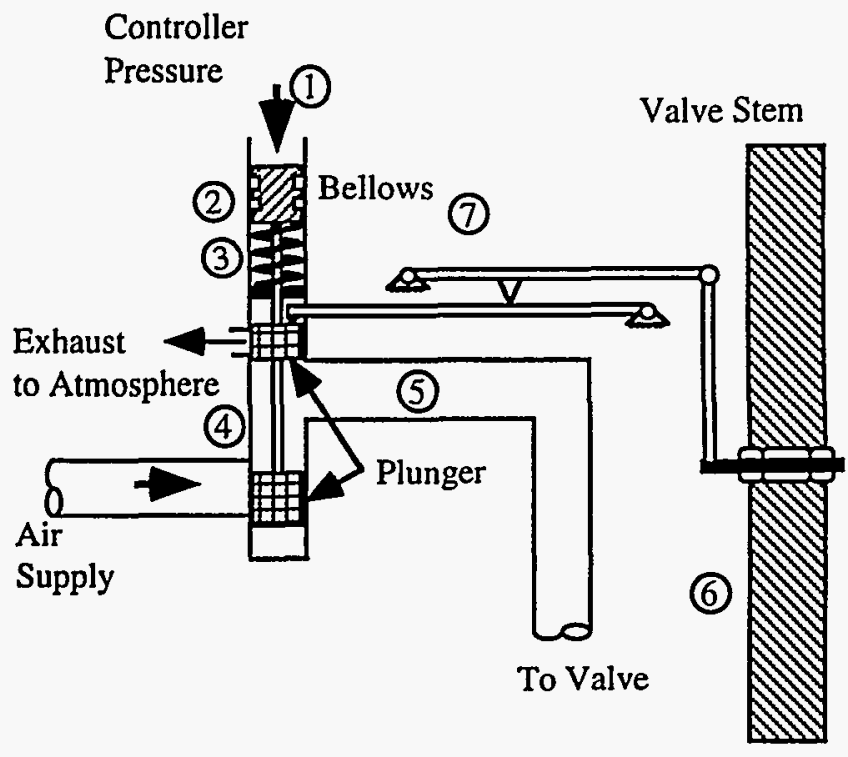

Figure 3.9 Positioner schematic

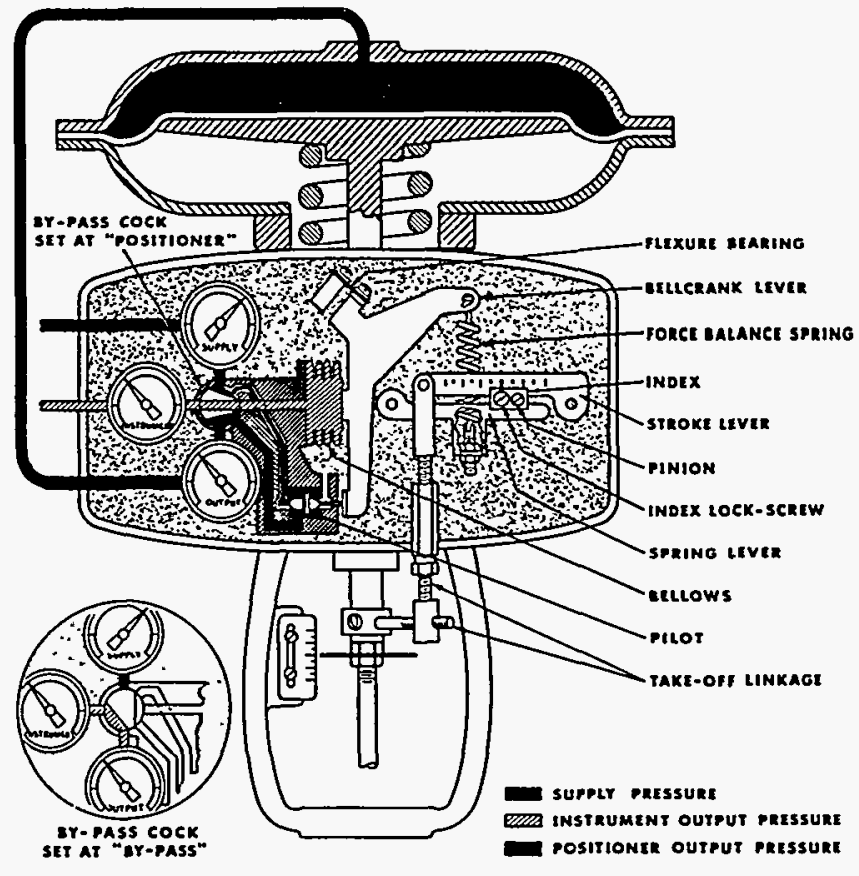

MODEL T4OO POSITIONER

Figure 3.10 Typical valve positioner with pneumatic input and output. Source: Reprinted with permission from Masoneilan North America Operations, Dresser Valve and Controls Division, Specification Data CS3000E, Houston, Texas, 1982

Fig. 3.9, in response to a low flow condition, the controller output signal to the positioner (1) would increase. When this pressure increases, the bellows (2) will extend, compressing the bellows spring (3). This causes the plunger covering the supply port to the valve actuator (4) to move. This uncovers the air supply port, while maintaining partial coverage of the exhaust port. This increases the air supply pressure to the actuator (5). The actuator will respond by lifting the valve stem (6) and increasing flow through the valve. Valve stem position is fed back to the positioner through a linkage (7), which is rigidly attached to the valve stem. As the linkage moves upward the bellows spring and the controller pressure will be the only two forces acting to restore equilibrium to the plunger. As flow approaches the set point the two opposing forces will reach an equilibrium, and the valve stem will come to rest in its new position.

\subsection{Description of Operation}

The following describes a typical loop for a control valve. A signal is transmitted from sensor (transmitter) to the controller. This signal may be either electric or pneumatic. 


\section{Equipment}

The signal represents the measured value of the controlled variable (temperature, pressure, level, etc.). This signal is received by the controller. In the controller the measured parameter is compared to a preset value (set point). If the difference between the measured parameter and the set point is too large, the controller sends a signal to the positioner, causing the positioner to change valve position. The positioner is coupled to the valve stem and receives constant direct feedback concerning stem position. The positioner will continue to adjust valve position until the difference between the measured parameter and the set point is brought to an effective value of zero (within the range of control).

\subsection{Potential Stressors}

As a result of the failures examined, the following stressors are evaluated for their potential role in AOV failures:

- elevated temperatures

- radiation damage

- erosion

- contaminated air supply.

Unfortunately, NPRDS reports seldom disclose a root cause for reported failures. While specific component failures are reported, the root cause of the failure is often not stated. Therefore, potential stressors must be examined. The determination of these stressors is based on an understanding of what factors could cause the types of degradation that were reported.

Elevated Temperatures: Under conditions of elevated temperature, ${ }^{3}$ nonmetallic components, such as diaphragms and O-rings, tend to "age" at an accelerated rate. Degradation by thermal aging results in drying, cracking, and embrittlement. Such failures often occur suddenly and without warning. Elevated temperatures also contribute to lubricant and/or seal degradation and solenoid coil burnout.

Radiation Damage: Radiation can cause damage similar to that incurred from thermal aging. Radiation damages the molecular chains in elastomer diaphragms and O-rings, which subsequently leads to either hardening to the point of embrittlement, or softening to such a degree that tensile strength is reduced to the point of rupture.

Erosion: Erosion ${ }^{4}$ affects the valve body or valve trim (disc, seats, stem) and is evidenced by the wearing away of these components. Because it is impossible to isolate the valve trim from the controlled fluid, erosion is unavoidable. There are several causes of erosion damage. Four fundamental causes are
- abrasive fluids

- corrosion

- erosion/corrosion

- cavitation.

Abrasive fluids contain particles that are harder than the trim material. The constant impingement of these particles on the valve body or trim will accelerate the wear of these parts by grinding away the surface.

Corrosion is the chemical reaction of the valve materials to the process fluid. Sometimes the valve will develop a thin layer of corrosive products that protects the valve from further wear. An example of this is a thin layer of rust that can form inside a valve. As long as the layer is not removed, further corrosion or rusting will not take place.

Erosion/corrosion is a cycle of wear such that the valve develops a "protective" layer of corrosion, which is subsequently eroded away by abrasive fluids, cavitation, or other means of eroding away the "protective" layer. This process then exposes new valve material to the effects of the corrosive fluid. This process of corrode/erode subsequently wears away the valve body or trim.

Cavitation occurs when the pressure of the fluid drops below the fluid vapor pressure. This is usually the result of increased fluid velocity at a flow restriction. This allows vapor bubbles to form in the fluid. Downstream of the flow restriction, the pressure increases as fluid velocity decreases, causing the collapse of the vapor bubbles. It is the force of the vapor bubble implosions at the fluid and valve interface that damages the valve body or valve trim. Cavitation also causes significant vibration that can cause fittings and fasteners to loosen.

Contaminated Air Supply: Contaminants such as water, oil, dirt, and grit all degrade AOV components. Water always has the potential to cause corrosion products. This is especially true for air systems with carbon steel piping. In addition to contributing to the formation of corrosion products, moisture in the air system can temporarily degrade the response of controllers and positioners. This occurs when water or water vapor must pass through various small passages and orifices in controllers and positioners, which changes the air flow rates. This in turn changes the response time of the device, with the ultimate impact showing up as a degraded system response. After the device is dried out or the water passes through, the device response will return to normal. However this may go undetected as a 
cause of device degradation. Dirt, grit, or other particulate

has been found to have degraded or prevented air from venting through discharge orifices of solenoid air pilot valves and valve air operators. A clogged orifice changes the bleed-down rate, which affects the valve opening or closing times and can result in stuck valves. ${ }^{5}$
It must also be noted that valve damage may result from very high velocity flow, improper valve sizing, or wrong material selection. 


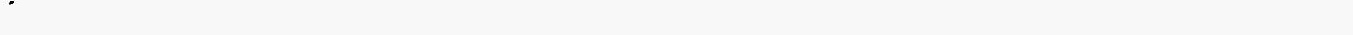




\section{Analysis of Failures}

\subsection{Procedure Used}

The NPRDS data base was screened for selected AOV failures as described in Sect. 1.3. More than 1500 records from the years 1988 through 1990 inclusive were selected for expansion of the coded fields. The new coding was performed manually by two analysts, and the data were entered and proofed by a data processing organization. After initial proofing, the data were randomly proofed again by a third analyst. Certain codes that proved to have considerable overlap or to be essentially the same were combined through computer manipulation of the data base. At this point the expanded data base was complete, and various sorts and data summaries were generated for this document.

\subsection{Coding Process and Codes Used}

This AOV coding effort essentially expanded the number of coded fields in the NPRDS data base. Failures were coded with information taken primarily from the following narrative fields in the NPRDS data base: Descriptive Narrative, Cause Narrative, and Corrective Action Narrative. Other useful information was gained from fields designated as component manufacturer, model number, nominal inlet size range, system status, valve type, valve actuator type, and others.

The expanded coded fields that were selected to be included for the purposes of this study are as follows:

- Plant Status at Failure

- Major Component Involved

- Specific Component Failed

- Severity of Failure

- Method of Detection

- Apparent Cause of Failure

- Ease of Correction

Each of these fields is discussed and the codes for each defined in the following sections. These fields collectively come very close to exhausting the codable information available in the narratives.

Information was not found in the narratives in a significant percentage of the records for fields such as Plant Status and Apparent Cause of Failure, and in such cases "unknown" was used.

\subsubsection{Plant Status Field}

This field describes the status of the plant at the time of the AOV failure. Inference was occasionally used when the narratives did not explicitly state the plant status at the time of failure but provided some suggestion that the plant was on-line. The narratives were explicit regarding plant status in all other cases where plant status was revealed. The plant status codes are shown in Table 4.1.

Table 4.1 Description of plant status at failure codes

\begin{tabular}{|c|c|}
\hline Category & Description \\
\hline On-line & $\begin{array}{l}\text { Plant is on-line (possibly at reduced } \\
\text { power) or presumed to be on-line } \\
\text { based on inference in narrative }\end{array}$ \\
\hline Startup & Plant is involved in startup operations \\
\hline Outage & $\begin{array}{l}\text { Refueling outages, cold shutdown, } \\
\text { maintenance and, in a few cases, an } \\
\text { unspecified outage }\end{array}$ \\
\hline Trip recovery & Immediately following a trip \\
\hline Hot standby & Hot standby \\
\hline Trip & During a trip or causing a trip \\
\hline Unknown & Unknown \\
\hline
\end{tabular}

\subsubsection{Major Component Field}

The Major Component field required that the AOV and its local support systems be divided up with a clear definition of all boundaries. Unfortunately, the plant personnel who originally prepared the narratives did not always see the same divisions. For instance, "Operator" was often used to describe nearly everything but the valve itself, while sometimes the positioner was recognized as a separate entity. Most workers had undoubtedly learned in training that the positioner and the solenoid valves are piece parts of the operator. This seems reasonable because the positioner and some solenoids are mounted on the side of the operator and they work together.

The defining of component bounds is, of course, arbitrary; however, consistency is necessary especially in a coding process such as this. A list of the major component codes and their definitions is shown in Table 4.2. 
Table 4.2 Description of major component codes

\begin{tabular}{|c|c|}
\hline Category & Description \\
\hline Valve & $\begin{array}{l}\text { Those components located generally beneath the actuator yoke including the body, } \\
\text { disc/plug/ball, cage, bonnet, and packing nuts, etc. }\end{array}$ \\
\hline Actuator & $\begin{array}{l}\text { The mechanism exerting force on the stem. Actuator or operator }{ }^{a} \text { includes either a diaphragm } \\
\text { and its casing or, in the case of a piston actuator, piston cylinder, and O-rings. The yoke, } \\
\text { spring, spring adjuster, limit switches, travel indicator, associated fasteners, etc. are also } \\
\text { included. }\end{array}$ \\
\hline Stem & $\begin{array}{l}\text { The valve stem and the actuator stem (sometimes called shaft, connector, etc.). In cases where } \\
\text { the valve stem failed along with valve subcomponents, the "Valve" code was generally used } \\
\text { and the stem included as a valve subcomponent. }\end{array}$ \\
\hline Control system & $\begin{array}{l}\text { Not only the controller but also the positioner, air regulator, solenoid valves, and associated air } \\
\text { lines and fittings }\end{array}$ \\
\hline Electrical support & Electrical support and other "far removed" miscellaneous support systems \\
\hline Unknown & Unknown \\
\hline
\end{tabular}

\subsubsection{Specific Component Field}

Components that have failed or fallen out of adjustment were listed in this field. Components, such as seals and gaskets, replaced solely for the sake of good maintenance practice on an already disassembled unit were not listed.

Perhaps the most troublesome component was the air solenoid valve. This component has many variations and names such as pilot valve assembly, control air solenoid, solenoid valve, air pilot solenoid, etc. This field was coded with an attempt at using consistent nomenclature for components that are the same or variations of the same. Those specific components contributing at least five failures to the data base are shown in Appendix A,Table A.1.

\subsubsection{Severity of Failure Field}

The severity of failure field looks at the effect of the anomaly on the control/functionality of the AOV; it does not consider the severity in terms of the overall damage/ degradation experienced by the valve (that is reflected in the "Ease of Correction" field). Hence, the most severe failure as defined by this field is a valve that is open when it should be closed and vice versa (i.e., a command fault). This is not a measure of failure effect on either the plant or the system. The severity of failure codes is shown in Table 4.3.

\subsubsection{Method of Detection Field}

The method of detection refers to the activity (e.g., testing activity, walkdown, inspection, etc.) or hardware/control panel indication that revealed the valve anomaly. The method of detection field codes are as shown in Table 4.4.

\subsubsection{Apparent Cause of Failure Field}

Selection of this code was based almost entirely on the narrative in the NPRDS data base. Occasionally, where the narrative expressed uncertainty regarding cause, or where the cause was not identified but self-evident, a code was assigned by the analyst based on the information available. Generally, if a cause was not identified and more than one cause was possible (almost always the case), an "unknown" cause code was selected. Apparent cause codes and their descriptions are shown in Table 4.5.

\subsubsection{Ease of Correction Field}

The ease of correction categorization was divided into five classifications: (1) adjust or calibrate, (2) replace parts, (3) major repairs, (4) replace unit, and (5) unknown. "Adjust or calibrate" was used when adjustment, cleaning, or calibration of components was performed as corrective action. This was applicable when disassembly of the valve or actuator was not required. "Replace parts" was used when a small number of parts was replaced or another type of corrective action was performed that required disassembly of the valve or actuator. "Major repairs" was 
Table 4.3 Description of severity of codes

\begin{tabular}{ll}
\hline \multicolumn{1}{c}{ Category } & \multicolumn{1}{c}{ Description } \\
\hline Severe & $\begin{array}{l}\text { Used in command faults where the valve can no longer be opened and closed using normal } \\
\text { operator controls. Included are cases where the valve begins to cycle in an uncontrolled man- } \\
\text { ner. This is not an indication of the effect of the failure on valve safety function or plant } \\
\text { operation. For many AOV failures the valve will move to its safety-related position. }\end{array}$ \\
Moderate & $\begin{array}{l}\text { Used in cases where the control of the valve position is degraded, where considerable position } \\
\text { efror is occurring, where response time is out-of-limits, where the position indication fails, } \\
\text { etc. }\end{array}$ \\
Insignificant & $\begin{array}{l}\text { Applied to minor seat leakage, small air leaks that do not affect valve response, a one-time } \\
\text { failure of a valve to respond that cannot be duplicated, etc. These events were deleted from } \\
\text { the population of records on which further analysis was performed, and therefore insignifi- } \\
\text { cant AOV failures were not given expanded, coded fields. }\end{array}$ \\
Unknown & $\begin{array}{l}\text { Specified primarily for the cases where it is not known what effect the identified fault would } \\
\text { have on the operability of a valve. }\end{array}$ \\
\hline
\end{tabular}

Table 4.4 Description of method of discovery codes

\begin{tabular}{ll}
\hline \multicolumn{1}{c}{ Category } & \multicolumn{1}{c}{ Description } \\
\hline Testing & $\begin{array}{c}\text { Problems discovered during required off-line test, surveillance or periodic testing, or miscella- } \\
\text { neous testing where a reason for the test was unspecified }\end{array}$ \\
Maintenance & $\begin{array}{c}\text { Problem discovered during a maintenance or troubleshooting action/procedure on the valve or } \\
\text { an unrelated piece of hardware }\end{array}$ \\
$\begin{array}{l}\text { Operational } \\
\text { abnormality }\end{array}$ & $\begin{array}{c}\text { Abnormality discovered as a result of valve control indication, inappropriate process parame- } \\
\text { ter (e.g., temperature, flow, pressure, etc.), or through any routine observation of an anomaly }\end{array}$ \\
Walkdowns & $\begin{array}{c}\text { Problem observed during walkdowns including quality control walkdowns, engineering walk- } \\
\text { downs, or while making the "rounds" }\end{array}$ \\
Special inspection & $\begin{array}{l}\text { Problem discovered during a special inspection performed for whatever reason } \\
\text { Unknown }\end{array}$ \\
\hline
\end{tabular}

Table 4.5 Description of failure cause codes

\section{Category}

Normal wear or aging

Cyclic fatigue

Vibration

Severe or abnormal service conditions

Water through air line

Description

Used in cases where the only indication of failure cause was normal wear or aging. Includes some instances of early wear-out failure due to unidentified causes (e.g., high temperature).

Used in cases where it was known or surmised that cyclic fatigue contributed to the failure. In the frequent instances where the NPRDS narrative pairs cyclic fatigue and aging/wear, this code alone was used.

Used for situations in which vibration was believed to be a contributing factor in a failure. In the instances where the NPRDS narrative pairs vibration and aging/wear, this code alone was used.

Assigned where it was clear in the NPRDS narrative that described service conditions, such as high temperature, dripping/spraying water, etc., were important factors leading to the failure.

Used in cases where water was discovered inside the diaphragm cover, apparently having entered from the instrument air line. A coding rule was adopted where all moisture-/water-induced failures were covered by the "severe service conditions" failure cause code except for water intrusion into the actuator via the instrument air line that uses this code. 


\begin{tabular}{|c|c|}
\hline Category & Description \\
\hline Improper maintenance & $\begin{array}{l}\text { Assigned in cases where it was stated/suggested that the failure resulted from improper maintenance } \\
\text { (e.g., wrong part used) or in cases where the circumstances of the failure indicated a lack of mainte- } \\
\text { nance (e.g., no lubrication, dirty, etc.). }\end{array}$ \\
\hline Foreign material & Assigned in cases where material from outside the valve assembly contributed to the failure. \\
\hline $\begin{array}{l}\text { Inappropriate valve } \\
\text { application }\end{array}$ & $\begin{array}{l}\text { Used in cases where it appeared that the wrong type of valve or actuator was used in an application } \\
\text { and failed for that reason. }\end{array}$ \\
\hline Human error & $\begin{array}{l}\text { Used when there were obvious indications that the failure was initiated by inappropriate or accidental } \\
\text { actions by a worker (e.g., tearing an instrument air line). However, care was taken not to assign this } \\
\text { code when it appeared that the design made hardware susceptible to damage. }\end{array}$ \\
\hline Missing parts & Used for assemblies having a missing part(s). \\
\hline $\begin{array}{l}\text { Design or } \\
\text { manufacturer } \\
\text { deficiency }\end{array}$ & $\begin{array}{l}\text { Used in cases where it was clear that poor design and/or manufacturing were significant contributors } \\
\text { to a failure. However, note that frequent hardware "wear-out" problems (e.g., solenoid valves) may } \\
\text { have unrecognized design flaws as their root cause; therefore this code may only have been used } \\
\text { effectively in somewhat isolated cases. }\end{array}$ \\
\hline Procedural weakness & Used where inadequate procedures existed for installation, adjustments, etc. \\
\hline Improper installation & Used for instances of poor assembly or component installation. \\
\hline Lack of use & $\begin{array}{l}\text { Assigned to cases where it was stated that the valve was rarely used, and this appeared relevant to the } \\
\text { failure (e.g., valve improved when cycled). }\end{array}$ \\
\hline Corrosion & Used when corrosion was observed and related to the failure symptoms \\
\hline Unknown & Unknown failure cause \\
\hline
\end{tabular}

reserved for corrective action including cutting a valve out of a line, replacing a large number of parts (excluding seals or gaskets), machining of plugs and seats, combinations of both extensive adjustments and part replacements, performing engineering investigations of root cause, or implementing modifications, repairing secondary failures (e.g., system interaction), etc. "Replace unit" was used for replacement of a valve and/or actuator as a complete unit. "Unknown" was assigned when no corrective action was apparent from the narrative. Ease of correction codes and their descriptions are shown in Table 4.6.

Table 4.6 Description of ease of correction codes

\begin{tabular}{ll}
\hline \multicolumn{1}{c}{ Category } & \multicolumn{1}{c}{ Description } \\
\hline Adjust or calibrate & $\begin{array}{c}\text { Adjustment, cleaning, and calibration of components/subsystems where disassembly of } \\
\text { valves or actuator is not required } \\
\text { Replacement of a small number of parts or another type of corrective action that requires } \\
\text { disassembly of valve or actuator }\end{array}$ \\
Major repairs & $\begin{array}{l}\text { Corrective actions including such things as replacing a large number of parts excluding } \\
\text { seals and gaskets, machining of plugs and seats, combinations of both extensive adjust- } \\
\text { ments and part replacements, performing engineering investigation of root cause or } \\
\text { implementing modifications, repairing secondary failures (e.g., system interaction), etc. }\end{array}$ \\
Replace unit & $\begin{array}{l}\text { Replacement of valve and/or actuator } \\
\text { Unknown }\end{array}$ \\
\hline
\end{tabular}




\subsection{Data Summary and Analysis}

Of the 1503 failures that were analyzed for the study, 337 were identified as "valve-only" failures and 1166 as failures of either the controls or the valve actuator. This is shown in Fig. 4.1. It is apparent from this breakdown that the emphasis for further study needs to be placed on the valve actuator and control subsystems.

The higher percentage of failures involving the actuator or controls category is expected based on the relatively large number of active electrical, mechanical, and pneumatic components contained in the controls and actuator. A summary of total numbers of failed components, representing the basis of Fig. 4.1, is provided in Appendix A, Table A.1.

\subsubsection{Combined Failures of Valves, Actuators, and Controls}

Data were grouped into one of three categories: (1) combined failures (including valve-only and other failures; this category comprises all 1503 failures); (2) valve-only failures; or (3) other failures (i.e., failures of actuators and/or control systems or those that could not be classified). This section applies to combined failures, so that all of the information contained here applies to the entire AOV assembly as shown in Fig. 3.1.

\subsubsection{Major Component}

Figure 4.1 illustrates the distribution in terms of major component area involved in all failures. Note that the actua- tor and control system categories together make up 78\% of the combined failures, while the valve-only category accounts for only $19 \%$ of the total. Only $3 \%$ of the total number of the 1503 total failures could not be classified by their major component area based on the NPRDS narrative.

The actuator and controls major components were involved equally in failures because each had serious reliability problems in a number of their components; that is, diaphragm ruptures and defective limit switches in the actuators, and solenoid valves, air lines, and air regulators in the controls. Of course many other components were involved in failures, especially in the controls.

\subsubsection{Valve Type}

As shown in Fig. 4.2, the valve type distribution for the population of all AOVs available to fail ${ }^{*}$ was comprised primarily of globe and butterfly valves. Globe valves comprised $48 \%$ of the total, butterfly valves $21 \%$, gate valves $13 \%$, and the remaining three types-check, plug/ball, ${ }^{\dagger}$ and diaphragm, made up about $17 \%$ of the

\footnotetext{
*The population available to fail consists of those actuators that meet the scope established in Sect. 1.3, without limiting the selection to valves that have actually failed in service.

tplug and ball valves together accounted for only $5 \%$ of the total number of failures and only $7 \%$ of the available population. Since their designs are similar, they are grouped together in this report for analysis purposes.
}

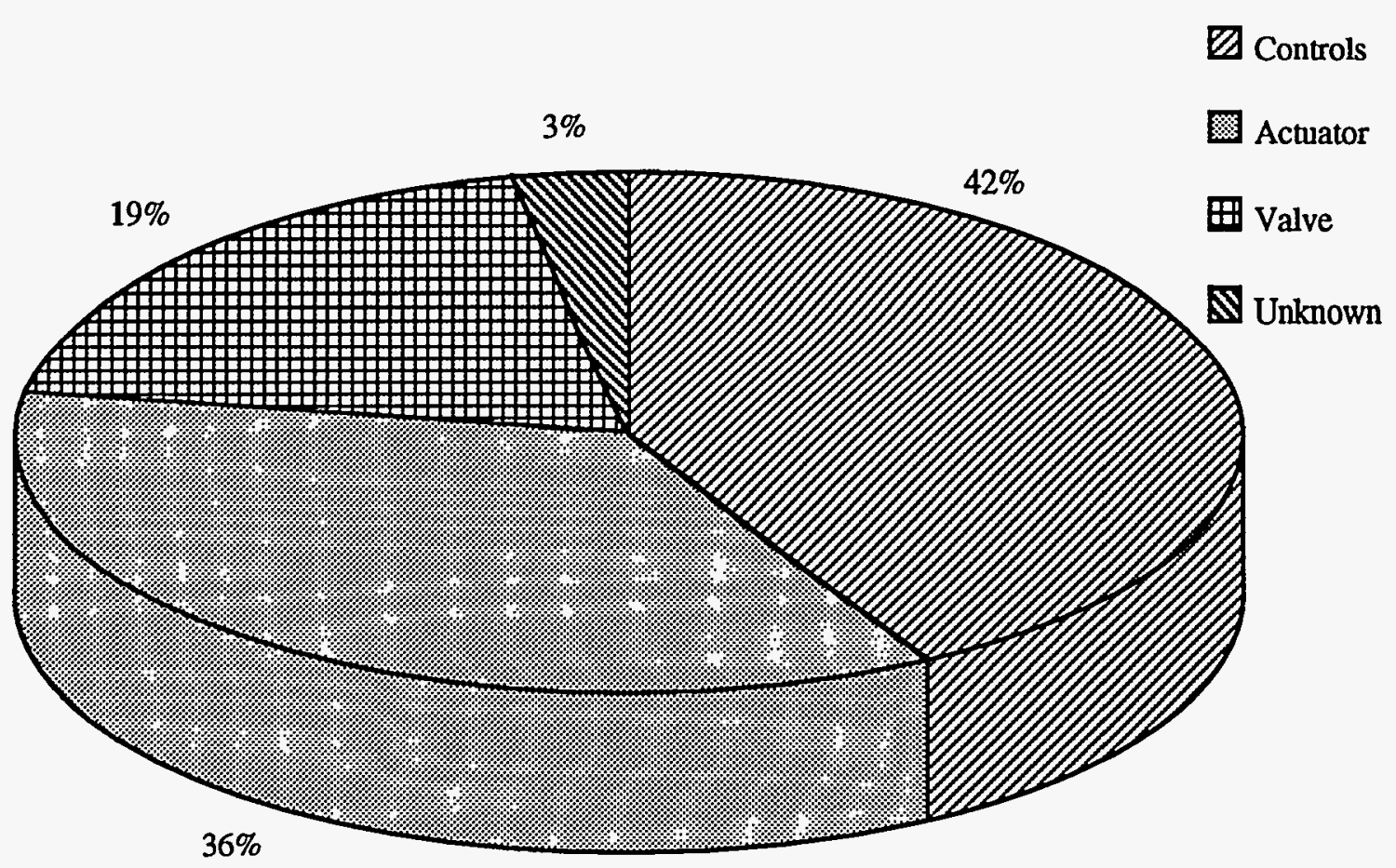

Figure 4.1 Major component area involved in failure 


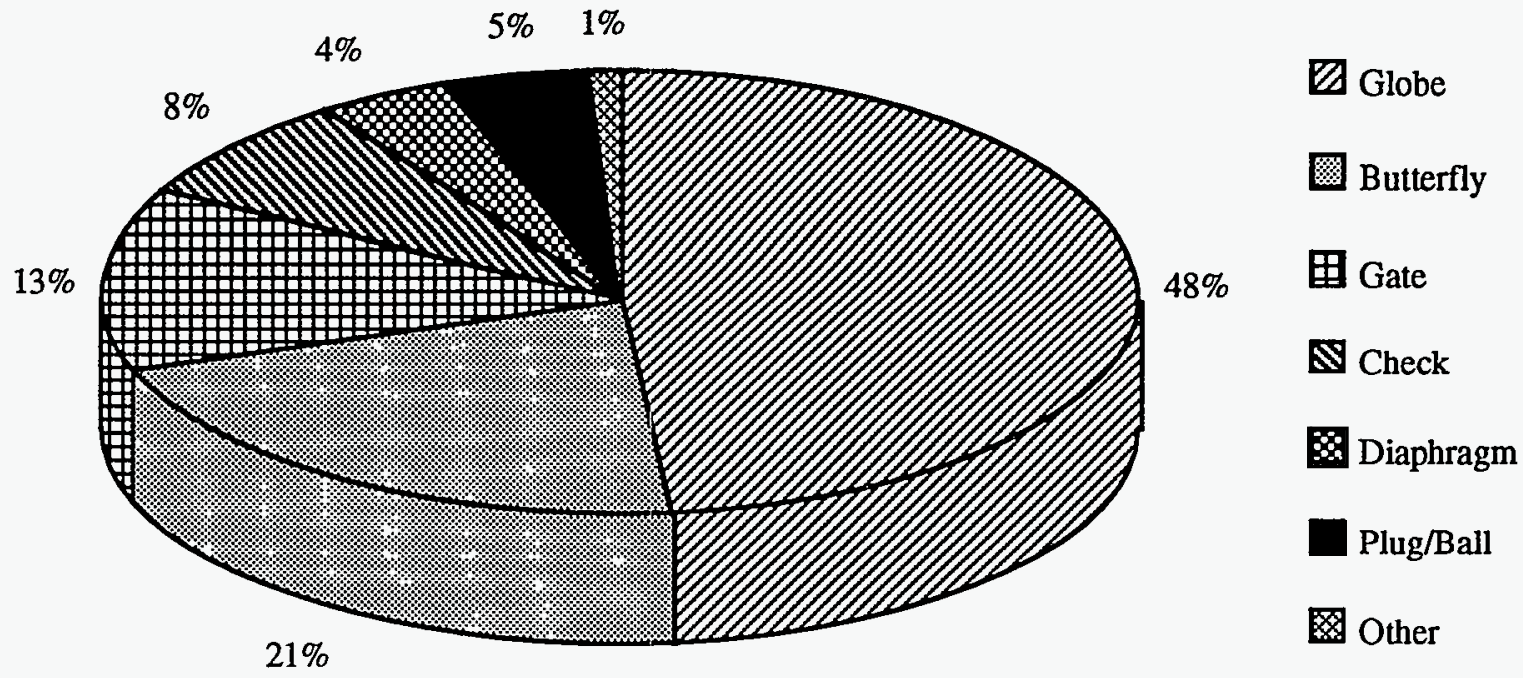

Figure 4.2 Valve type distribution from AOV population

population. The most common AOV valve type, globe, also happens to be the primary valve type for control applications.

\subsubsection{Normalizing the Data}

It should be noted that with data of this type, graphs of failures may be misleading if the raw data are presented. This is caused by the influence of the valve population in service during the time period being studied. For example, the data could show that a large percentage of valves over 60 in. failed. ${ }^{*}$ This could lead to undue attention to valves in this size range until it is discovered that this valve size range has a small population and therefore accounts for a small percentage of overall failures. Where normalized data are used in this report, the following procedure was used for normalizing the data. 6

1. Divide the failures for a given category, such as globe valves, by the number of years of service for that category of valves during 1988 to 1990 . The years of service are determined by taking the service life of each valve in the time period and summing the totals for all valves within the category. Therefore, a valve placed in service in 1986 would accumulate 3 years of service life between 1988 and 1990. A valve placed in service in 1989 would accumulate 2 years of service life between 1988 and 1990.

\footnotetext{
*This example is hypothetical and does not in any way represent actual data presented later in the report.
}

2. Determine the overall failure rate for all valves. This is accomplished by dividing the total number of failures in the study $(1,503)$ by the total number of years of service $(154,742)$. The result, 0.0097 , is applied to the individual category failure rates to establish the "Relative Failure Rate."

3. Therefore, for example, the failure rate for valves $2 \mathrm{in}$. to $3.99 \mathrm{in}$. would be

$$
\frac{537}{62,029}=0.0086 \text {. }
$$

The relative failure rate for valves in this size range is calculated to be

$$
\frac{0.0086}{0.0097}=0.89 \text {. }
$$

\subsubsection{Valve Size}

Figure 4.3 illustrates the relationship between relative failure rate by valve size range and the fraction of total valve population. Supporting data are contained in Table 4.7. Note that valves $<2$ in. in size are not included in this study. It is clear that a greater number of valves are in service in the smaller size ranges ( $\leq 19.99$ in.) than in the larger sizes; however, the relative failure rate is nearly constant for valves in all size ranges up to $60 \mathrm{in}$. The number of valves in service over 60 in. drops significantly, to only $1.8 \%$ of the total population. In terms of choosing which valves to emphasize in plant preventive/predictive maintenance and 


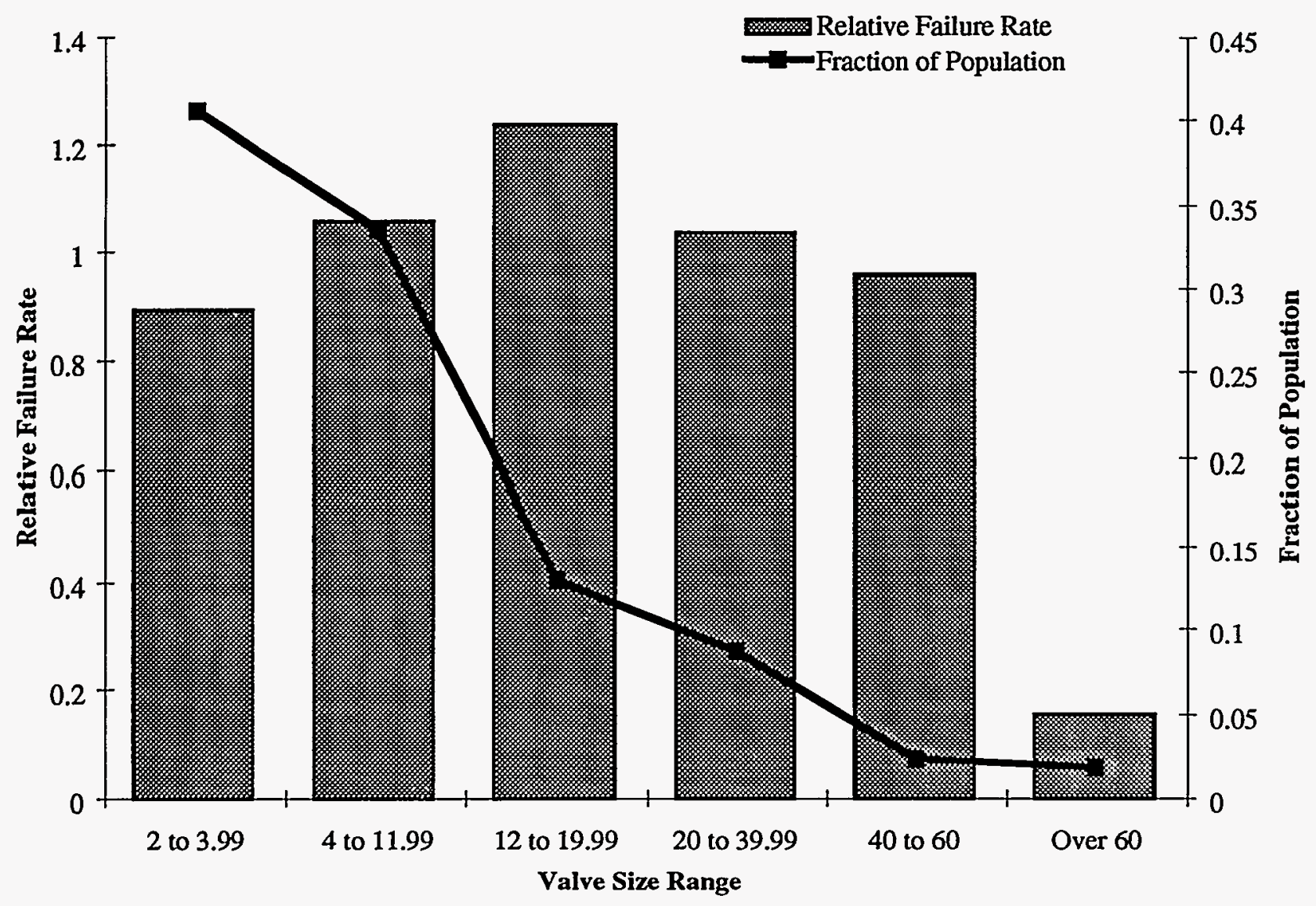

Figure 4.3 Relative failure rate of combined components compared to valve population for valve size range

Table 4.7 Relative failure rate of combined components compared to component population for valve size range

\begin{tabular}{lccccccc}
\hline & \multicolumn{7}{c}{ Valve size range (in.) } \\
\cline { 2 - 7 } & $\mathbf{2}$ to 3.99 & $\mathbf{4}$ to 11.99 & $\mathbf{1 2}$ to 19.99 & $\mathbf{2 0}$ to 39.99 & $\mathbf{4 0}$ to 60 & Over 60 \\
\hline Relative failure rate & 0.89 & 1.06 & 1.24 & 1.04 & 0.96 & 0.15 \\
Fraction of population & 0.41 & 0.33 & 0.13 & 0.09 & 0.02 & 0.02 \\
\hline
\end{tabular}

monitoring programs, the highest relative rate of return (i.e., economic return) for reliability improvements would likely be obtained by monitoring the valves 20 in. and larger. Valves in the 12- to 19.99-in. range, however, exhibited the highest relative failure rate, so it is possible that improved monitoring of these valves would yield a greater return from the aspect of plant safety and reliability. Valves $<12$ in. might be selected individually for enhanced monitoring based on function and required reliability. Obviously, factors other than size should also be considered.

Valves over 60 in. are generally used in ventilation systems. Their lower rate of failure is therefore due primarily to the fact that they are operated at low temperature and very low pressure and are subjected to low flow rates. Their reliability may also be due to an increase in the margin of safety or "overdesign" that designers create for large valves.

\subsubsection{Plant Status at Failure Discovery}

Plant status at time of failure discovery was also tabulated. From Fig. 4.4, it can be seen that most of the failures occurred or were found either during an outage (37\% of the total) or while the plant was on-line at power ( $31 \%$ of the total). It will be seen in a later figure that there is a correlation between plant status at time of failure and discovery 


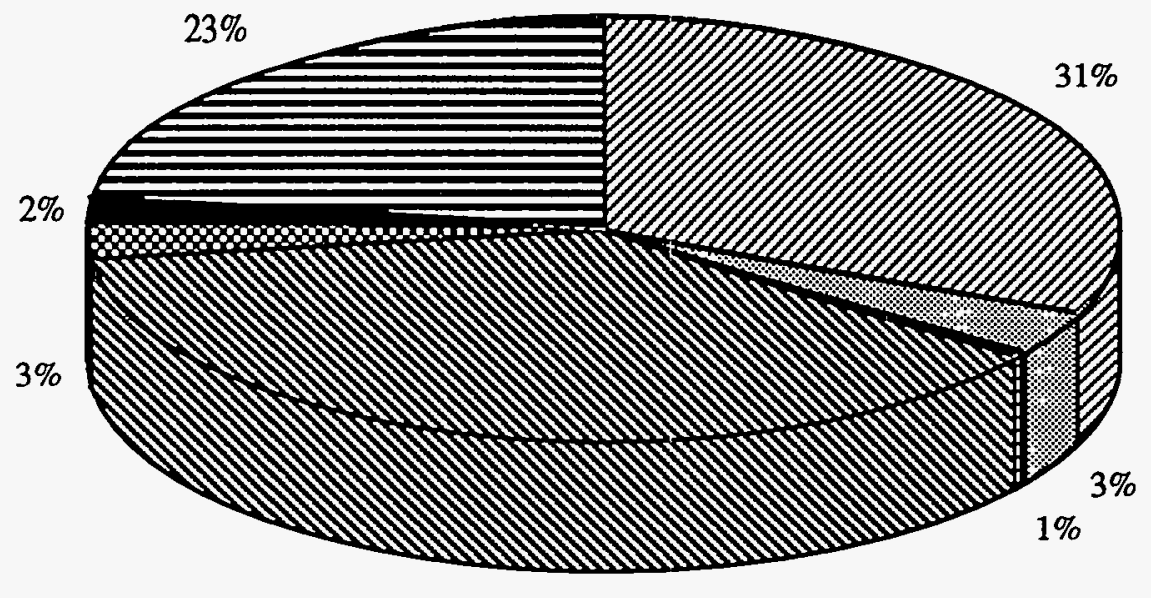

Z On-line

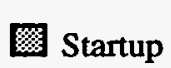

Trip Recovery

Outage

因 Hot Standby

Trip

$37 \%$

Figure 4.4 Plant status at failure for combined components

method; that is, most of the on-line failures were detected by either operational abnormality or during walkdown, and most of the outage failures were detected by testing. The NPRDS narratives did not identify the plant status at failure in a significant number of failures, accounting for $23 \%$ of the total. That a large percentage of failures were discovered while the plant was on-line at power is expected because for most valves the number of actuations/demands is greatest during this condition. Failure discovery is also high during refueling because (1) some systems remain operational at this time, (2) certain systems are most active during refueling, (3) a large percentage of valve testing is performed during refueling, and (4) some valves are only accessible while the unit is shutdown.

\subsubsection{Method of Detection}

Failures were most commonly detected by either operational abnormality, 44\%, or testing, 36\% (including miscellaneous, surveillance, and required testing). Failures discovered during maintenance activities, special inspection, and walkdown each accounted for $<10 \%$ of the total (Fig. 4.5). In 5\% of the cases, the NPRDS narrative failed to identify a method of discovery.

The $44 \%$ of failures discovered through operational abnormalities resulted in corrective maintenance. This number appears rather high and may possibly be reduced. AOVs contain certain high failure rate components (Appendix $\mathrm{A}$, Table A.1) that compromise the AOVs normal function and that, in some cases, might be readily replaced in a costeffective preventive maintenance program.
Nevertheless, the chart also shows that testing, walkdowns, and special inspection account for $45 \%$ of the failures detected, thereby precluding many upsets to operations due to AOV failures. Walkdowns, which are essential even apart from the surveillance of valves, require a modest amount of time for the valuable returns gained in overall surveillance of the systems. Walkdowns and observations during area maintenance operations are quite effective in discovering audible instrument air leaks, bent stems, and lack of stem lubrication, all of which may compromise normal AOV function.

\subsubsection{Severity of Failure}

Clearly, the combined failures were evenly divided between moderate and severe: $44 \%$ and $43 \%$, respectively (Fig. 4.6). Only $13 \%$ of the total number of failures were listed as having an unknown level of severity. Insignificant failures (e.g., minor seat leakage) were not included in the data analysis.

\subsubsection{Apparent Cause}

Figure 4.7 shows the distribution of failures according to apparent cause (of failure). It should be noted that the total number of failures listed in Table 4.8 is greater than 1503; this is due to cases where multiple apparent failure causes were listed.

Thirty-one percent of the failures were classified as normal wear or aging according to the NPRDS narratives. This can 


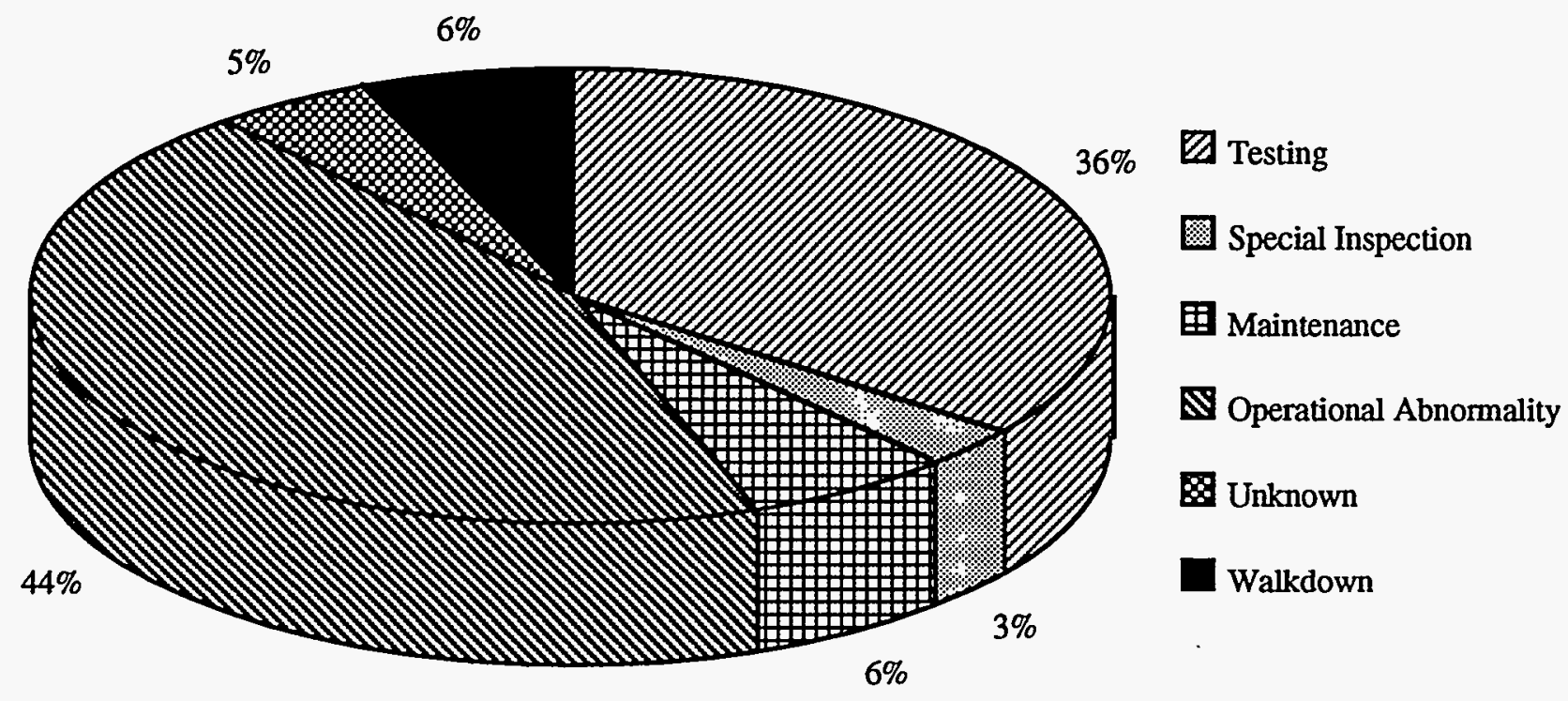

Figure 4.5 Method of detection for combined components

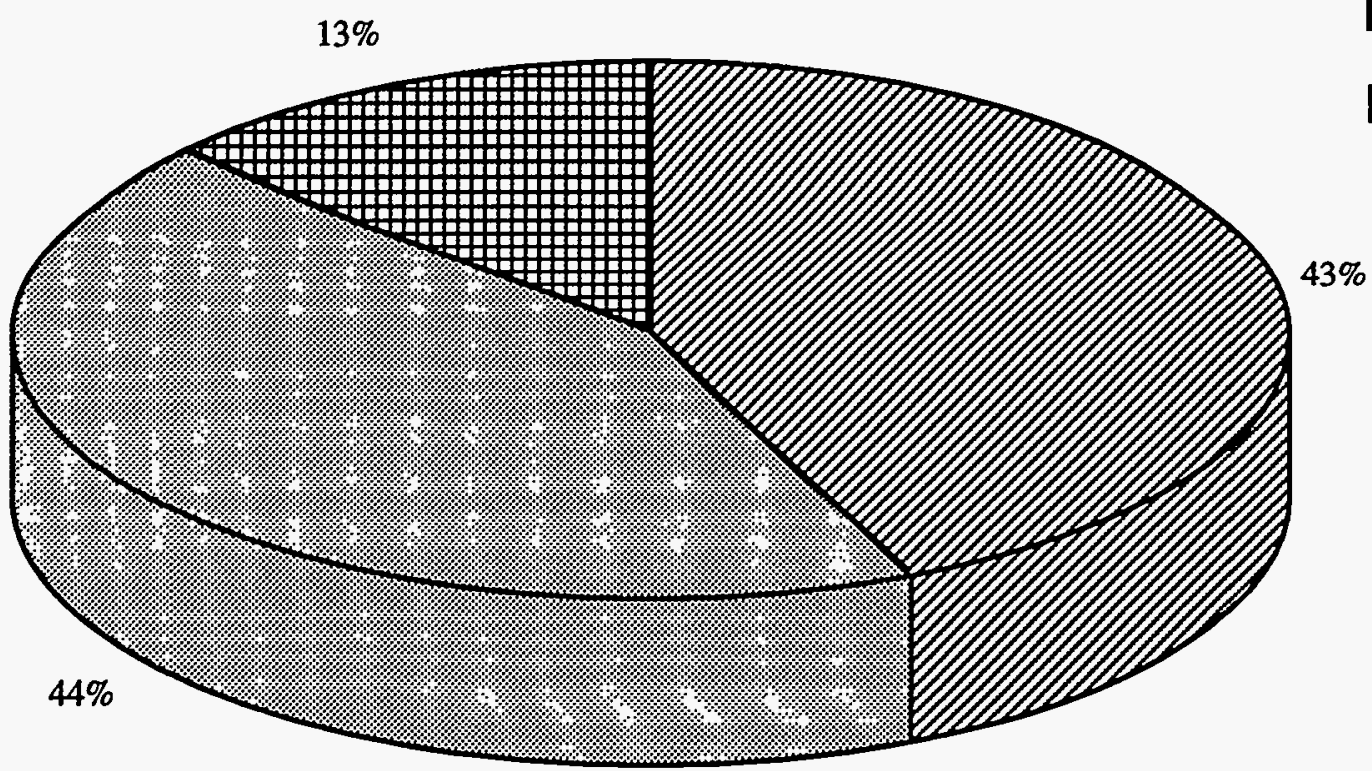

$\bigotimes$ Severe

Moderate

世 Unknown

Figure 4.6 Severity of failure for combined components 


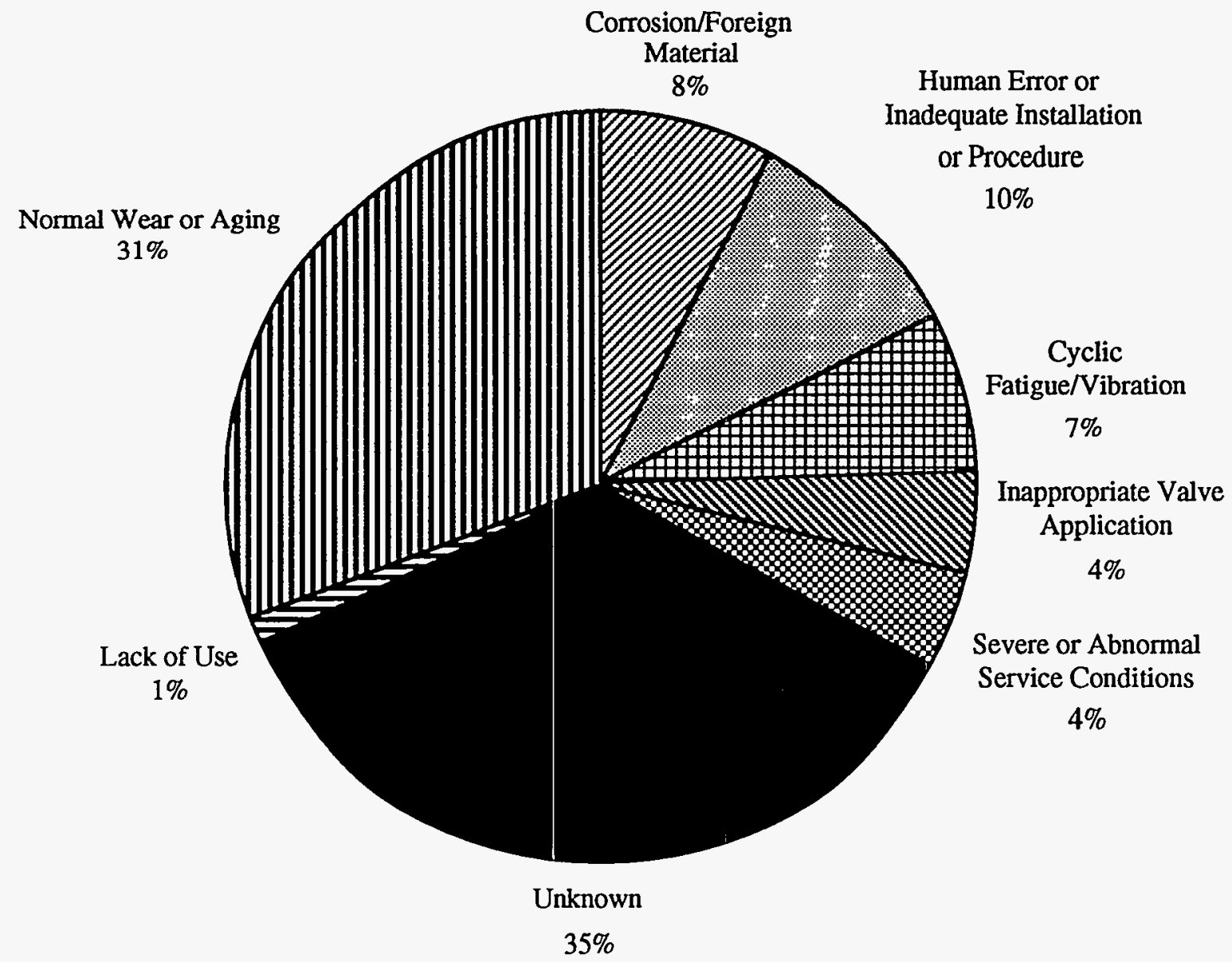

Figure 4.7 Distribution of failures by apparent cause for combined failures

Table 4.8 Distribution of failures by apparent cause

\begin{tabular}{lc}
\hline \multicolumn{1}{c}{ Apparent cause of failure } & Failure count \\
\hline Corrosion/foreign material & 120 \\
Human error or inadequate installation & 159 \\
or procedure & \\
Cyclic fatigue/vibration & 108 \\
Inappropriate valve application & 70 \\
Severe or abnormal service conditions & 66 \\
Unknown & 553 \\
Lack of use & 19 \\
Normal wear or aging & 485 \\
Total & 1580 \\
\hline
\end{tabular}

perhaps be attributed to a lack of root cause analyses performed for each failure. In many cases, it appeared as though normal wear or aging was listed in the narrative as a default failure cause. For uniformity, the assessment in the narrative description was accepted unless uncertainty was expressed in the narrative, in which case the "unknown" code was assigned.
In $35 \%$ of the failures reviewed, no cause was listed, or it was stated that the failure cause was unknown. Other common causes listed in the NPRDS narratives included human error or inadequate installation or procedure, and the presence of corrosion/foreign material in the valve. Cyclic fatigue and/or vibration were also commonly listed failure causes and were frequently combined with normal wear and aging in the failure narratives. Note that in many cases, the narratives did not specifically list an apparent failure cause. In these cases, it was left up to the analyst to infer the cause, if possible, based on the text.

In addition to the code combinations specified in the chart, "severe or abnormal service conditions" also includes the "water through air line" code, "human error" also includes "missing parts" and "maintenance", and "inappropriate valve application" also includes "poor design/ manufacture."

That normal wear or aging was assigned as the failure cause in almost $50 \%$ of the "known" cases is expected in processes where repairs are generally made as corrective 
maintenance as opposed to a preventive maintenance schedule. Many actuator diaphragms and solenoid valves were determined to be "worn out;" however, in light of these high relative failure rates, one should hesitate to accept wear out as unavoidable and inevitable. It may be prudent to question whether design or maintenance improvements should be explored to ensure that the components "wear out" later instead of earlier. Another alternative may be a preventive maintenance program in which certain subcomponents are routinely replaced just prior to predicted wear-out failures. The division between wear out and both corrosion and fatigue was uncertain in many instances for the narrative writer and analyst. For instance, it was not known if a diaphragm tear was due to a material aging process, fatigue, or both.

\subsubsection{Ease of Failure Correction}

Figure 4.8 shows that most corrective actions involved only minor repairs or part replacement [i.e., $83 \%$ of the total failures analyzed were corrected by either adjustment/ recalibration or part(s) replacement]. Only $5 \%$ of the actions taken to correct a failure involved unit replacement, and only $12 \%$ involved a major repair effort. Adjustment/ calibration generally required the least amount of effort of the four categories. The positioner, with its cams, linkages, and adjustable stops, was the item requiring most of the adjustments/calibrations; however, valve stem travel and the stem spring also required adjustment in many cases. The large number of part replacements reflects primarily the high frequency of wear out and fatigue of many of the specific components shown in Appendix A, Table A.1. These components were either often found to be nonfunc- tional (e.g., degraded solenoid valves, air regulator, limit switch, etc.) and/or appeared to be obviously nonrepairable or required major effort to repair (e.g., torn diaphragm, severed air line, scored/eroded seat and disc, etc.).

\subsubsection{Comparison of Severity and Plant Status}

The severity of failure vs plant status at time of failure detection is illustrated in Fig. 4.9. Supporting data are shown in Table 4.9. Although the severe failure classification is applied to $92 \%$ of the failures occurring during a reactor trip, the reader should note that following a reactor trip it is not unexpected that failures involving degraded performance would go unnoticed. Rather, during the recovery process unit operators would only be concerned with component failures that compromised the ability of the component to function. Investigation showed that no one component was involved on a consistent basis and that $75 \%$ of the failures were discovered through operational abnormality. Review of testing frequency and stroke time requirements for the valves also did not provide any insight into this imbalance in severity. The reader is cautioned against assigning undue significance to these figures without further study into the details surrounding each reported failure. Other notable information includes an almost $52 \%$ rate of severe failures for occurrences during plant startup, $50 \%$ as severe following a reactor trip, and $48 \%$ as severe while the plant was on-line. Also notable was that nearly $54 \%$ of the failures detected during hot standby were classified as moderate. Division of failures into severe vs moderate was almost even (in the 40 to $48 \%$ range) for those occurring while the plant was on-line or during an outage.

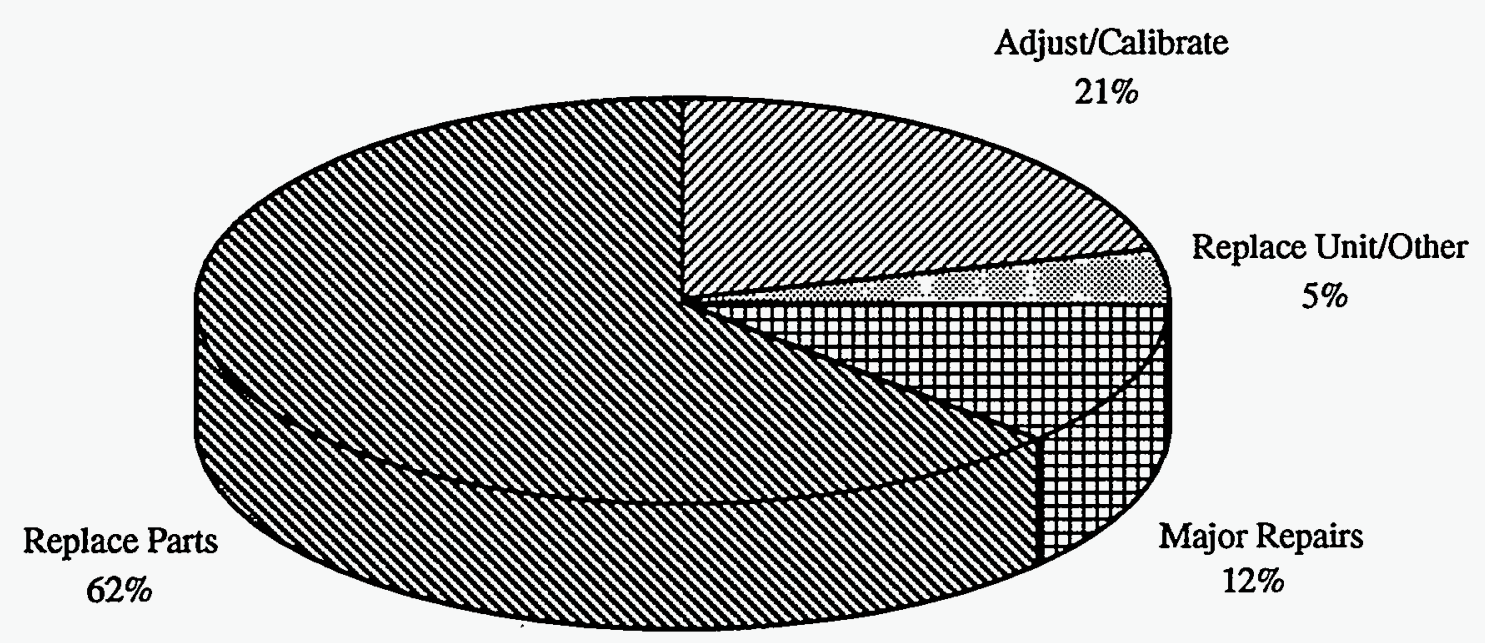

Figure 4.8 Ease of failure correction for combined components 


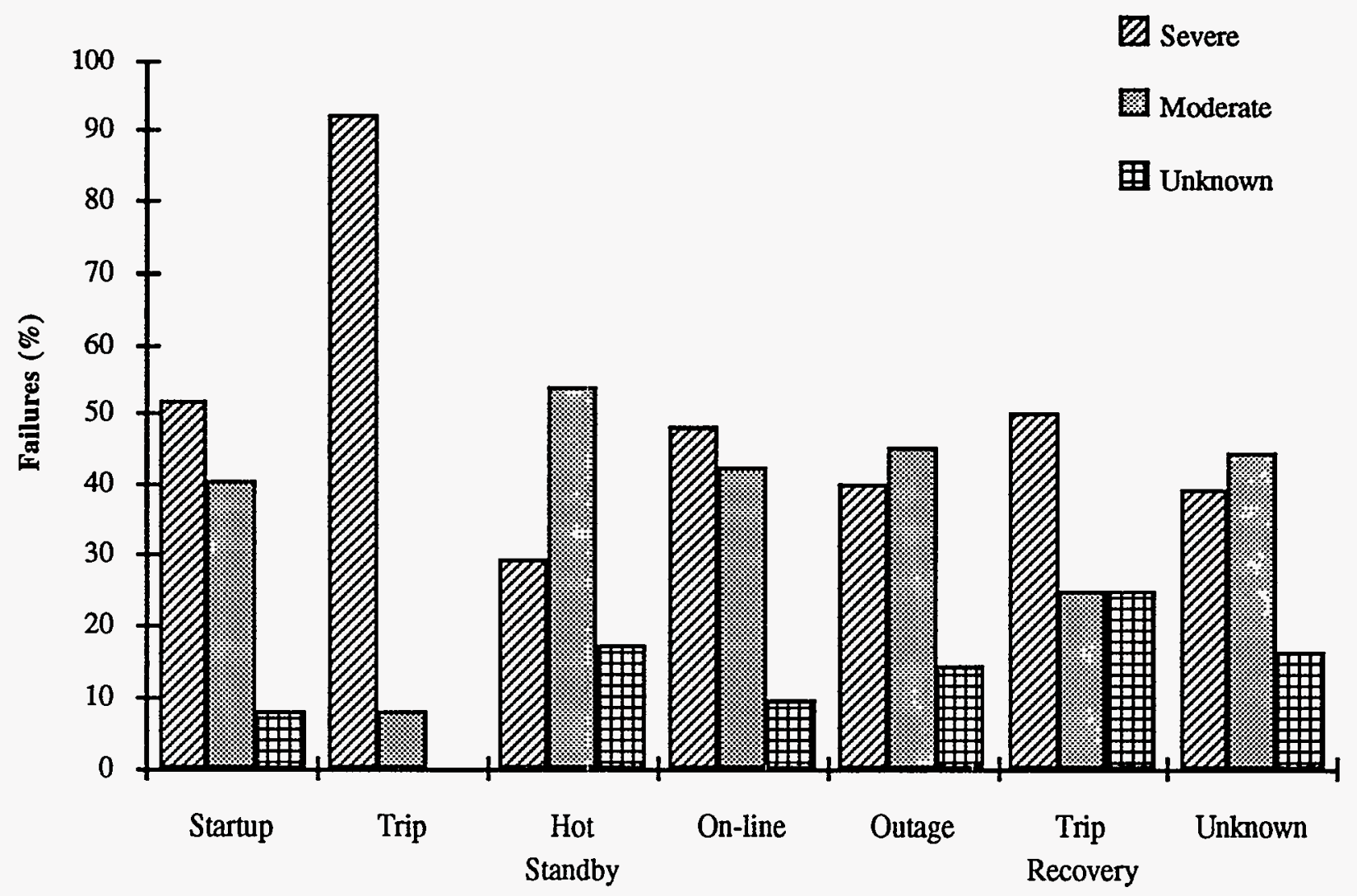

Plant Status at Failure

Figure 4.9 Distribution of combined failures by severity of failure and plant status at failure

Table 4.9 Distribution of combined failures by severity of failure and plant status at failure

\begin{tabular}{lccc}
\hline & \multicolumn{3}{c}{ Failure (\%) } \\
\cline { 2 - 4 } Plant status & Severe & Moderate & Unknown \\
\hline Startup & 51.9 & 40.4 & 7.7 \\
Trip & 92.0 & 8.0 & 0.0 \\
Hot standby & 29.3 & 53.7 & 17.1 \\
On-line & 48.0 & 42.5 & 9.5 \\
Outage & 40.2 & 45.4 & 14.4 \\
Trip recovery & 50.0 & 25.0 & 25.0 \\
Unknown & 39.2 & 44.4 & 16.4 \\
\hline
\end{tabular}

The high percentage of severe failures during or immediately following a trip was due to common mode failures in several valves used for pressure relief in the main steam system. The failures involved set point drift and/or corrosion-induced bonding of the pilot valve disc to the pilot valve seat surface. It will be shown later that only 25 failures were encountered during trips and that these were discovered through operational abnormalities.

Few moderate failures were discovered during trips most likely because anomalies such as a slow response time or incorrect position indication or other less severe problems are not readily discovered in a trip situation due to the focus of attention on trip response and recovery.

That the percentage of moderate severity failures is so much higher than serious failures during hot standby is probably due to the fact that nonfunctional valves were already discovered while going off-line and, if applicable, while in cold shutdown.

Also, in cases where cold shutdown precedes hot standby, thorough monitoring and inspection activities during hot standby testing to ensure that the plant is ready for startup may have been effective in discovering the more subtle anomalies in valves (i.e., moderate severity).

\subsubsection{Method of Failure Detection}

Figure 4.10 shows the method of failure detection by valve size range for combined failures. Supporting data are shown in Table 4.10. It can be seen that for valves $<20$ in., the primary methods of detection were operational abnormality and testing. Testing includes required off-line testing 


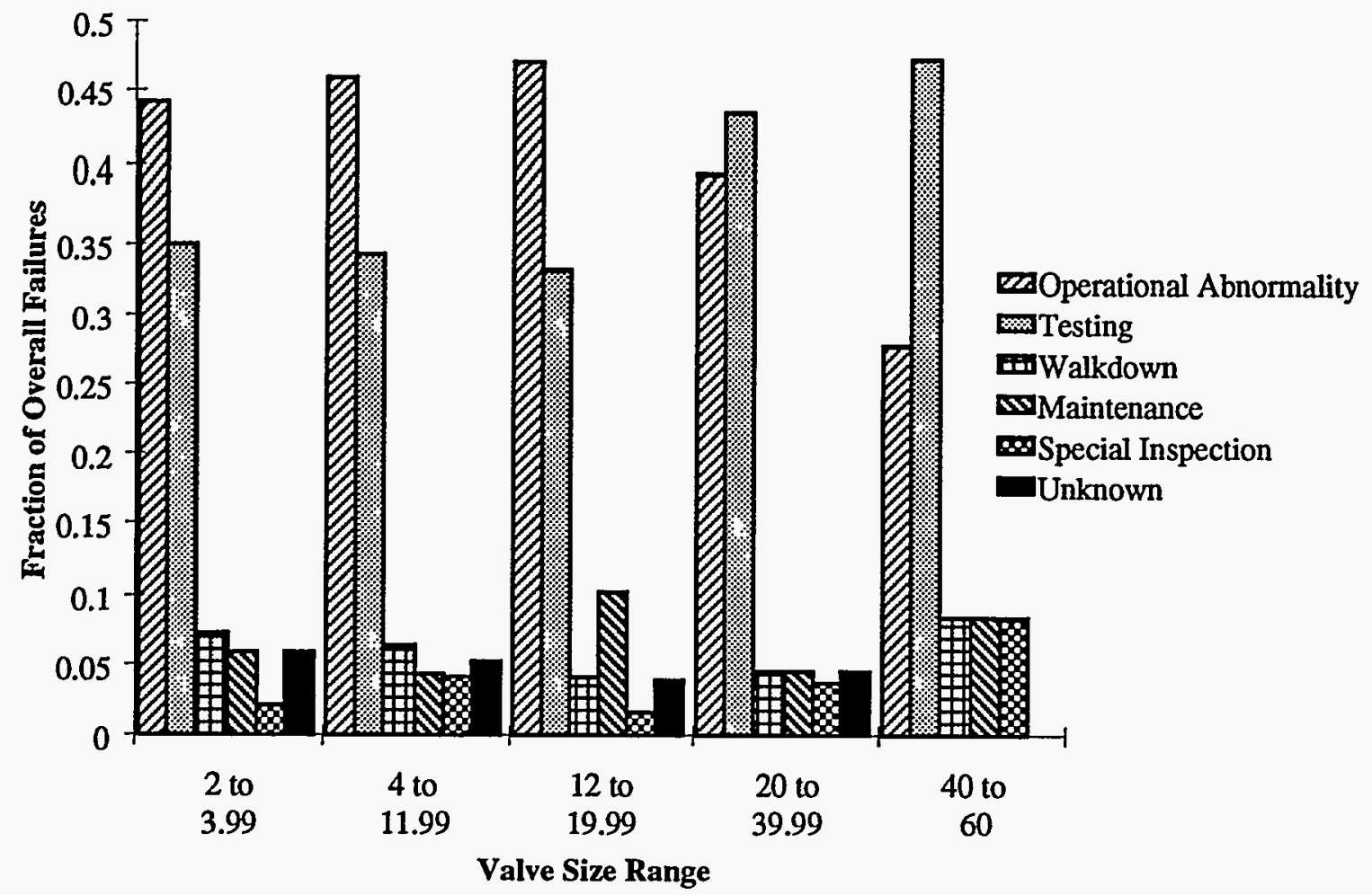

Figure 4.10 Fraction of combined component failures for each size range by method of failure detection

Table 4.10 Fraction of combined component failures for each size range by method of failure detection

\begin{tabular}{lrrrrrrrr}
\hline & \multicolumn{7}{c}{ Valve size range (in.) } & \\
\cline { 2 - 7 } Method of discovery & $\mathbf{2}$ to $\mathbf{3 . 9 9}$ & $\mathbf{4}$ to $\mathbf{1 1 . 9 9}$ & $\mathbf{1 2}$ to $\mathbf{1 9 . 9 9}$ & $\mathbf{2 0}$ to $\mathbf{3 9 . 9 9}$ & $\mathbf{4 0}$ to $\mathbf{6 0}$ & Over $\mathbf{6 0}$ & Total \\
\hline Testing & 187 & 180 & 88 & 59 & 17 & $\mathbf{3}$ & 534 \\
Special inspection & 11 & 21 & 4 & 5 & 3 & 0 & 44 \\
Maintenance & 31 & 23 & 27 & 6 & 3 & 0 & 90 \\
Operational abnormality & 237 & 242 & 125 & 54 & 10 & 0 & 668 \\
Unknown & 32 & 27 & 10 & 6 & 0 & 0 & 75 \\
Walkdown & 39 & 33 & 11 & 6 & 3 & 0 & 92 \\
Total & 537 & 526 & 265 & 136 & 36 & 3 & 1503 \\
\hline
\end{tabular}

and surveillance and miscellaneous testing. The fraction of overall failures for valves $<20$ in. was fairly constant for both operational abnormality and testing $(\sim 0.46$ and 0.34 , respectively), but the trend reverses for valves $>20$ in., where testing becomes the primary means of failure detection. This trend increases with increasing valve size; for valves in the 40 - to 60 -in. size range, the fraction of overall failures detected by testing is 0.47 , while those detected by operational abnormality is only 0.28 . This can be explained by the fact that these failures are large butterfly valves that are seldom operated and are exposed to mild operating conditions (i.e., low temperature, pressure, and flow rate).
Only three failures were reported in valves over 60 in., and all three of these were detected by testing. All three valves were related to the ventilation system, were tested every quarter, and did not have flow-related wear as is common in liquid or steam-carrying systems. Because the valves were tested frequently and had mild service conditions, it is not unexpected that the failures were discovered by the testing program. It should be noted that a cross tabulation of size range vs severity of failure did not yield any discernible trend as has been seen in some other valve types. 


\section{Analysis}

No other methods of detection were found to be particularly effective, except that a slight rise in failures detected during maintenance was evident in valves in the 12- to 19.99-in. range. Figure 4.3 shows that the relative failure rate is highest among valves in this size range, or approximately 1.2 times the overall rate. The slight increase in number of failures detected by maintenance for these valves may be due to an increase in number of maintenance activities associated with these valves.

It is suggested by this figure that for valves $<20$ in., the effectiveness of detecting failures through testing should be improved if this is at all practical. Testing programs should be reviewed with emphasis on identifying inadequate testing procedures or test frequencies or programs where an insufficient number of valves are tested.

\subsubsection{Comparison of Severity and Major Component}

Figure 4.11 clearly shows that the overwhelming majority of the failures documented in this study involved either the valve actuator or its control system; that is, either the actuator or the controller/positioner/air system were involved in 1144 failures. Failures of the valve itself were involved in 254 of the cases, while those involving electrical/support systems, stem(s), and unknown causes accounted for considerably fewer failures. Only $11 \%$ of the severe failures involved the valve body. This is expected because failures of the seat and disc generally degrade valve performance rather than cause a loss of valve function. Even failures of the valve packing cause erratic or slow stem movement (i.e., moderate failure) more frequently than a frozen stem (i.e., severe failure).

Forty-nine percent of the severe failures involved the controller/positioner/air system. Because this system contains several high failure rate components (e.g., limit switch, solenoid, air line, positioner linkage arm, etc.), their failures frequently compromise normal valve function. The high fraction of "unknowns" assigned to the controllerl positioner/air system may reflect the complexity of these interacting systems and the resultant difficulty in speculating what effect a discovered anomaly may have on the operability of the valves especially in cases where the anomaly was discovered before any opportunity to see its operational effect on the valve.

Failures involving the electrical support systems, while few in number, were nearly always classified as severe, that is, 16 out of 17 occurrences, or $94 \%$ of the time. Likewise,

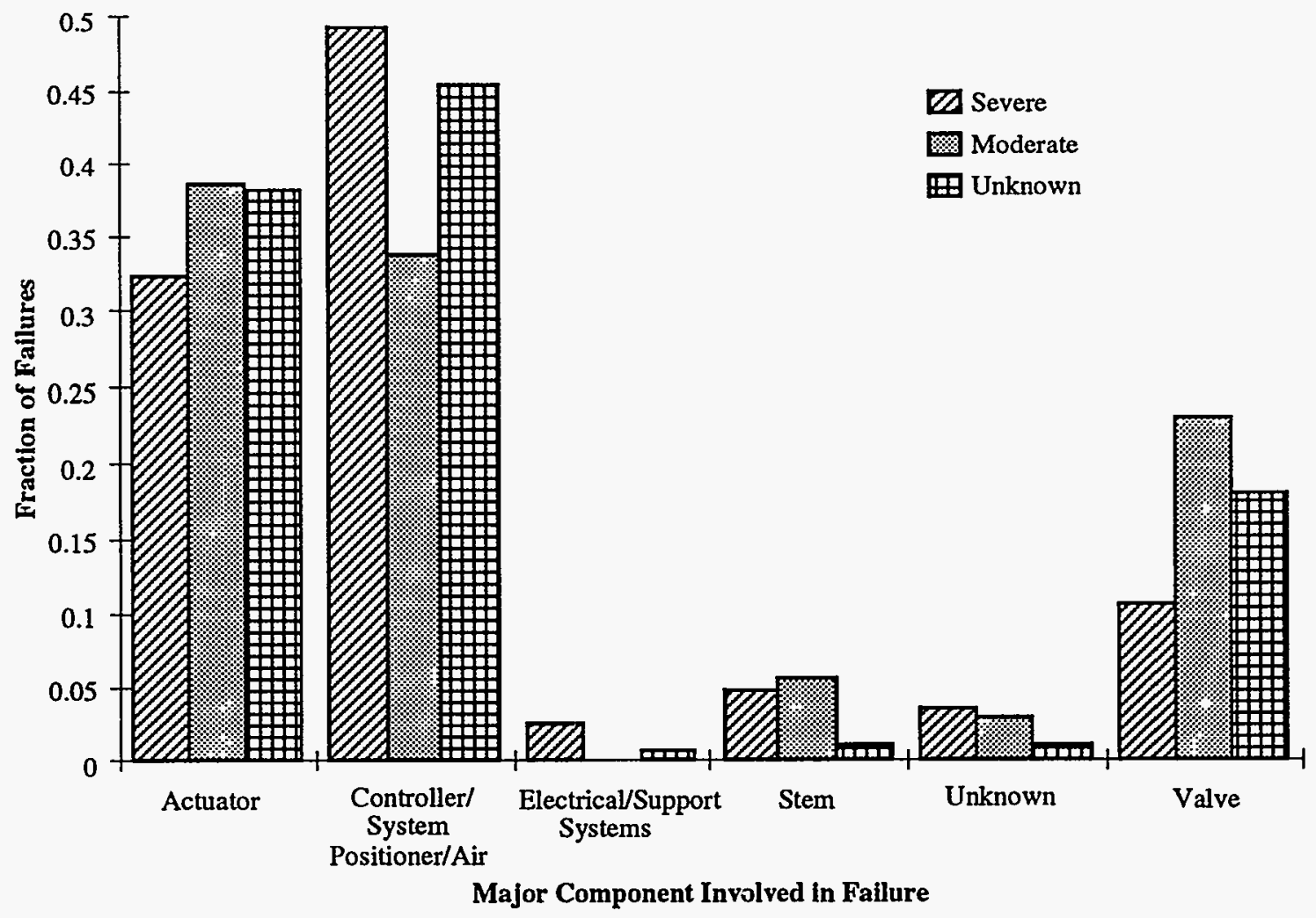

Figure 4.11 Fractional distribution of severity of failure by major component involved. Because multiple components could be involved in a failure, this figure represents the fraction of failures for each level of severity 
failures involving an unknown major component were slightly more likely to be classified as severe than as moderate or unknown.

\subsubsection{Method of Detection vs Plant Status}

Figure 4.12 provides a graphical representation of the method of failure detection vs plant status at detection of failure. It should be pointed out that 1377 failures occurred while the plant was either on-line, in an outage, or in an unknown status, thus accounting for nearly $92 \%$ of the total failures analyzed in this study. For this reason, failures occurring during other operational modes (as shown in Table 4.11) were omitted from Fig. 4.12 to enhance its clarity. It can be seen that the predominant method of failure detection during a plant outage is testing (including required surveillance, and miscellaneous testing), which accounted for $50 \%$ of the failure discoveries in that operational mode. Operational abnormalities accounted for the second largest group with $28 \%$ of the failures. This was followed by other activities normally performed more often during an outage situation, such as maintenance $(7 \%)$ and special inspection (3\%). For another $6 \%$ of the outage failures, however, the NPRDS narratives were too vague to identify a method of detection, and $6 \%$ were found during walkdowns. Failures that occurred while the plant was online, in contrast, were most often detected by operational abnormality, which accounted for $61 \%$ of the on-line failures. Only $21 \%$ were found during testing, however, and only $4 \%$ during maintenance. This can be attributed to the relative reduction in those activities while the plant is online. Eight percent of the on-line failures were detected during quality control or engineering walkdowns.

\subsubsection{Failures Specific to Valves}

This section applies to the 337 failures of the valve body and valve internals (excluding the actuator and controller), as shown in Fig. 3.1. They comprise $19 \%$ of the total failures.

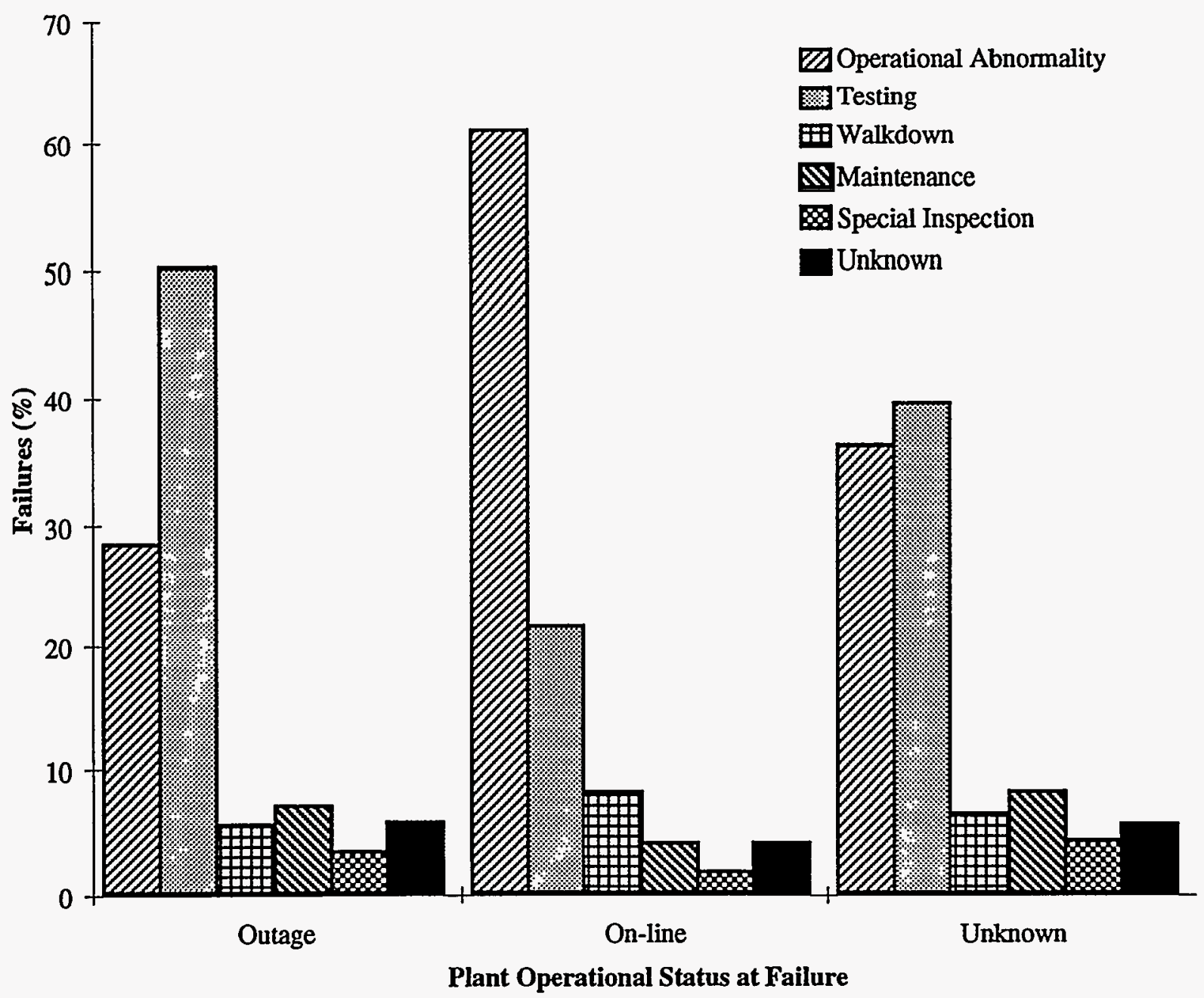

Figure 4.12 Percentage of failures for method of detection by plant status at failure 
Table 4.11 Distribution of failures for method of detection by plant status at failure

\begin{tabular}{lccccccc}
\hline & \multicolumn{5}{c}{ Failure according to method of detection } & \\
\cline { 2 - 7 } $\begin{array}{l}\text { Plant status at } \\
\text { failure }\end{array}$ & $\begin{array}{l}\text { Operational } \\
\text { abnormality }\end{array}$ & Testing & Walkdown & Maintenance & Unknown & $\begin{array}{c}\text { Special } \\
\text { inspection }\end{array}$ & Total \\
\hline Outage & 159 & 281 & 31 & 40 & 32 & 19 & 562 \\
On-line & 288 & 101 & 38 & 19 & 19 & 8 & 473 \\
Unknown & 123 & 135 & 22 & 28 & 19 & 15 & 342 \\
Startup & 42 & 5 & 1 & 1 & 3 & 0 & 52 \\
Hot standby & 25 & 11 & 0 & 2 & 2 & 1 & 41 \\
Trip & 25 & 0 & 0 & 0 & 0 & 0 & 25 \\
Trip recovery & 6 & 1 & 0 & 0 & 0 & 1 & 8 \\
Total & 668 & 534 & 92 & 90 & 75 & 44 & 1503 \\
\hline
\end{tabular}

\subsubsection{Failures by Valve Type and Population}

The failure rate by valve type and population distribution for the valves available for inclusion in the study is illustrated in Fig. 4.13 with supporting data in Table 4.12. From this figure, it is apparent that the largest class of valves is the globe design (49\%). Butterfly valves accounted for $21 \%$ of the valves available for the study, and gate valves made up $13 \%$ of the total.

The relative failure rates were highest for globe and gate, while the plug/ball and diaphragm types were the most reli- able. This relationship will be looked at in more detail in a later figure.

\subsubsection{Relative Failures by Valve Function}

Figure 4.14 presents the relative failure rate by valve function and corresponding population distribution graph for valves that were available for inclusion in the study. Supporting data are shown in Table 4.13.

It is apparent that the majority (54\%) of the AOVs available for this study are used to provide an isolation function. Flow control is the second most commonly encountered

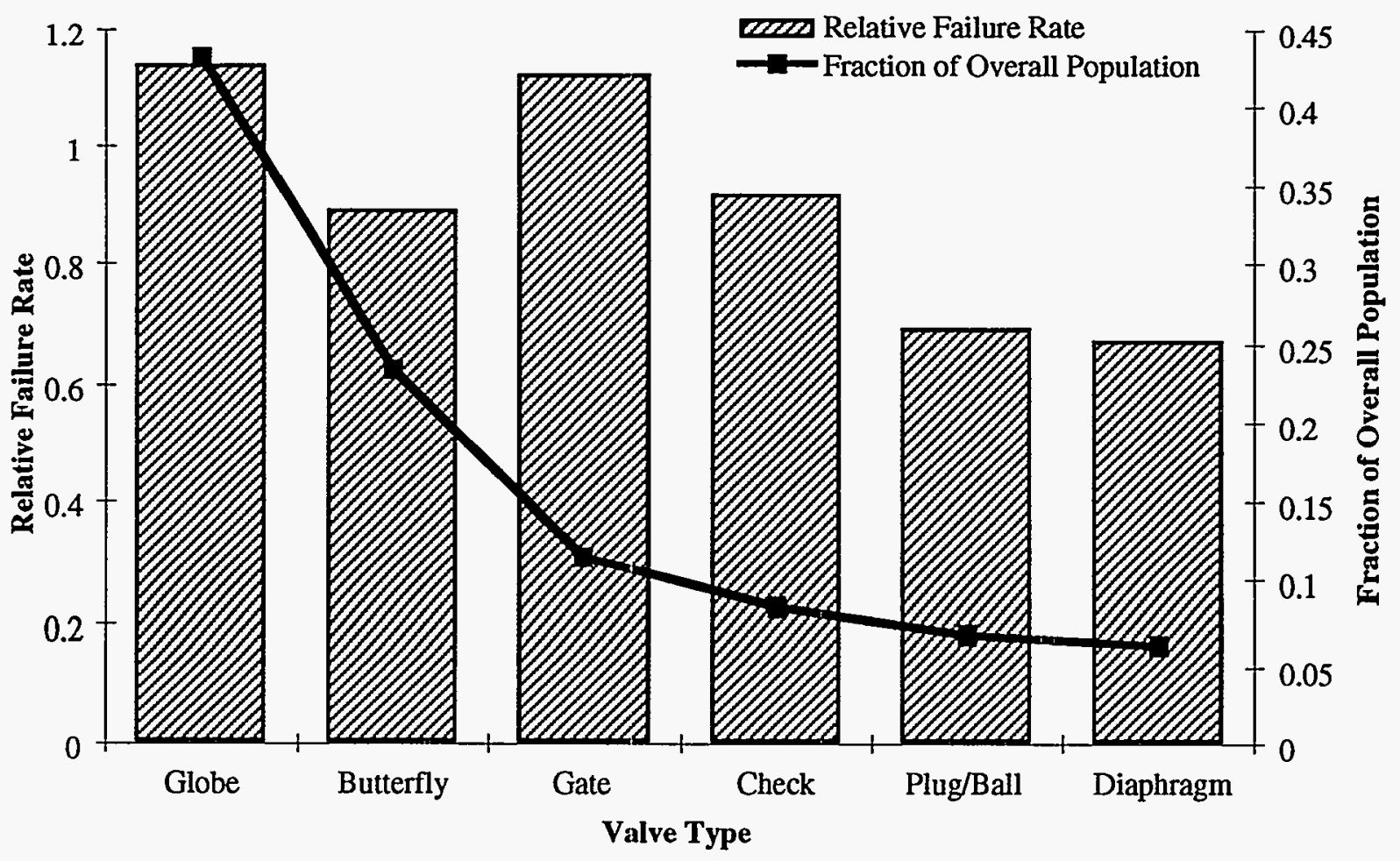

Figure 4.13 Distribution of valve-only failures by reported valve type 
Table 4.12 Distribution of valve-only failures by reported valve type

\begin{tabular}{lc}
\hline Valve type & Failure count \\
\hline Globe & 165 \\
Butterfly & 70 \\
Gate & 43 \\
Check & 26 \\
Diaphragm & 14 \\
Plug/ball & 16 \\
Other & 3 \\
Grand total & 337 \\
\hline
\end{tabular}

Table 4.13 Distribution of valve population available to fail by valve-only function

\begin{tabular}{lrc}
\hline Description & Count & \% of population \\
\hline Isolation & 3861 & 54.2 \\
Flow control & 1637 & 23.0 \\
Others & 442 & 6.2 \\
Pressure control & 341 & 4.8 \\
One-way flow & 334 & 4.7 \\
Pressure relief & 311 & 4.4 \\
Vacuum relief & 198 & 2.8 \\
Total valve count & 7124 & \\
\hline
\end{tabular}

valve application, making up $23 \%$ of the total. Note that the control function of safety-related valves may not be the safety-related function. The most common safety-related function of these valves is to isolate flow. Other less common functions include pressure control, one-way flow control, pressure relief, vacuum relief, and miscellaneous. None of these less common applications exceeds $10 \%$ of the total AOV population.

The high failure rate shown for pressure relief valves is a result of a generic problem with this valve function where the pressure set point of the valve drifts out of the narrow pressure range specification. In response to this problem, many of these valves are calibrated at each outage.

\subsubsection{Comparison of Valve Type and Severity of Failure}

The data for Table 4.14 were normalized by establishing the failure rate for the valve type and severity of failure. The failure rate was obtained by dividing the number of failures by the number of valve years for the valve type. The failure rate was then divided by the failure rate for the population to establish a relative failure rate for each valve type and severity of failure. For example, the relative failure rate for severe failures of globe valves would be $(45 / 33,481)+(337 / 77,442)$, or 0.31 .

The failure rate for each category of severity of failure was established by dividing the number of failures for the

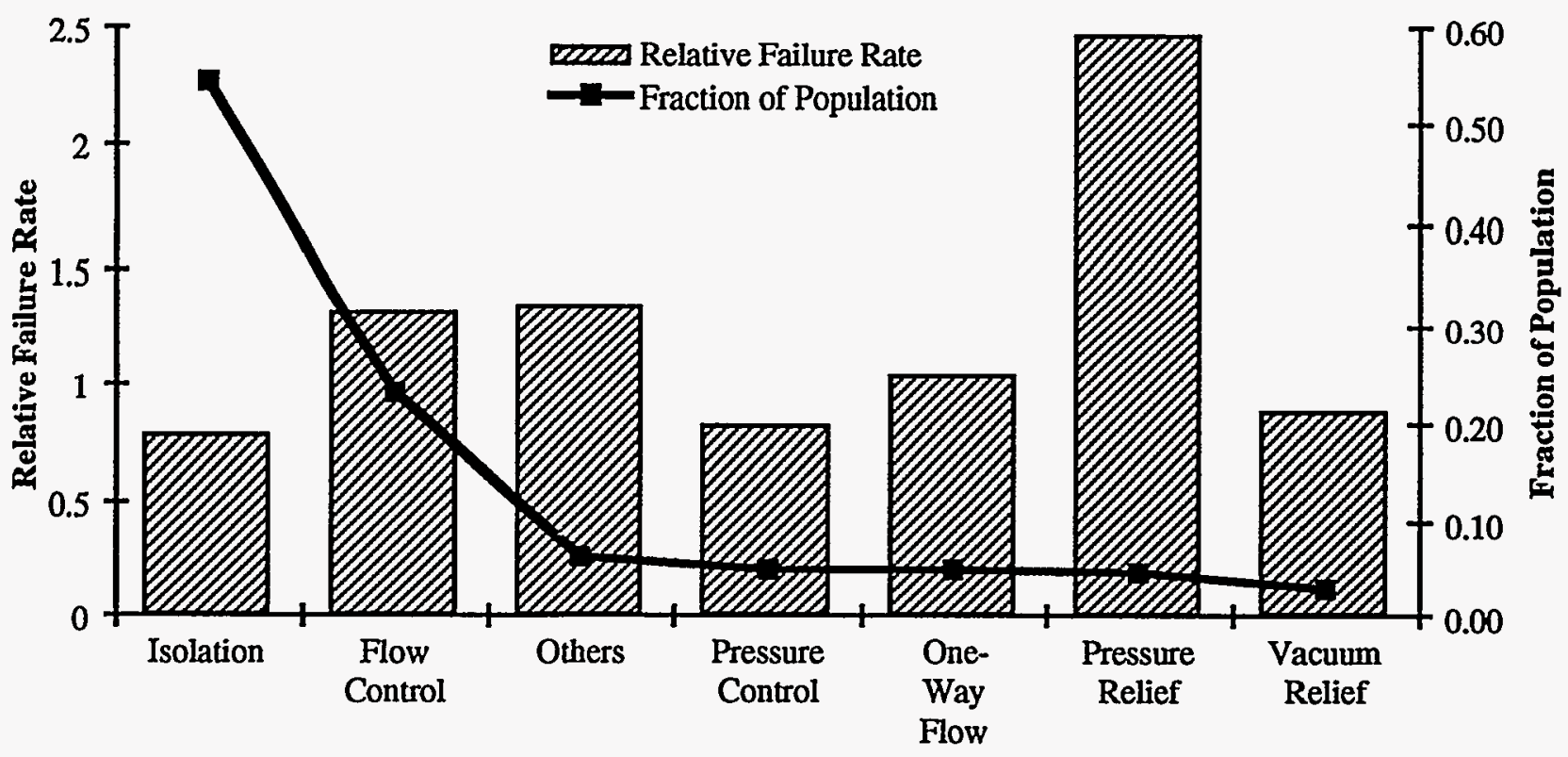

Valve Function

Figure 4.14 Relative failure rate by valve-only function and distribution of valve population available to fail by valve function 
Table 4.14 Relative failure of valve type vs severity of failure

\begin{tabular}{lrrrrrrrrr}
\hline & \multicolumn{3}{c}{ Severity of failure } & & & \multicolumn{3}{c}{ Normalized data } \\
\cline { 2 - 3 } Type of valve & Severe & Moderate Unknown & \multirow{2}{*}{$\begin{array}{c}\text { Number of } \\
\text { failures }\end{array}$} & $\begin{array}{c}\text { Valve } \\
\text { years }\end{array}$ & Severe & Moderate & Unknown \\
\hline Globe & 45 & 103 & 17 & 165 & 33,481 & 0.31 & 0.71 & 0.12 \\
Butterfly & 20 & 41 & 9 & 70 & 18,160 & 0.25 & 0.52 & 0.11 \\
Gate & 20 & 21 & 2 & 43 & 8,853 & 0.52 & 0.55 & 0.05 \\
Check & 11 & 13 & 2 & 26 & 6,549 & 0.39 & 0.46 & 0.07 \\
Diaphragm & 4 & 8 & 2 & 14 & 4,824 & 0.19 & 0.38 & 0.10 \\
Plug & 4 & 11 & 1 & 16 & 5,373 & 0.17 & 0.47 & 0.48 \\
Other & 0 & 3 & 0 & 3 & 202 & 0.00 & 3.41 & 0.00 \\
Total & 104 & 200 & 33 & 337 & 77,442 & 0.31 & 0.59 & 0.10 \\
\hline
\end{tabular}

category by the total number of failures. This provides a number that can be used for comparison of relative failure rates for a given severity of failure. For example, the failure rate for severe failures is 104/337. Therefore, it can be seen that the relative failure rate for globe valves with severe failures is equal to the failure rate for all severe failures, $0.31+0.31=1$; whereas with severe failures the relative failure rate for gate valves is $1.68(0.52 \div 0.31)$.

Table 4.14 shows that of the 337 total valve-only failures, nearly two-thirds were classified as moderate. In fact, there were nearly twice as many failures listed as moderate (200) than severe (104). Only 33 failures were classified as unknown. The difference between the failure rates for severe and moderate failures of check valves and gate valves is less pronounced than the difference for the other valve types. Also significant is the fact that both globe and butterfly valves experienced only $31 \%$ and $25 \%$ severe failures, respectively. Figure 4.15 graphically illustrates these relationships.

Globe valves and butterfly valves account for almost $70 \%$ of the failures and have a low fraction of severe failures, but apparently for different reasons. These reasons are discussed below for globe and butterfly valves. Diaphragm and plug valves account for $<9 \%$ of the failures and are not discussed further in this section.

Globe valves represent the largest percentage of any valve type and experience the highest overall failure rate. Cavitation or abrasive particle service make globe valves susceptible to erosion that may cause serious leakage. However,

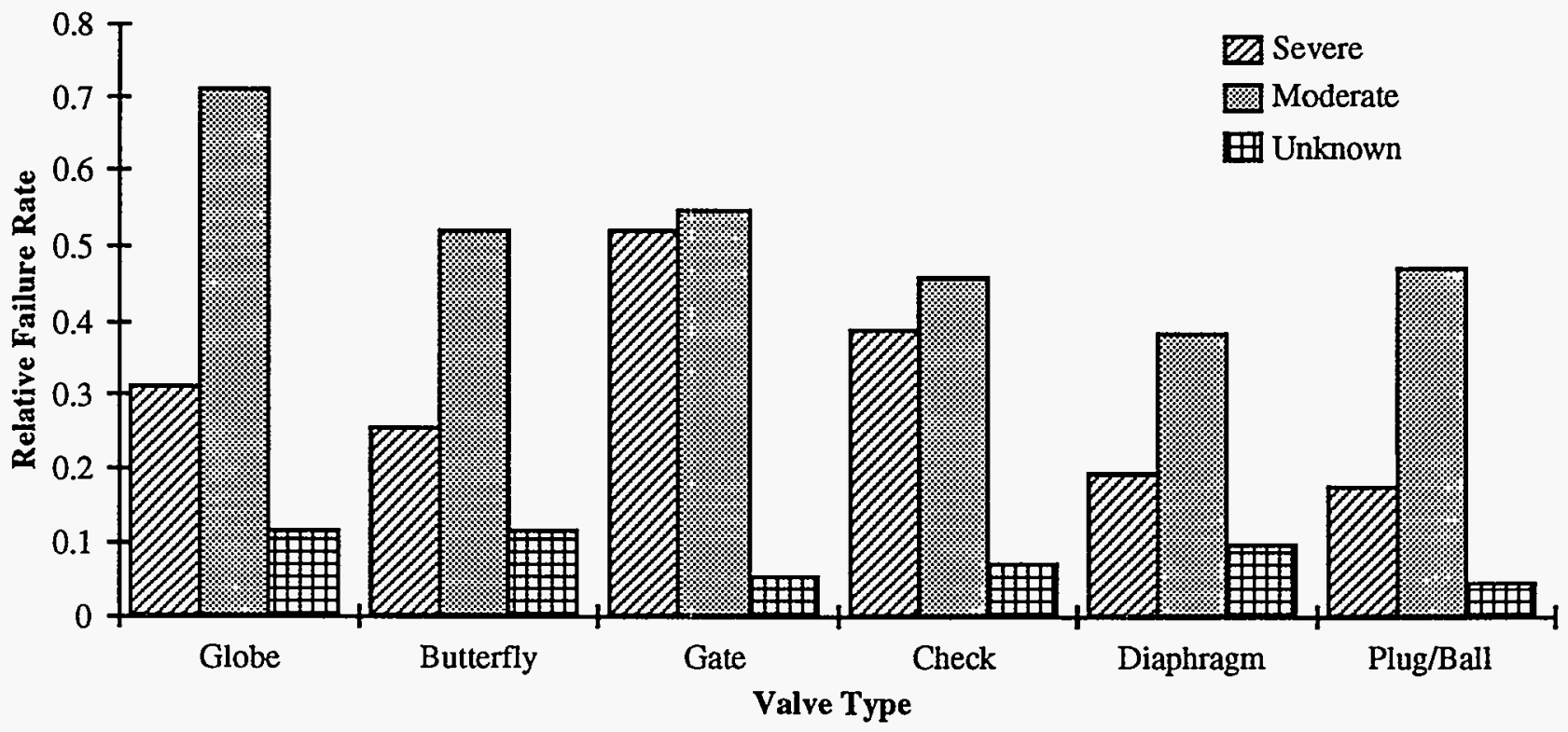

Figure 4.15 Relative failures of valve type vs severity of failure 
these types of failures would not be considered "severe" since the valve's ability to fully stroke would not normally be affected. Furthermore, degraded control valves are readily identifiable in process operations when flow, pressure, etc. ranges out of specification, and for this reason the globe valves tend to be involved in a greater number of moderate failures.

Butterfly valves, on the other hand, appear to have fewer severe failures because they are tested more frequently than any other valve type except check valves. NPRDS data show a high rate of testing for butterfly valves especially on a quarterly basis. This high level of testing and failure discovery by testing have resulted in a corresponding low rate of failure discovery through operational failures as will be seen later.

\subsubsection{Severity of Failure vs Valve Function}

Figure 4.16 shows the distribution of valve-only failures by severity of failure and valve function. The percentage of failures vs the NPRDS reported valve function is plotted according to the severity of failure distribution for each function. Of the 337 total valve-only failures, $\sim 59 \%$ were classified as moderate, $31 \%$ as severe, and $10 \%$ as unknown. This trend is consistent for the two most common valve functions, isolation and flow control, as well as for pressure control and bypass. Pressure relief valves had by far the lowest percentage incidence of failures classified as severe $(\sim 3 \%)$ and the highest percentage of failures classified as moderate, $\sim 77 \%$. A miscellaneous function classification resulted in a failure grouping of $20 \%$ severe, $70 \%$ moderate, and $10 \%$ unknown.

The very low percentage of severe failures for pressure relief functions is due at least in part to the in-service inspection set-point test. The testing program tended to locate many valves with marginal performance as opposed to severely failed, and for this reason the percentage of moderate pressure relief valve failures is higher than for the other valve functions.

It is interesting to note that although the total number of failures for isolation valves was greater than for any other classification, their percent of failed population (42\%) was less than their overall percent of the population (54\%) by the greatest margin for any valve as indicated in Table 4.15 .

Table 4.15 Percentage of valve-only failures for severity of failure by valve function

\begin{tabular}{lrcc}
\hline & \multicolumn{3}{c}{ Severity of failure (\%) } \\
\cline { 2 - 4 } \multicolumn{1}{c}{ Function } & Severe & Moderate & Unknown \\
\hline Isolation & 34 & 59 & 8 \\
Flow control & 32 & 55 & 13 \\
Pressure relief & 3 & 77 & 19 \\
One-way flow & 47 & 47 & 5 \\
Pressure control & 36 & 57 & 7 \\
Bypass & 43 & 57 & 0 \\
Other & 20 & 70 & 10 \\
\hline
\end{tabular}

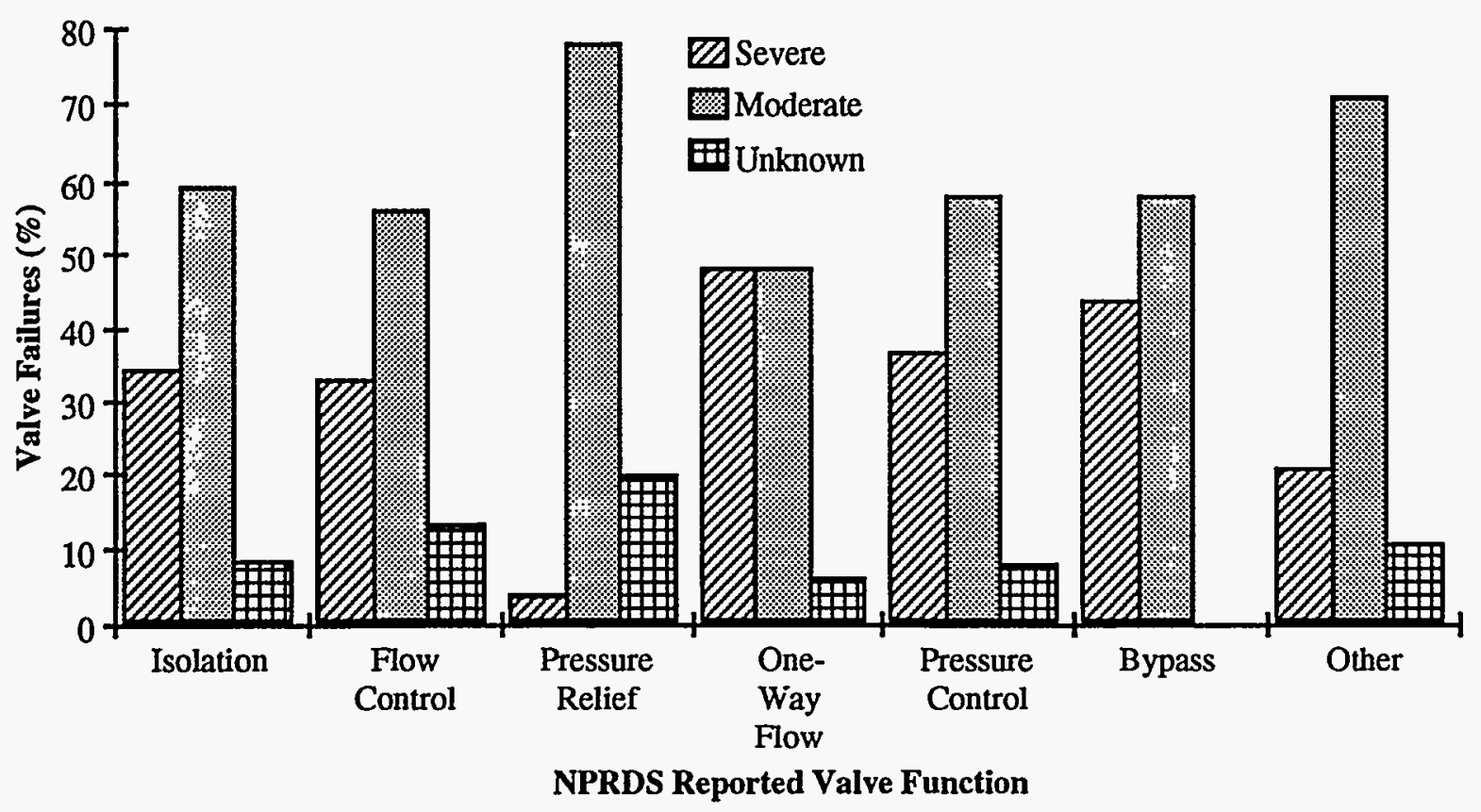

Figure 4.16 Valve-only failures for severity of failure by valve function 


\section{Analysis}

In contrast, flow control valves made up nearly $23 \%$ of the total population, but failed at a higher rate, over $28 \%$. Similarly, although pressure relief valves constitute only $4 \%$ of the total available valve population, they failed at over double that rate, or $9 \%$.

\subsubsection{Comparison of Valve Type and Method of Detection}

From Fig. 4.17 and Table 4.16 it is apparent that most valve-only failures were detected by either operational abnormality -131 failures, or $-39 \%$, or testing (including required, surveillance, or miscellaneous testing) -140 failures, or $-42 \%$. The other $19 \%$ were detected by either special inspection, QC or engineering walkdowns, maintenance, or other means. Operational abnormalities were used to detect a nearly identical number of flow control and isolation valve failures, while testing detected more than twice the number of isolation valve failures than flow control valve failures.

Pressure relief valve-only failures were discovered by operational abnormality in only $6 \%$ of the cases, as compared

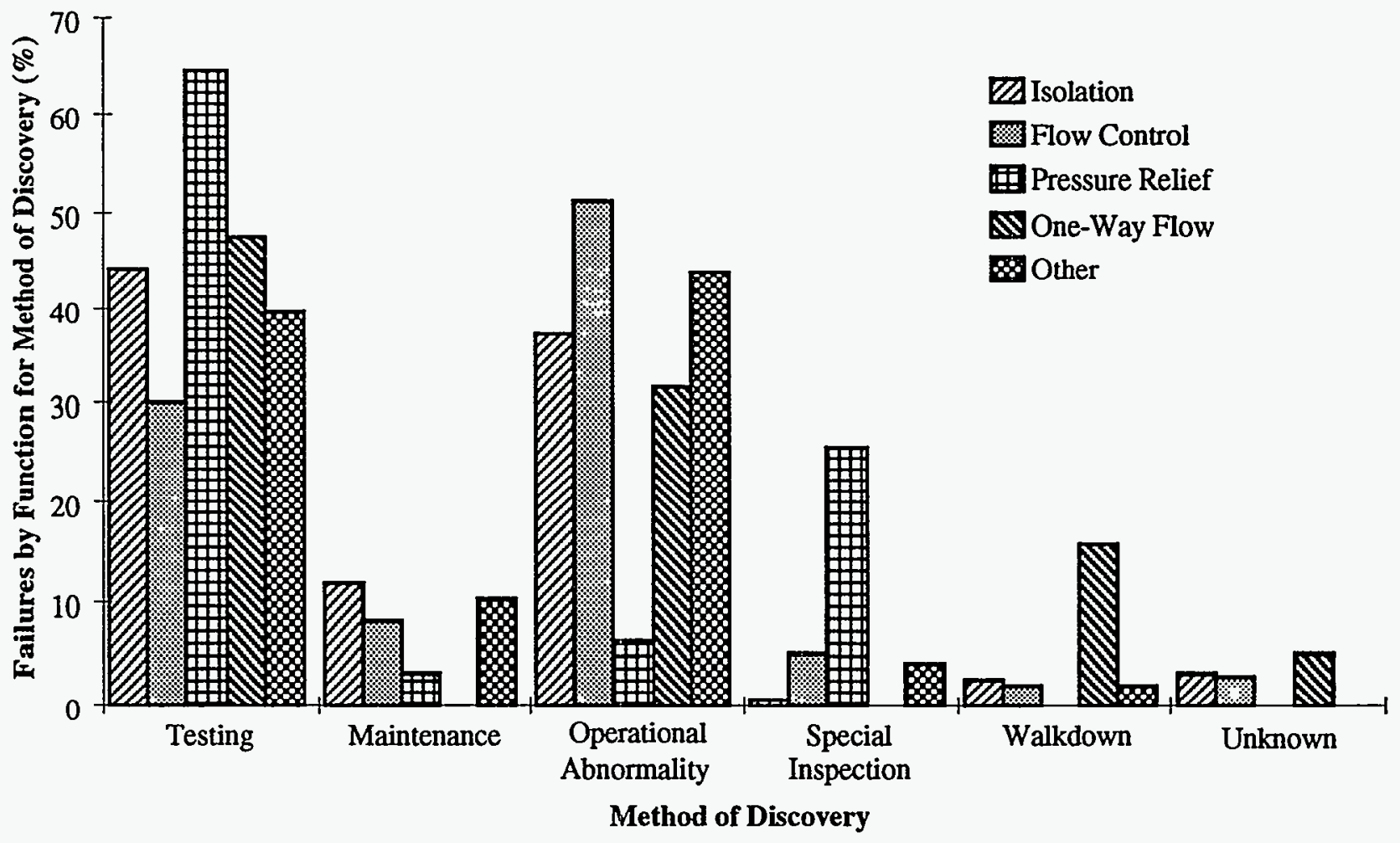

Figure 4.17 Distribution of valve-only failures by function and method of detection

Table 4.16 Distribution of valve-only failures by function and method of detection

\begin{tabular}{lrrrrrr}
\hline Method of detection & Isolation & $\begin{array}{c}\text { Flow } \\
\text { control }\end{array}$ & $\begin{array}{c}\text { Pressure } \\
\text { relief }\end{array}$ & $\begin{array}{c}\text { One-way } \\
\text { flow }\end{array}$ & Other & Total \\
\hline Testing & 63 & 29 & 20 & 9 & 19 & 140 \\
Maintenance & 17 & 8 & 1 & 0 & 5 & 31 \\
Operational abnormality & 53 & 49 & 2 & 6 & 21 & 131 \\
Special inspection & 1 & 5 & 8 & 0 & 2 & 16 \\
Walkdown & 4 & 2 & 0 & 3 & 1 & 10 \\
Unknown & 5 & 3 & 0 & 1 & 0 & 9 \\
Total & 143 & 96 & 31 & 19 & 48 & 337 \\
\hline
\end{tabular}


to $31 \%$ to $51 \%$ for other types of valve applications. This low percentage is due to the special maintenance program for pressure relief valves. Because of a generic problem where the pressure set point drifts out of range, many of these valves are calibrated at each outage. Some utilities replace critical relief valves with spares that have already been recalibrated. The relief set point for the valve that is removed is then calibrated, and the valve is placed in stores as a replacement for another valve. Note that valves with pressure control and vacuum relief functions were omitted because of their small populations.

\subsubsection{Comparison of Function to Apparent Cause}

Figure 4.18 illustrates the fraction of overall failures for the four valve functions with the highest percentage of valveonly failures vs apparent cause of failure.

The figure does not represent all functions. Vacuum relief, pressure control, and "others" were excluded as they represented only $15 \%$ of the failures and only served to clutter the chart.

Note that in the chart, "corrosion" includes the code for foreign material; "human error" includes inadequate instal- lation or procedure, missing parts, and maintenance; and "inappropriate application" includes vibration.

No particularly strong trends are evident from this figure, except that a very high number of failures for each valve function were attributed to unknown causes. This could be due to the fact that no root cause analysis was performed for many failures. A large fraction of the failures was attributed to normal wear, especially for pressure relief valves. Again, this may be due to the NPRDS coding process, since many failures appeared to be listed as being due to normal wear where no other failure cause was apparent. Both isolation and flow control valves (which together account for $71 \%$ of the total number of valve-only failures) failed due to a variety of causes, including corrosion and human error. A number of check valves failed due to severe service conditions.

\subsubsection{Comparison of Function and Ease of Correction}

A distribution of valve-only failures by valve function and ease of correction is illustrated in Fig. 4.19. Supporting data are shown in Table 4.17. Replacing parts was the most common method of correction. More involved corrections,

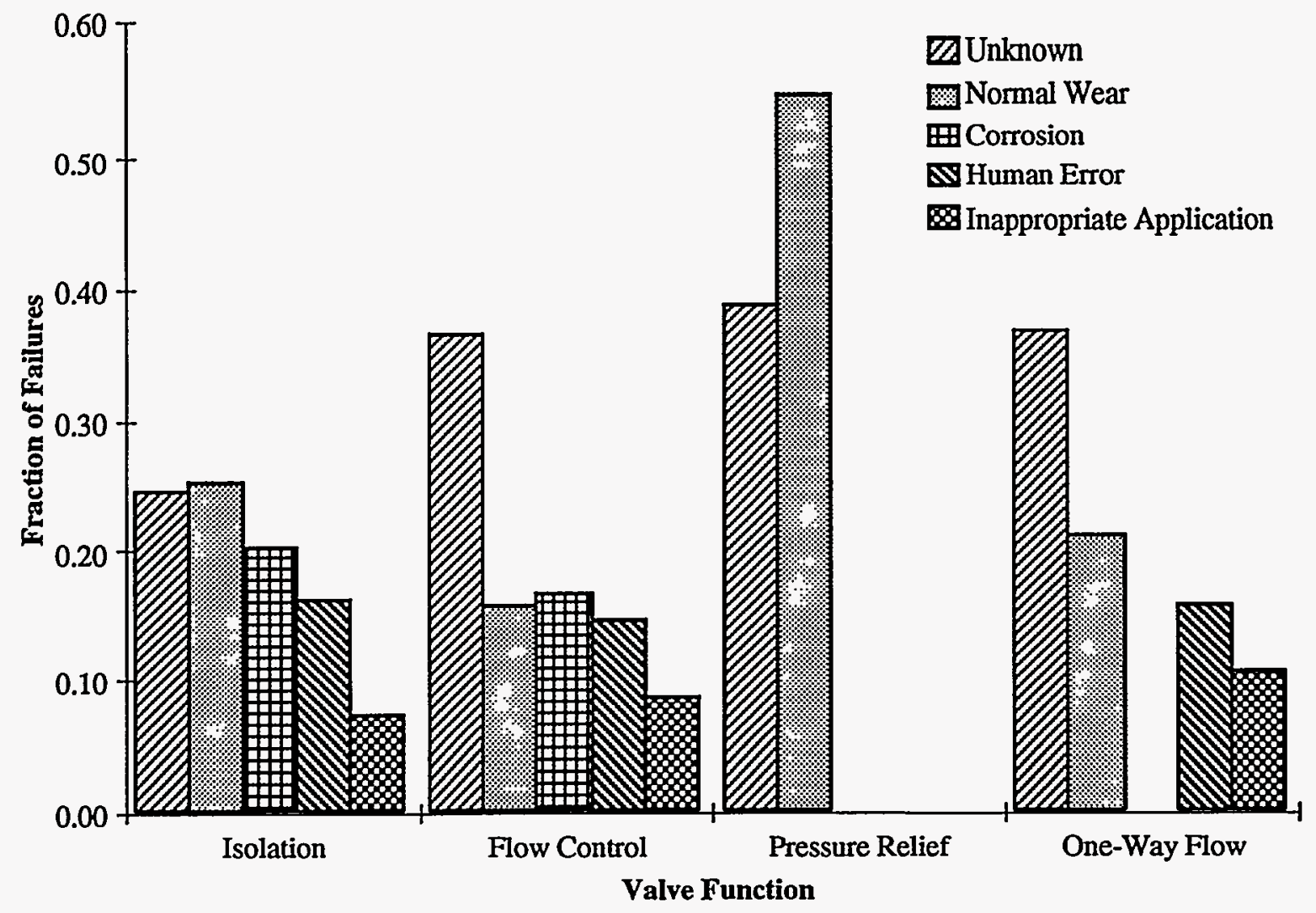

Figure 4.18 Valve-only failure distribution: fraction of valve failures for function vs apparent cause of failure 


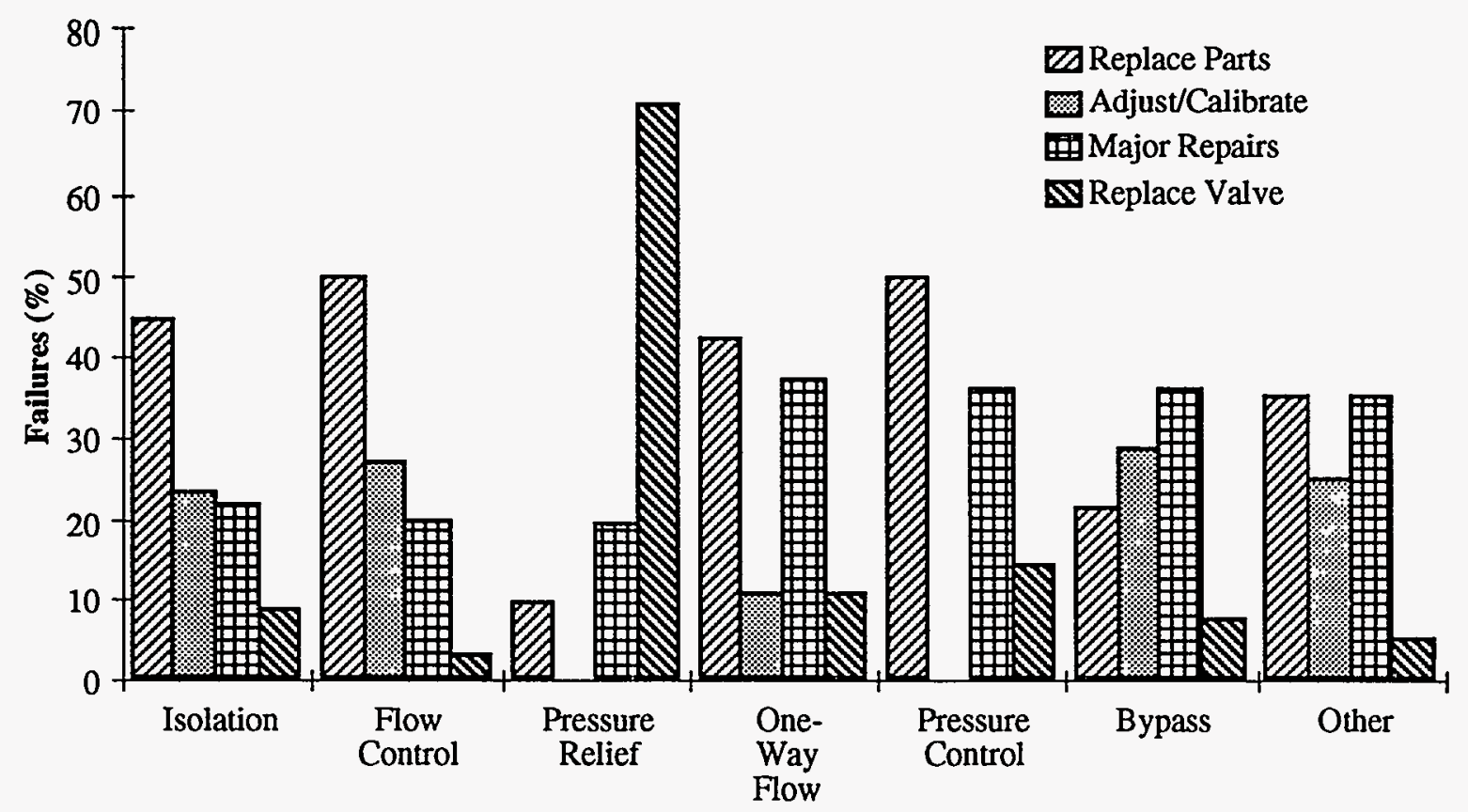

Valve Function

Figure 4.19 Percentage of failures reported as valve failure by function and ease of correction

Table 4.17 Percentage of failures reported as valve failure by function and ease of correction

\begin{tabular}{lcccccccr}
\hline $\begin{array}{c}\text { Ease of } \\
\text { correction }\end{array}$ & Isolation & $\begin{array}{c}\text { Flow } \\
\text { control }\end{array}$ & $\begin{array}{c}\text { Pressure } \\
\text { relief }\end{array}$ & $\begin{array}{c}\text { One-way } \\
\text { flow }\end{array}$ & Bypass & $\begin{array}{c}\text { Pressure } \\
\text { control }\end{array}$ & Other & Total \\
\hline Replace parts & 64 & 48 & 3 & 8 & 3 & 7 & 7 & 140 \\
Adjust/calibrate & 33 & 26 & 0 & 2 & 4 & 0 & 5 & 70 \\
Major repairs & 31 & 19 & 6 & 7 & 5 & 5 & 7 & 80 \\
Replace valve & 12 & 3 & 22 & 2 & 1 & 2 & 1 & 43 \\
Unknown & 3 & 0 & 0 & 0 & 1 & 0 & 0 & 4 \\
Total & 143 & 96 & 31 & 19 & 14 & 14 & 20 & 337 \\
\hline
\end{tabular}

including valve replacement or major repairs, accounted for $37 \%$ of all failures. Of these, there were 80 major repairs and only 43 actual valve replacements. The ratio of minor to major repairs was highest for flow control valves, which had $\sim 77 \%$ repairs categorized as minor. One interesting result, however, is the number of pressure relief valve failures $(71 \%)$ that were corrected by valve replacement. This is due to 22 occurrences of valve replacement in kind after failure of an off-site in-service inspection set-point test. The original valves were refurbished and placed back into stores for future use.

\subsubsection{Comparison of Type and Method of Detection}

Figure 4.20 and Table 4.18 clearly show that the two most common methods of valve-only failure detection were operational abnormality and testing (including required, surveillance, and miscellaneous testing). These two detection methods together accounted for $\sim 70$ to $88 \%$ of the failures.

It should be noted that testing was not found to be a particularly effective method of failure detection for diaphragm valves (and to a lesser extent ball/plug valves), perhaps because these failures were first revealed by operational abnormality. Testing was more effective than the detection by operational abnormality for butterfly and check valves. For check valves, this is likely the case because of an increased industry-wide programmatic effort directed toward check valve testing. NPRDS data also show a high rate of testing for butterfly valves, usually on a quarterly basis. 


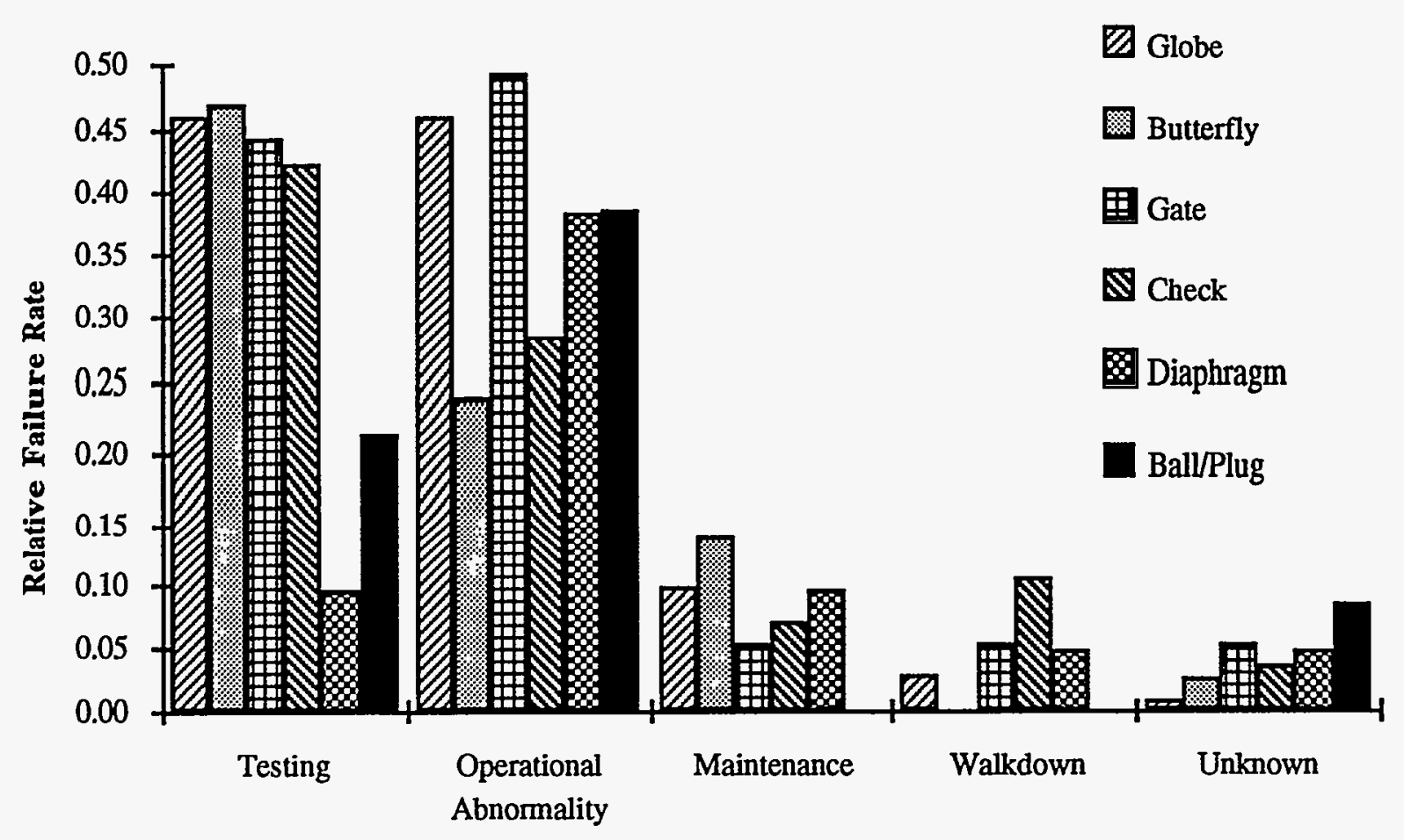

Method of Detection

Figure 4.20 Relative valve-only failures by valve type for method of detection

Table 4.18 Failure counts (valve-only) by valve type and method of detection

\begin{tabular}{lrrrrrrr}
\hline Type of valve & Testing & $\begin{array}{c}\text { Special } \\
\text { inspection }\end{array}$ & Maintenance & $\begin{array}{c}\text { Operational } \\
\text { abnormality }\end{array}$ & Unknown & Walkdown & Total \\
\hline Globe & 67 & 12 & 14 & 67 & 1 & 4 & 165 \\
Butterfly & 37 & 1 & 11 & 19 & 2 & 0 & 70 \\
Gate & 17 & 1 & 2 & 19 & 2 & 2 & 43 \\
Check & 12 & 0 & 2 & 8 & 1 & 3 & 26 \\
Diaphragm & 2 & 0 & 2 & 8 & 1 & 1 & 14 \\
Ball/Plug & 5 & 0 & 0 & 9 & 2 & 0 & 16 \\
Other & 0 & 2 & 0 & 1 & 0 & 0 & 3 \\
Total & 140 & 16 & 31 & 131 & 9 & 10 & 337 \\
\hline
\end{tabular}

\subsubsection{Comparison of Type and Ease of Correction}

Figure 4.21 reiterates that most valve-only failures were corrected by relatively minor repairs, such as replacing parts or performing some type of adjustment or calibration. Supporting data are shown in Table 4.19. Diaphragm valves, in particular, experienced very few major repairs. Several corrective actions involving major repairs of globe valves were most likely due to the severe effects that steam has on control valves such as these. The repair of steaminduced erosion damage on the globe and seat frequently require machining and grinding operations (i.e., a "major repair").
The high incidence of replaced parts and low incidence of major repairs for diaphragm valves is due to the fact that diaphragm replacement was by far the most frequently performed repair for this type of valve.

The relatively high rate of adjustments/calibrations performed on the gate valve is due to adjustments being made in response to two types of gate valve failure modes. The adjustments are to the packing nuts to restore free movement and to stem nuts and the actuator to ensure that the gate valve is closed completely but not closed with 
Analysis

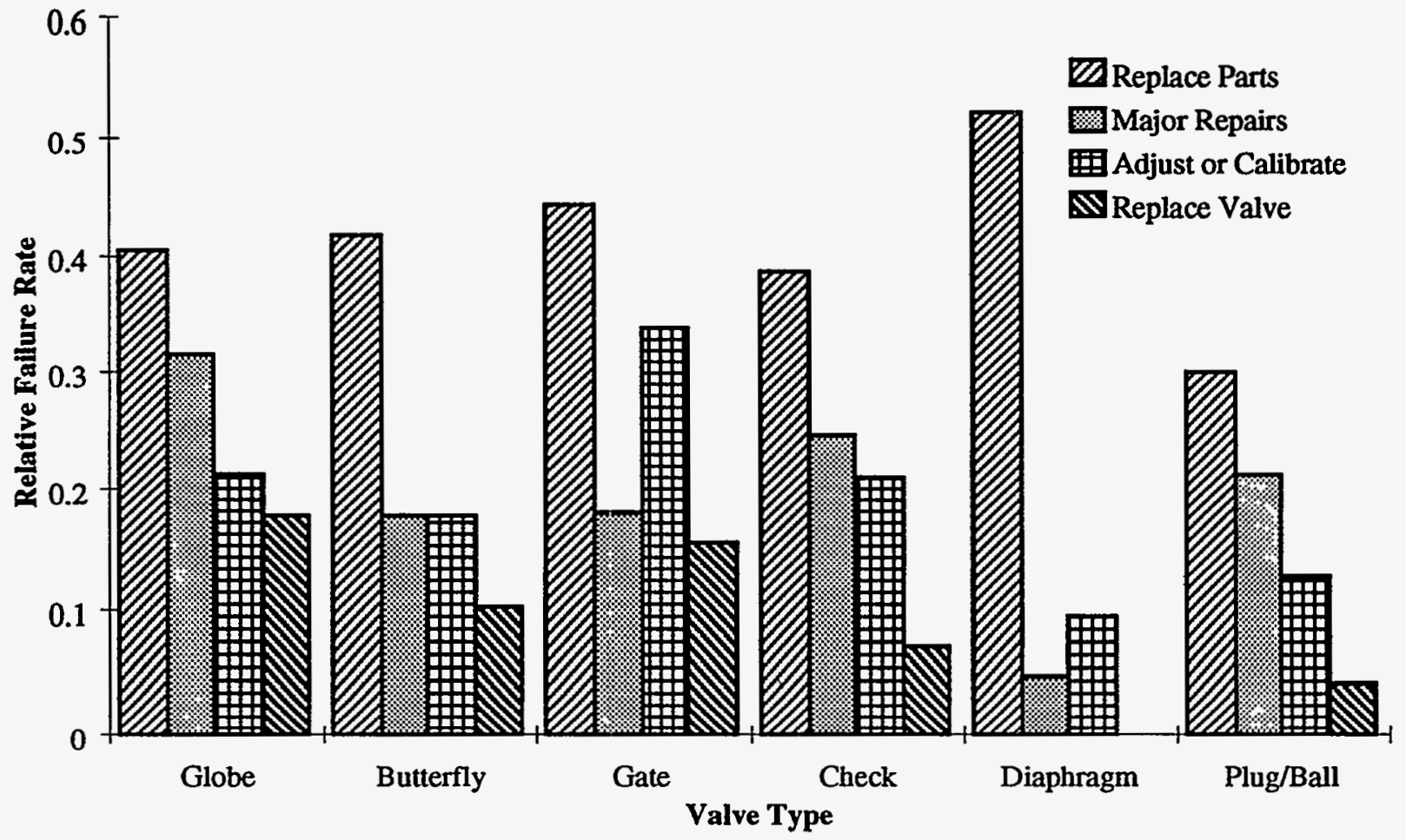

Figure 4.21 Relative failures (valve-only) by valve type for ease of correction

Table 4.19 Failure counts by valve type and ease of correction

\begin{tabular}{lcccccr}
\hline & $\begin{array}{c}\text { Replace } \\
\text { parts }\end{array}$ & $\begin{array}{c}\text { Major } \\
\text { repairs }\end{array}$ & $\begin{array}{c}\text { Adjust or } \\
\text { calibrate }\end{array}$ & $\begin{array}{c}\text { Replace } \\
\text { valve }\end{array}$ & Unknown & Total \\
\hline Globe & 59 & 46 & 31 & 26 & 3 & 165 \\
Butterfly & 33 & 14 & 14 & 8 & 1 & 70 \\
Gate & 17 & 7 & 13 & 6 & 0 & 43 \\
Check & 11 & 7 & 6 & 2 & 0 & 26 \\
Diaphragm & 11 & 1 & 2 & 0 & 0 & 14 \\
Ball/plug & 7 & 5 & 3 & 1 & 0 & 16 \\
Other & 2 & 0 & 1 & 0 & 0 & 3 \\
Total & 140 & 80 & 70 & 43 & 4 & 337 \\
\hline
\end{tabular}

excessive force that could cause the stem to bend and/or the gate to wedge shut and not open on demand.

\subsubsection{Failures Specific to Actuators and Controls}

This section pertains to the remaining $81 \%$ of the total failures that were not classified as valve-only failures. There were 1166 failures specific to actuators and controls.

Figure 4.22 and Table 4.20 show the failure rate based on method of detection for each type of actuator. The chart shows a consistent pattern regardless of actuator type. For all actuators, operational abnormality is the leading method of detection, followed by testing and walkdowns. The chart also highlights the failure of programmatic methods historically used to detect actuator degradation. This can be seen in the number of degradations that proceeded to failure and were discovered as operational abnormalities rather than being detected in the incipient phase.

Figure 4.23 shows the relationship between severity of failure and actuator type for all 1166 failures. Supporting failure counts are shown in Table 4.21. The most striking feature of this graph is the relative number of failures that 


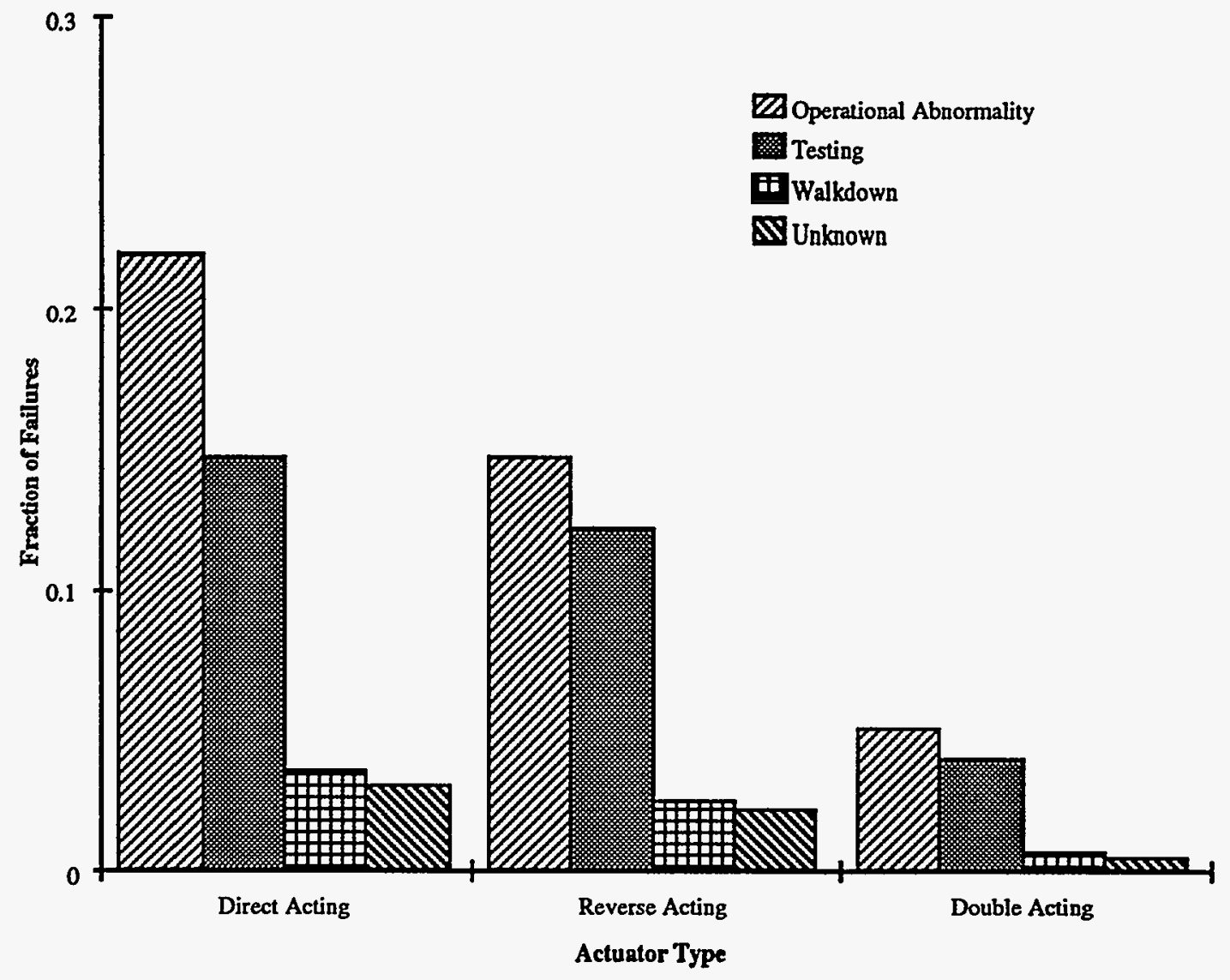

Figure 4.22 Fraction of failures for actuator/controls by method of detection

Table 4.20 Distribution of failures for actuator/controls by method of detection

\begin{tabular}{lcccccc}
\hline Actuator type & $\begin{array}{l}\text { Operational } \\
\text { abnormality }\end{array}$ & Testing & Walkdown & Unknown & Other & Total \\
\hline Direct acting & 254 & 171 & 41 & 35 & 42 & 543 \\
Reverse acting & 171 & 140 & 28 & 25 & 29 & 393 \\
Double acting & 58 & 46 & 7 & 4 & 10 & 125 \\
Other & 54 & 37 & 6 & 2 & 6 & 105 \\
Total & 537 & 394 & 82 & 66 & 87 & 1166 \\
\hline
\end{tabular}

were classified as severe; that is, there were more severe than either moderate or unknown failures listed for all types of actuators. This is probably due to the large number of diaphragm ruptures, solenoid valve failures, and air line failures that resulted in a complete loss of valve function. The trends are consistent regardless of actuator type, with $\sim 45$ to $50 \%$ of failures classified as severe, 35 to $40 \%$ classified as moderate, and 13 to $18 \%$ as unknown.

The ratios of severe to moderate show little variation from one actuator type to another. The rate of "unknowns" shows a modest increase for double-acting actuators that is expected with the modest increase in mechanical complexity (e.g., double solenoids, double-acting positioner, and double seals).
Figure 4.24 shows failure rates and the number of failures for each category of "ease of correction" and for each actuator type. Part replacement is by far the most common type of repair, followed by adjustments and/or calibration.

Where correction is by parts replacement, the failure rate for all actuator types is approximately the same order of magnitude. When repairs are made by adjustment or calibration, the failure rate for direct- and reverse-acting actuators is approximately twice that of the other two actuator types. When correction requires major repairs to the component, nonstandard actuators have a failure rate 
Analysis

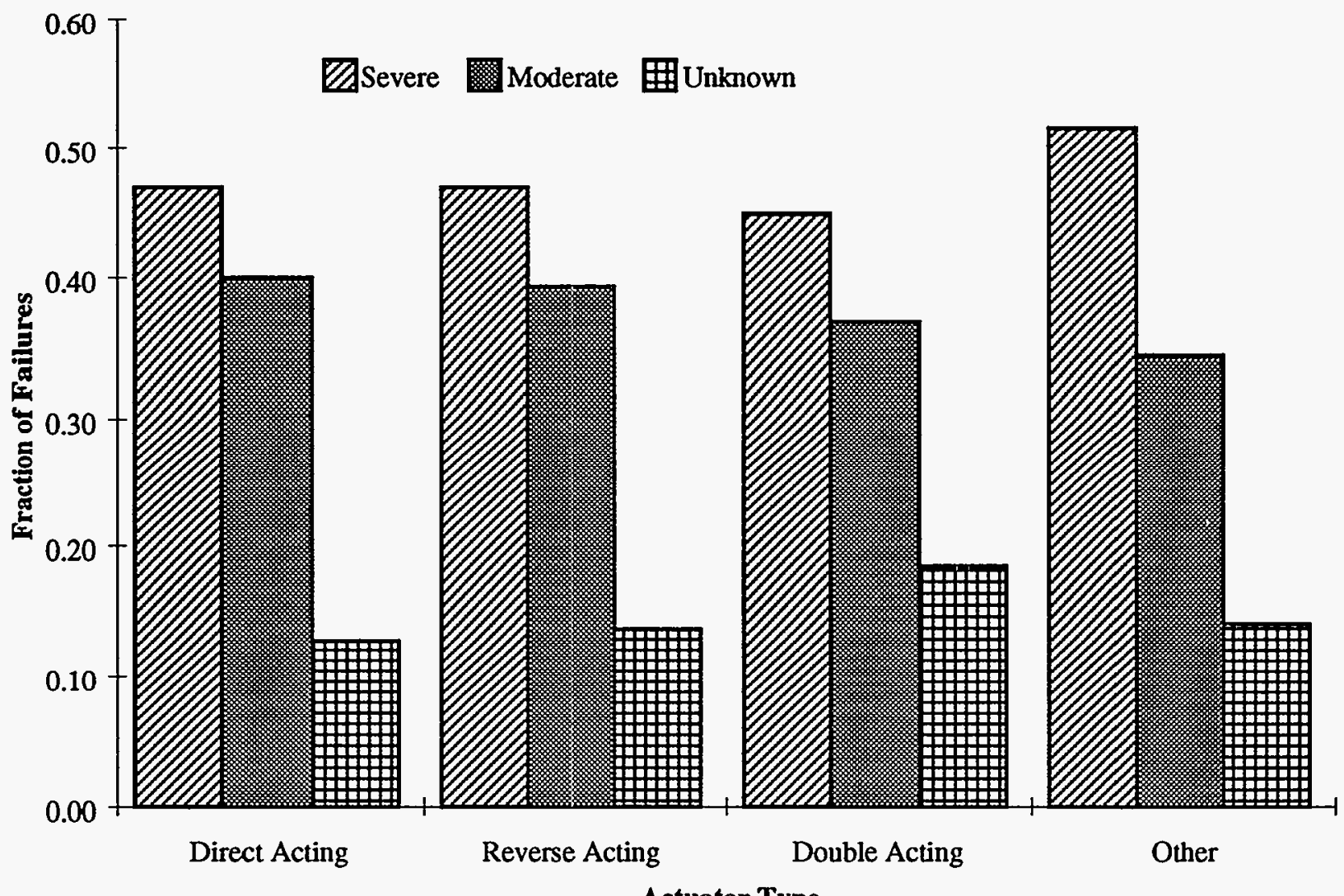

Actuator Type

Figure 4.23 Fraction of failures attributed to valve operator vs severity of failure

Table 4.21 Fraction of failures attributed to valve operator vs severity of failure

\begin{tabular}{lcccc}
\hline Actuator type & Severe & Moderate & Unknown & Total \\
\hline Direct acting & 255 & 218 & 70 & 543 \\
Reverse acting & 184 & 155 & 54 & 393 \\
Double acting & 56 & 46 & 23 & 125 \\
Other & 54 & 36 & 15 & 105 \\
Total & 549 & 455 & 162 & 1166 \\
\hline
\end{tabular}

that is at least 2.5 times that of the other actuator types. The data also show that when the unit must be replaced doubleacting actuators have a failure rate twice that of the other actuator types. However, the number of failures for this category is small, and the failure rate may not represent an actual trend.

\subsection{Data Summary and Analysis}

Air-operated globe valves were the most common valve type in this study, comprising $44 \%$ of the population as compared to butterfly valves (24\%) and less than $12 \%$ for each of the remaining valve types. The relative failure rates were highest for globe and gate valves, while the plug/ball and diaphragm types were the most reliable. Also significant is the fact that both globe and butterfly valves experienced only about $30 \%$ severe valve-only failures. Globe valves and butterfly valves have a low fraction of severe failures for apparently different reasons. The globe valve, being the primary type of control valve and therefore frequently in steam service, is susceptible to steam erosion that may cause serious leakage resulting in "moderate" failures since the normal control function would not be lost. Furthermore, degraded control valves are readily 


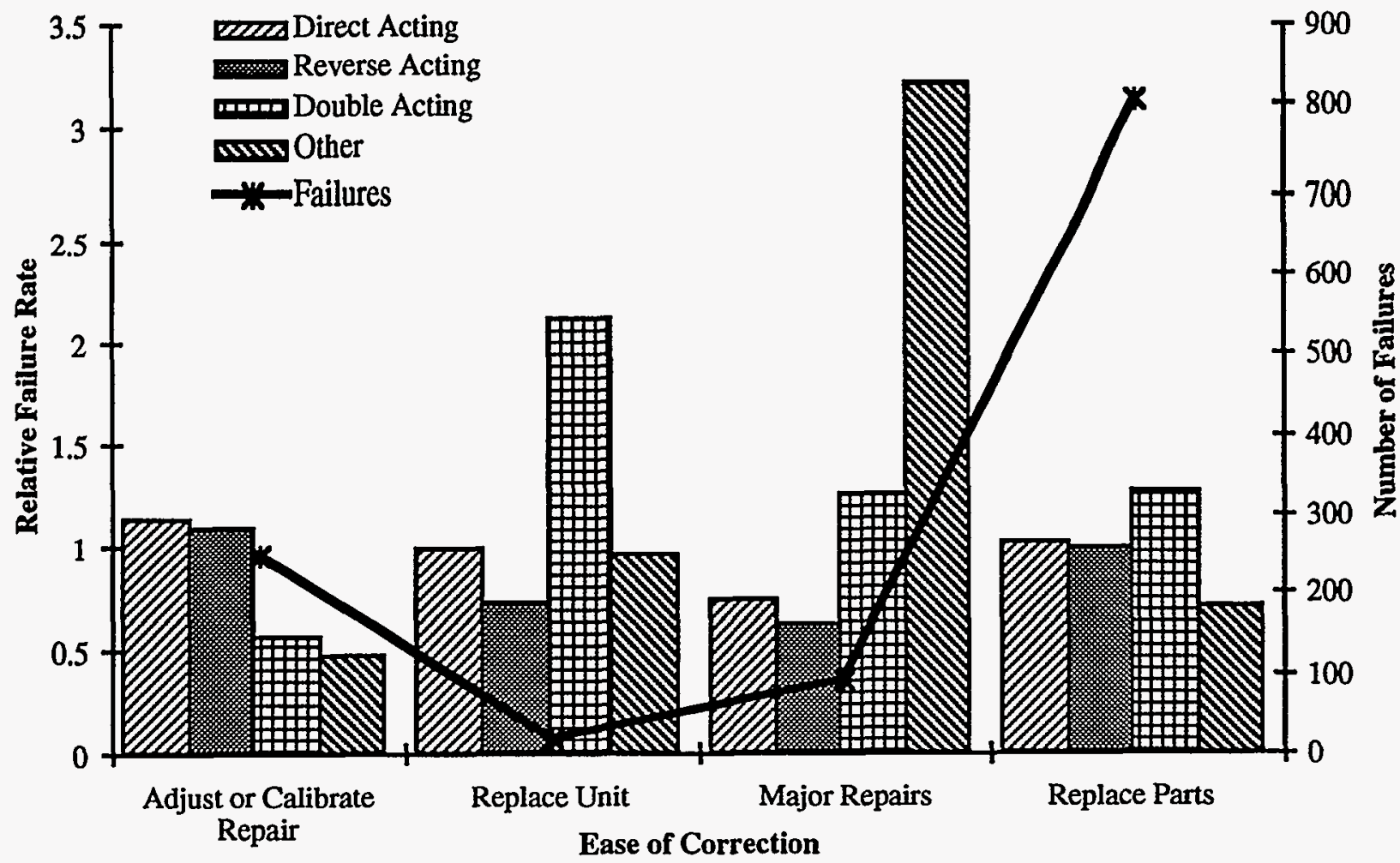

Figure 4.24 Actuator type vs ease of correction

identifiable in process operations when flow, pressure, etc. ranges out of specification, and for this reason the globe valves tend to be involved in more "moderate" failures. The AOV controls and actuator made up $78 \%$ of the total combined failures, while the valve body, seat, disc, etc. accounted for only $19 \%$ of the combined failures, with $11 \%$ of the severe failures involving the valve body.

One notable finding was that failures involving the controls (i.e., controller/positioner/air system) comprised $49 \%$ of the severe failures. The controls system was responsible for a large fraction of the severe failures due to the fact that this system contains several high failure rate components (e.g., air regulator, solenoid, air line, fittings, etc.), the failure of which frequently compromises normal valve function. As seen in Appendix A, Table A.1, the failures in the controls and actuator were due to failures of only a few specific components: diaphragms and limit switches in the actuators, and solenoid valves, air lines, and air regulators in the controls. The failures were attributed primarily to wear out and fatigue; however, it is believed that these classifications tended to be used as a catch-all for failures whose root cause was unknown. Failures of the valve seat and discs were generally due to steam erosion, pitting corrosion, presence of foreign material, etc., all of which resulted in serious internal leakage in an otherwise functional valve (i.e., moderate failures). Preventive maintenance programs either do not exist or are inadequate at preventing or predicting failures.

AOVs used in pressure relief applications do have a preventive maintenance program, of sorts, in response to a generic problem where the pressure set point of the pressure relief valve drifts out of the narrow pressure range specification. Many of these valves are calibrated at each outage. Some utilities replace critical relief valves with spares that have already been recalibrated. The relief set point for the valve that is removed is then calibrated, and the valve placed in stores as a replacement for another valve. As a result of this special treatment, pressure relief valves have by far the lowest percentage incidence of valve-only failures classified as severe $(-3 \%)$ and the highest percentage of failures classified as moderate, $\sim 77 \%$. Furthermore, pressure relief valve-only failures were discovered by operational abnormality in only $6 \%$ of the cases as compared to $31 \%$ to $51 \%$ for other types of valve applications. The replacement and refurbishment program for pressure relief valves has effectively improved the condition of the overall population of this valve type. Thus, the testing program has demonstrated how preventive maintenance can be used to locate valves whose performance is marginal, correct the faults, and dramatically reduce both the number of failures discovered by operational abnormality and valves whose normal function has been compromised (i.e., severe failures). 


\section{Analysis}

The high percentage of severe combined failures discovered during or immediately following a trip was due to common mode failures in several relief valves in the main steam system. The failures involved set-point drift and/or corrosion-induced bonding of the pilot valve disc to the pilot valve seat surface. Only 25 failures were encountered during trips, and all of these were discovered through operational abnormalities. Few moderate failures were discovered during trips, most likely because anomalies such as a slow response time, incorrect position indication, or other less severe problems are not observed in a trip situation. 


\section{Testing}

Two basic types of testing were considered for this report: (1) surveillance or in-service testing and (2) diagnostic testing. Surveillance testing is done to verify that valves, their actuators, and their position-indicating mechanisms are functioning properly. It is not always practical to test plant equipment in such a way as to verify the ability of the equipment to function properly under all potential conditions. Many valves are required to operate at design basis conditions, which are impractical or impossible to simulate during normal plant operation. Therefore, critical parameters must be examined to give indication of valve and operator readiness. This need led to the development of many of the diagnostic systems currently on the market.
The purpose of testing is to verify several parameters. For this report, testing and its relationship to failure detection and prevention are examined. Figure 5.1 shows a clear relationship between functional testing frequency and the fraction of failures discovered under demand conditions. The data supporting Fig. 5.1 are in Table 5.1. The difference between the fraction of failures discovered by test and the fraction of failures discovered during demand conditions is greatest when periodic functional testing is not done.

Table 5.2 shows that the percentage of failures for components that are tested quarterly vs the percentage of

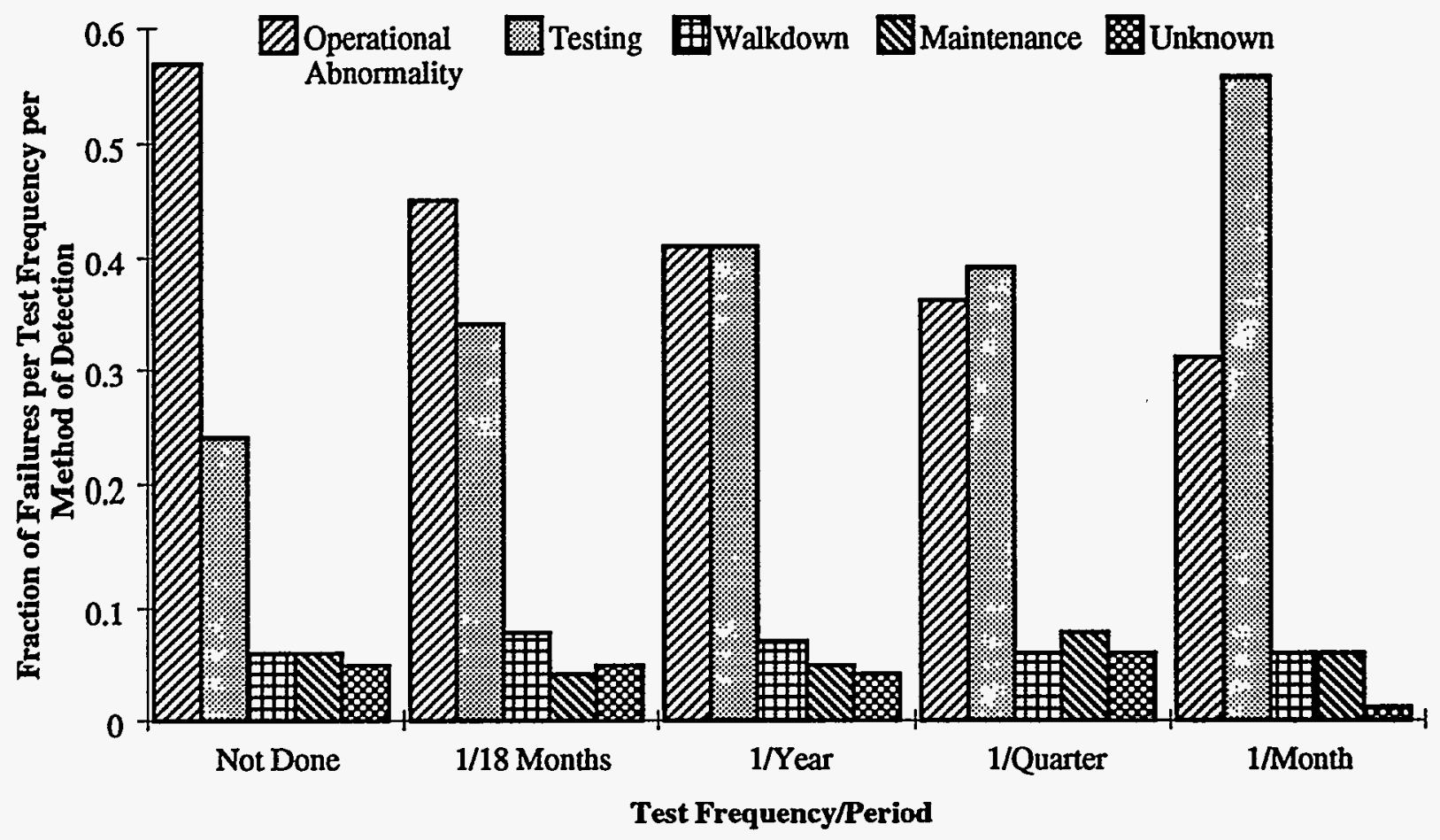

Figure 5.1 Comparison of test frequency and method of detection

Table 5.1 Failure distribution for functional test frequency by method of detection

\begin{tabular}{lcccccc}
\hline $\begin{array}{c}\text { Functional test } \\
\text { frequency/test } \\
\text { period }\end{array}$ & $\begin{array}{c}\text { Operational } \\
\text { abnormality }\end{array}$ & Testing & Walkdown & Maintenance & Unknown & $\begin{array}{c}\text { Special } \\
\text { inspection }\end{array}$ \\
\hline Not done & 0.57 & 0.24 & 0.06 & 0.06 & 0.05 & 0.02 \\
2 per 3 years & 0.45 & 0.34 & 0.08 & 0.04 & 0.05 & 0.04 \\
1/year & 0.41 & 0.41 & 0.07 & 0.05 & 0.04 & 0.026 \\
1/quarter & 0.36 & 0.39 & 0.06 & 0.08 & 0.06 & 0.04 \\
1/month & 0.31 & 0.56 & 0.06 & 0.06 & 0.01 & 0.00 \\
\hline
\end{tabular}


Table 5.2 Comparison of major component to test frequency

\begin{tabular}{|c|c|c|c|c|c|c|c|}
\hline \multirow[b]{2}{*}{ Major component } & \multicolumn{7}{|c|}{ Functional test frequency } \\
\hline & $0 / 00$ & $2 / 3$ years & 1/year & 1/quarter & 1/month & Other & Total \\
\hline & \multicolumn{7}{|c|}{ Number of failures } \\
\hline Actuator & 132 & 101 & 65 & 166 & 32 & 42 & 538 \\
\hline Controller & 180 & 111 & 57 & 180 & 42 & 62 & 632 \\
\hline Valve & 77 & 58 & 33 & 73 & 27 & 21 & 289 \\
\hline Unknown & 10 & 22 & 2 & 8 & 1 & 1 & 44 \\
\hline \multirow[t]{2}{*}{ Total } & 399 & 292 & 157 & 427 & 102 & 126 & 1503 \\
\hline & \multicolumn{7}{|c|}{ Percentage of failures } \\
\hline Actuator & 9 & 7 & 4 & 11 & 2 & 3 & 36 \\
\hline Controller & 12 & 7 & 4 & 12 & 3 & 4 & 42 \\
\hline Valve & 5 & 4 & 2 & 5 & 2 & 1 & 19 \\
\hline \multirow[t]{2}{*}{ Unknown } & 1 & 1 & 0 & 1 & 0 & 0 & 3 \\
\hline & \multicolumn{7}{|c|}{ Failure rate } \\
\hline Controller & 0.41 & 0.54 & 0.30 & 0.45 & 0.29 & 0.49 & \\
\hline Actuator & 0.30 & 0.50 & 0.34 & 0.42 & 0.22 & 0.33 & \\
\hline Valve & 0.18 & 0.28 & 0.17 & 0.18 & 0.19 & 0.17 & \\
\hline Unknown & 0.02 & 0.11 & 0.01 & 0.02 & 0.01 & 0.01 & \\
\hline
\end{tabular}

components that are not tested on a periodic basis are almost identical. This is true when the failures are considered as a percentage of total failures and also when failures are normalized and considered on a relative basis. This implies that current testing is not effective at detecting component degradation and is useful only for detecting failed components.

Functional testing is often equivalent to surveillance testing, such as that required by the federal regulation. ${ }^{7}$ Federal regulations subsequently endorse the ASME Boiler and Pressure Vessel Code, ${ }^{8}$ which further references industry standards in the form of the OM-10 (which is in transition to section ISTC of the OM Code). ${ }^{9}$ This testing, however, does not yield a clear, predictive picture of valve health because the parameters measured during surveillance testing are more likely to indicate valve failure rather than a trendable pattern of degradation. Code requirements are limited to testing stroke time, leak rate, and position indication. While measurement of these parameters will give indication of valve failure, they are not good indicators of incipient failure. This type of testing does not give a clear indication of degradation in several major components of pneumatic valve operators. Degradation of the solenoid, diaphragm, bench set, ${ }^{*}$ obturator seating force, etc., is not indicated.

\footnotetext{
* Bench set is the pressure range over which the actuator begins and ends its stroke when disconnected from the valve.
}

The highest numbers of failures are occurring in components that are not currently tested for incipient failures. These components are the actuator diaphragm and the solenoid valves. However, nonintrusive testing of the solenoid valve may be possible. For reasons of practicality such testing should be simple and easily implemented. Recent research has determined

... that a promising means of fulfilling this need is to use the copper winding of the solenoid as a selfindicating, permanently available resistance thermometer. To do so requires only in situ measurement of coil dc resistance (or ac impedance) combined with prior knowledge of the temperature coefficient of resistivity for the copper winding and the coil resistance (or impedance) at a single known temperature...2

Such testing could yield accurate temperature measurements of the solenoid coil under operating conditions. This information could then be used to calculate the useful life of various nonmetallic components of the solenoid valve, which would be input into the preventive maintenance or replacement program for the utility.

As a result of the above referenced research, an intrusive technique has also been examined for determining relative freedom of movement for the solenoid plunger. To test, the standard power supply must be disconnected, and a power supply capable of uniformly ramping the voltage up or down must be attached. As the plunger changes 
position, the current drawn will make a step change. Comparing the current trace for a valve in known good condition with the current trace for a valve in questionable condition can indicate the presence of plunger binding.

As previously mentioned, several components, such as the diaphragm and solenoids, are not routinely tested for degradation. These components are indirectly tested for function when the rest of the AOV is tested. However, for these components this is only a pass/fail type test, not a measure of degradation. When compared to those components whose function is more directly verified during testing, such as packing, lubrication, positioner, controller, and actuator springs, a relationship between components and method of failure detection can be seen. Failures are more often detected as operational abnormalities for those components whose function can only be indirectly verified during current testing. Failures are more often detected during testing for those components for which degradation is evident under testing methods. This can be seen in Table 5.3.

While Table 5.3 does not show all of the components that failed it does show some of the components with more prevalent failures. An example of this is solenoids, where
$-50 \%$ of the failures are discovered during operational abnormalities vs $34.5 \%$ for testing. Likewise diaphragm failures are detected $-30.5 \%$ of the time during testing vs 42.4\% for demand failures. Conversely, degraded packing has a tendency to increase the friction between the valve stem and the packing. This is then manifested as degraded stroke times or partial stroking of the valve. Spring adjustments are another example (20.8\% discovered during operational abnormalities vs $62.5 \%$ for testing). A more complete list of specific failed components can be found in Appendix A.

It should be noted that certain types of failures are at best difficult to predict at the incipient stage, and at times prediction is impossible. Therefore, it should be understood that diaphragm or solenoid failures do not necessarily indicate the quality of effort being expended by any particular utility. Rather they indicate the difference between current capabilities in diagnostic testing and desired capabilities in diagnostic testing. It is impossible to quantify this further based on the NPRDS data alone because there is no requirement to report incipient failures to NPRDS. Therefore, there is no direct way of comparing incipient failures to the more severe failures. It may be beneficial in other studies to compare incipient failures to the more severe failures for individual facilities.

Table 5.3 Comparison of method of detection and component failed

\begin{tabular}{lcccccc}
\hline Component & \multicolumn{7}{c}{ Method of detection } \\
\cline { 2 - 7 } & $\begin{array}{c}\text { Operational } \\
\text { abnormality } \\
(\boldsymbol{\%})\end{array}$ & $\begin{array}{c}\text { Special } \\
\text { inspection } \\
(\boldsymbol{\%})\end{array}$ & $\begin{array}{c}\text { Maintenance } \\
(\boldsymbol{\%})\end{array}$ & $\begin{array}{c}\text { Unknown } \\
(\boldsymbol{\%})\end{array}$ & $\begin{array}{c}\text { Walkdown } \\
(\boldsymbol{\%})\end{array}$ & $\begin{array}{c}\text { Testing } \\
(\boldsymbol{\%})\end{array}$ \\
\hline Solenoid & 50.0 & 2.0 & 2.0 & 4.0 & 7.5 & 34.5 \\
Diaphragm & 42.4 & 2.5 & 5.1 & 6.8 & 12.7 & 30.5 \\
Trim & 30.8 & 6.4 & 18.0 & 5.1 & 1.3 & 38.5 \\
Air line & 45.2 & 1.6 & 6.5 & 1.6 & 19.4 & 25.8 \\
Seals & 47.2 & 1.6 & 11.2 & 4.0 & 9.6 & 26.4 \\
Packing & 40.5 & 8.1 & 0.0 & 0.0 & 2.7 & 48.7 \\
Lubrication & 30.0 & 0.0 & 0.0 & 0.0 & 10.0 & 60.0 \\
Positioner & 52.2 & 0.0 & 0.0 & 17.4 & 0.0 & 30.4 \\
Regulator & 43.5 & 4.4 & 8.7 & 4.4 & 0.0 & 39.1 \\
Unknown & 38.0 & 16.0 & 0.0 & 2.0 & 2.0 & 42.0 \\
Air regulator & 33.3 & 5.6 & 2.8 & 8.3 & 19.4 & 30.6 \\
Limit switch & 42.9 & 2.9 & 0.0 & 5.7 & 2.9 & 45.7 \\
Spring & 20.8 & 0.0 & 12.5 & 0.0 & 4.2 & 62.5 \\
Pilot assembly & 30.4 & 0.0 & 0.0 & 0.0 & 0.0 & 69.6 \\
\hline
\end{tabular}





\section{Conclusions}

Globe valves were the most common valve type in this study. The largest population of valves was $<12$ in. in size. However, the portion of the population with the highest failure rate was between 12 and 20 in. in size. The relative failure rates were highest for globe and gate valves, while the plug/ball and diaphragm types were the most reliable.

The AOV controls and actuator made up $78 \%$ of the total combined failures, while the valve body, seat, disc, etc. accounted for $19 \%$ of the combined failures. Only $11 \%$ of the severe failures involved the valve body.

One notable finding was that failures involving the controls (i.e., controller/positioner/air system) comprised $49 \%$ of the severe failures. The controls system was responsible for a large fraction of the severe failures because this system contains several high failure rate components (e.g., air regulator, solenoid, air line, fittings, etc.), the failures of which frequently compromise normal valve function. As evident in Appendix A, Table A.1, the failures in the controls and actuator were due to failures of only a few components: diaphragms and limit switches in the actuators, solenoid valves, air lines, and air regulators in the controls. A comparison of failures by frequency of periodic testing reveals that preventive maintenance programs are not being effective (Table 5.2). This can be seen in the similarity of the number of failures detected in components that receive quarterly testing and those components that receive no periodic testing. Because these numbers are so close (when compared as numbers of failures, percentage of failures, or relative failure rates), it is apparent that current methods of periodic testing are better suited to failure detection than to trending component degradation.

On the basis of data examined, current test programs are not being effective in detecting incipient component failures. This appears to be due to the current inability to test the components that are degrading at the highest rates. 



\section{Recommendations}

As a result of this study several actions are recommended. The ultimate result of any action should be an increase in the reliability of safety-related equipment. Because diagnostic systems for AOVs are increasing in usage at nuclear power plants, a follow-up study is recommended. This study should concentrate on trends in failures in recent years in light of the increasing use of relatively new diagnostic systems. Additionally, new test methods need to be developed to determine levels of degradation in both diaphragms and solenoid valves under augmented preventive maintenance programs.

In addition to these actions it is recommended that a more detailed study be undertaken to determine the actual root cause of failures and determine how elevated temperatures and radiation may impact component degradation. 



\section{References}

1. U.S. Nuclear Regulatory Commission, Office of Nuclear Regulatory Research, "Nuclear Plant Aging Research (NPAR) Program Plan," USNRC Report NUREG-1144 Rev. 2, July 1991.

2. R. C. Kryter, "Aging and Service Wear of SolenoidOperated Valves Used in Safety Systems of Nuclear Power Plants," USNRC Report NUREG/CR-4819 Vol 2, July 1992.*

3. Handbook of Plastics and Elastomers, C. A. Harper, Ed., McGraw-Hill Book Company, New York, 1975.

4. Instrument Society of America Handbook of Control Valves, J. W. Hutchinson, Ed., The Instrument Society of America, Pittsburgh, Pennsylvania, 1971.

5. H. A. Omstein, "Operating Experience Feedback Report-Air Systems Problems," USNRC Report NUREG-1275 Vol. 2, December 1987.*
6. U.S. Nuclear Regulatory Commission, "A Characterization of Check Valve Degradation and Failure Experience in the Nuclear Power Industry," USNRC Report NUREG/CR-5944.*

7. U.S. Code of Federal Regulations, Part 50.55a, Title 10, "Energy." $†$

8. "ASME Boiler and Pressure Vessel Code," Section XI, Division 1, Subarticle IWV-1100, 1986, 1987, and 1988 Addenda and 1989 Edition, American Society of Mechanical Engineers, New York. ${ }^{\dagger}$

9. "Operation and Maintenance of Nuclear Power Plants," ANSI/ASME OM-10, American Society of Mechanical Engineers, New York. ${ }^{\dagger}$

* Available for purchase from National Technical Information Service, Springfield, VA 22161.

$\dagger_{\text {Available in public technical libraries. }}$ 



\section{Appendix A-Specific Components Contributing to AOV Failure}

The listing of failed components or subcomponents is shown in Table A.1. By far, the two most frequently failing components shown are the solenoid valves in the control system and the actuator diaphragms. The reliability of AOVs would be dramatically improved if the service life of these two components were more in line with other components shown. The next three components listed are actuator seals, which are used primarily in the piston or reverse-acting designs, valve trim (e.g., disc, plug, ball, cage, etc.), and instrument air lines. Of the first 20 components shown, only trim and packing are valve compo- nents, while most of the remainder belong to either the actuator or controls systems.

Far more components were entered into the data base than there were number of failures because a large percentage of the failures involved more than one defective component. The table does not show the long list of components for which there were only 1 to 4 recorded failure incidents.

Table A.1 Specific components contributing to $\mathrm{AOV}$ failure

\begin{tabular}{lc}
\hline Component & $\begin{array}{c}\text { Count of } \\
\text { component }\end{array}$ \\
\hline Solenoid & 202 \\
Diaphragm & 128 \\
Seals & 88 \\
Trim & 78 \\
Air line & 70 \\
Stem & 56 \\
Limit switch & 49 \\
Packing & 37 \\
Air regulator & 34 \\
Fastener & 33 \\
Fitting & 24 \\
Positioner & 24 \\
Pilot assembly & 23 \\
Regulator & 22 \\
Spring & 22 \\
Stem, trim & 20 \\
Pilot valve & 17 \\
Misc. parts & 13 \\
Actuator & 12 \\
Lubrication & 12 \\
Controls & 10 \\
Fuse & 9 \\
Valve & 9 \\
Adjustment & 6 \\
Air cylinder & 5 \\
Arm & 5 \\
Eductor gasket & 5 \\
Linkage & 5 \\
Servo valve & 5 \\
\hline & \\
\hline & 5 \\
\hline
\end{tabular}





\section{Internal Distribution}

1. C.W. Ayers

2. D. A. Casada

3. R. D. Cheverton

4-24. D.F. Cox

25. E. C. Fox

26. R. G. Gilliland

27. H. D. Haynes

28. J. D. Kueck

29. K. H. Luk

30. K. L. McElhaney

\author{
31. A. B. Poole \\ 32. C. E. Pugh \\ 33. C. C. Southmayd \\ 34. R. H. Staunton \\ 35. ORNL Patent Office \\ 36. Document Reference Section \\ 37. Central Research Library \\ 38-40. Laboratory Records Department \\ 41. Laboratory Records (RC)
}

\section{External Distribution}

42. G. Sliter, Electric Power Institute, P.O. Box 10412, Palo Alto, CA 94303

43. J. W. Tills, Institute for Nuclear Power Operations, 1100 Circle 75 Parkway, Atlanta, GA 30339-3064

44. R. J. Lofaro, Brookhaven National Laboratory, Bldg. 130, Upton, NY 11973

45. R. P. Allen, Battelle-PNL, MS P8-10, P.O. Box 999, Richland, WA 99532

46. J. P. Vora, U.S. Nuclear Regulatory Commission, Office of Nuclear Regulatory Research, Electrical, Materials, and Mechanical Engineering Branch, MS T-10 E10, Washington, DC 20555

47. G. H. Weidenhamer, U.S. Nuclear Regulatory Commission, Office of Nuclear Regulatory Research, Electrical, Materials, and Mechanical Engineering Branch, MS T-10 E10, Washington, DC 20555

48. M. E. Mayfield, U.S. Nuclear Regulatory Commission, Office of Nuclear Regulatory Research, Electrical, Materials, and Mechanical Engineering Branch, MS T-10 E10, Washington, DC 20555

49. O. P. Gormley, U.S. Nuclear Regulatory Commission, Office of Nuclear Regulatory Research, Electrical, Materials, and Mechanical Engineering Branch, MS T-10 E10, Washington, DC 20555

50. J. E. Jackson, U.S. Nuclear Regulatory Commission, Office of Nuclear Regulatory Research, Engineering Issues Branch, MS T-10 C9, Washington, DC 20555

51. P. L. Campbell, U.S. Nuclear Regulatory Commission, Office of Nuclear Reactor Regulation, Electrical and Mechanical Engineering Branch, OWFN, 7E23, Rockville, MD 20852-2738

52. C. F. Nelson, Sandia National Laboratory, P.O. Box 5800, MS 0737, Albuquerque, NM 87185

53. H. L. Magleby, Idaho Engineering Laboratory, MS 2406, P.O. Box 1625, Idaho Falls, ID 83415

54. Office of Assistant Manager for Energy Research and Development, Department of Energy, Oak Ridge Operations, Oak Ridge, TN 37831

55-56. Office of Scientific and Technical Information, P.O. Box 62, Oak Ridge, TN 37831 
(See instructions on the rev erse)

NUREG/CR-6016

ORNL/TM-6789

2. TITLE AND SUBTITLE

Aging and Service Wear of Air-Operated Valves Used in Safety-

Related Systems at Nuclear Power Plants

5. AUTHORIS

D. F. Cox, K. L. McElhaney, R. H. Staunton \begin{tabular}{|c|c}
3. & \multicolumn{2}{c}{ DATE REPORT PUBLISTE } \\
\hline N:ONTH & I! \\
May & 1995
\end{tabular}

4. FINOR GRANT NUN:BER B0828

6. TYPE OF REPORT

7. PERIOD COVERED /InElusive Da:LS)

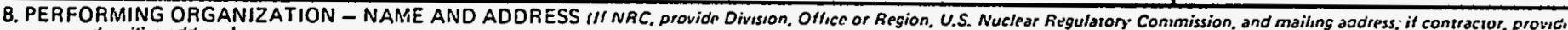
name and mailing address.)

Oak Ridge National Laboratory

P.0. Box 2009

Oak Ridge, TN 37831

9. SPONSORING ORGANIZATION - NAME AND ADDRESS "/ NAC, ivpe "Same as above"; if contractor, provide NRC Division. Office or Fegion, U.S. Nuclear Regulatory Commission. and mailing address.)

Division of Engineering Technology

Office of Nuclear Regulatory Research

U. S. Nuclear Regulatory Commission

Washington, DC 20555-0001

10. SUPPLEMENTARY NOTES

11. ABSTRACT 1200 words or less)

Air-operated valves (AOVs) are used in a variety of safety-related applications at nuclear power plants. They are often used where rapid stroke times are required or precise control of the valve obturator is required. They can be designed to operate automatically upon loss of power, which is often desirable when selecting components for response to design basis conditions.

The purpose of this report is to examine the reported failures of AOVs and determine whether there are identifiable trends in the failures related to predictable causes. This report examines the specific components that comprise a typical AOV, how those components fail, when they fail, and how such failures are discovered. It also examines whether current testing frequencies and methods are effective in predicting such failures.

12. KEY WORDS!DESCR!PTORS IList words or phrases that will assist researchers in locating the report. I AOV, valve, aging, air-operated, failure, control valve

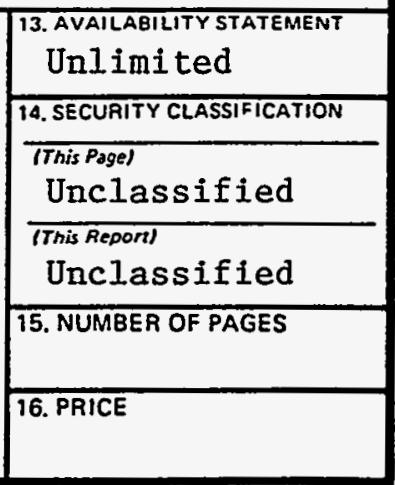

